UNIVERSIDADE DE SÃO PAULO

POLYTECHNIC SCHOOL

BRUNO SCARANO PATERLINI

Assessment of Connected and Autonomous Vehicles impacts on traffic flow through microsimulation 
BRUNO SCARANO PATERLINI

Assessment of Connected and Autonomous Vehicles impacts on traffic flow through microsimulation

\section{Revised Version}

Dissertation presented at the Polytechnic School, Universidade de São Paulo to obtain a degree in the Master of Science

Supervisor: Prof. Dr. Leopoldo Rideki Yoshioka. 
BRUNO SCARANO PATERLINI

Assessment of Connected and Autonomous Vehicles impacts on traffic flow through microsimulation

\section{Revised Version}

Dissertation presented at the Polytechnic School, Universidade de São Paulo to obtain a degree in the Master of Science

Area of concentration: Electronic Systems Engineering

Supervisor: Prof. Dr. Leopoldo Rideki Yoshioka.

\section{São Paulo}


Autorizo a reprodução e divulgação total ou parcial deste trabalho, por qualquer meio convencional ou eletrônico, para fins de estudo e pesquisa, desde que citada a fonte.

Este exemplar foi revisado e alterado em relação à versão original, sob responsabilidade única do autor e com a anuência de seu orientador.

São Paulo, 08 de fevereiro de 2021

Assinatura do autor:

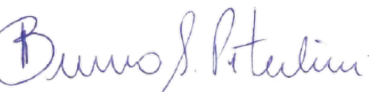

Assinatura do orientador:

\section{Catalogação-na-publicação}

Paterlini, Bruno Scarano

Assessment of Connected and Autonomous Vehicles impacts on traffic flow through microsimulation / B. S. Paterlini -- versão corr.--São Paulo, 2021. $116 \mathrm{p}$.

Dissertação (Mestrado) - Escola Politécnica da Universidade de São Paulo. Departamento de Engenharia de Sistemas Eletrônicos.

Orientador: Prof. Dr. Leopoldo Rideki Yoshioka.

1.Veículos autônomos e conectados; 2 . Microssimulação de tráfego; 3. Comboio Autônomo I. Universidade de São Paulo. Escola Politécnica. Departamento de Sistemas Eletrônicos II.t. 
Name: PATERLINI, Bruno Scarano

Title: Assessment of Connected and Autonomous Vehicles impacts on traffic flow through microsimulation

Dissertation presented at the Polytechnic School, Universidade de São Paulo to obtain the degree in the Master of Science

Approved on: 12/ 10 / 2021

Examination committee

Prof. Dr. LEOPOLDO RIDEKI YOSHIOKA

Institution: USP - UNIVERSIDADE DE SÃO PAULO

Assessment: APPROVED

Prof. Dr. HUMBERTO DE PAIVA JUNIOR

Institution: UFABC - UNIVERSIDADE FEDERAL DO ABC

Assessment: APPROVED

Prof. Dr. MAX MAURO DIAS SANTOS

Institution: UTFPR - UNIVERSIDADE TECNLÓGICA FEDERAL DO PARANÁ

Assessment: APPROVED 
I dedicate this work in the first place to God.

To my wife Amanda, my daughter Lívia, to my new baby Gael, my parents Ednei and Marcia, and all who gave me support from different perspectives during this journey. 


\section{ACKNOWLEDGMENTS}

To Prof. Dr. Leopoldo Rideki Yoshioka for dedication and guidance.

To Prof. Dr. Claudio Luiz Marte for his cooperation, guidance, and support.

To Prof. Dr. Armando Laganá, I mention a big dreamer from education as a path to change people's lives. He did not measure efforts to make this realization possible for me and to many other colleagues.

To PTV for providing VISSIM software. In special to Mr. Antunez and Mrs. Luisa de Moura Chaves, Brazil's PTV representatives allowed an excellent interface between the company and the university. 


\section{RESUMO}

Veículos Autônomos e Conectados (CAVs) são parte importante do futuro das vias inteligentes ao redor mundo. Eles são objeto de interesse dos órgãos mundiais de trânsito e da sociedade por apresentarem um grande potencial para melhoria no fluxo de tráfego, redução no número de acidentes, aumento da eficiência enérgica e redução dos níveis de emissão. A indústria e a academia vêm aumentado seus esforços e investimentos para desenvolver as várias tecnologias que irão integrar o CAV assim como avaliar o seu impacto nas vias. As fases de transição apresentam maior complexidade devido a coexistência de veículos autônomos e não autônomos na mesma via, e assim necessitam ser cuidadosamente avaliadas. Esta dissertação tem como principal objetivo desenvolver uma metodologia para avaliar o impacto dos CAVs no fluxo de tráfego em vias urbanas e rodoviárias. São também focos do estudo as fases de transição que incluem o tráfego misto dos veículos dirigidos por humanos (HDVs), veículos autônomos (AVs) e veículos autônomos e conectados. Além disso, a pesquisa avaliou como estas tecnologias afetam os tempos de viagem na presença de distúrbios e também o impacto da função de comboios automatizados pra todos os cenários dentro de ambientes urbanos ou rodoviários. O estudo foi realizado por meio de microsimulação de tráfego utilizando o software PTV VISSIM, onde os modelos de car-following foram desenvolvidos e calibrados. Os resultados mostraram que cenários com $100 \%$ de CAVs combinados com as configurações de tamanhos ótimos de comboio levaram a redução de até $71 \%$ nos tempos de viagem em aplicações urbanas, e de $43 \%$ em aplicações rodoviárias, quando comparados com cenários onde $100 \%$ dos veículos eram dirigidos por humanos. O estudo também traz uma avaliação focada na aplicação dos comboios autônomos em cidades e rodovias. Em general, eles apresentaram um papel importante na redução do tempo de viagem. Finalmente, os estudos mostraram que os impactos medidos no desempenho do tráfego podem variar significativamente, dependendo das características da rede e da configuração da capacidade dos CAVs. O ponto convergente é que apresentam impactos positivos.

Descritores: Veículos Autônomos e Conectados. Veículos Autônomos. Tráfego autônomo heterogêneo. Microssimulação de tráfego. Comboios Automatizados. 


\begin{abstract}
Autonomous and Connected Vehicles (CAVs) are an essential part of the future of intelligent roads around the world. They are an object of interest to the world traffic authorities and society. They have great potential for improving traffic flow, reducing the number of accidents, increasing energy efficiency, and reducing emission levels. Industry and academia have increased their efforts and investments to develop the various technologies that will integrate the CAV and assess its impact on the roads. The transition phases are more complicated due to the coexistence of autonomous and non-autonomous vehicles on the same path and need to be carefully evaluated. This dissertation's main objective is to develop a methodology to assess the impact of CAVs on traffic flow on urban and highway roads. The study also includes the transition phases that include mixed human-driven vehicle traffic (HDVs), autonomous vehicles (AVs), and autonomous and connected vehicles. The research evaluated how these technologies affect travel times in the presence of disturbances and the impact of automated trains' function for all scenarios within urban or road environments. The study was carried out employing traffic microsimulation using the PTV VISSIM software, where the car-following models were developed and calibrated. The results showed that scenarios with 100\% CAVs combined with optimal train size settings led to a reduction of up to $71 \%$ in travel times in urban applications and $43 \%$ in road applications than scenarios where humans drove $100 \%$ of vehicles. The study also shows a specific assessment platooning applied to cities and highways. In general, the platoons can place an essential role in minimizing travel time. Finally, studies have shown that the impacts measured on traffic performance can vary significantly, depending on the network's characteristics and the configuration of the capacity of the CAVs. The convergent point is that they have positive impacts.
\end{abstract}

Keywords: Connected and Autonomous Vehicles (CAV). Autonomous Vehicles (AV). Autonomous Heterogeneous Traffic. Traffic Microsimulation. Platooning. 


\section{LIST OF FIGURES}

FIG. 1. CONTEXT AND FIELDS IN WHICH THE RESEARCH LOCALIZES..................................18

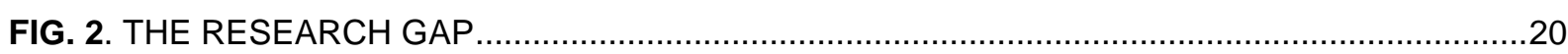

FIG. 3. TAXONOMY TIMELINE OF VEHICLE AUTOMATION LEVEL STANDARDIZATION............22

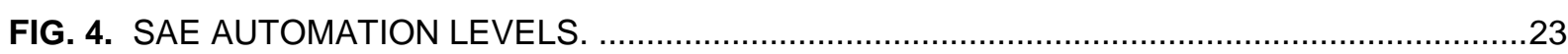

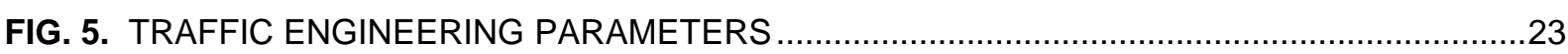

FIG. 6. V2V ALLOWS CAV VEHICLES TO SCAN A BROADER VEHICLE ECOSYSTEM BEYOND

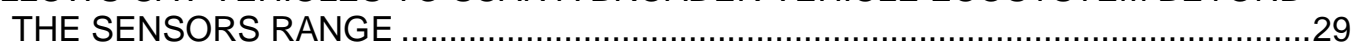

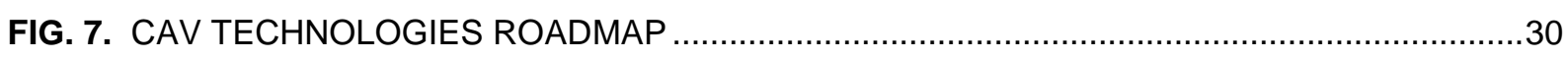

FIG. 8. MATHEMATICAL MODELS EVOLUTION FROM AVS, CVS, AND CAVS ….........................33

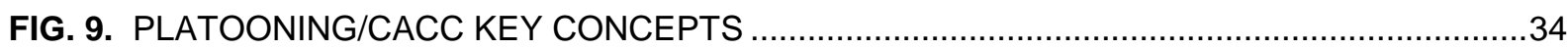

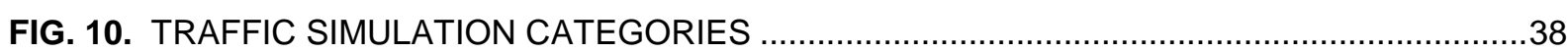

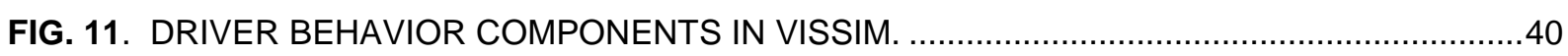

FIG. 12. ILLUSTRATION OF THE DRIVING REGIMES FROM THE WIEDEMANN MODEL. ............41

FIG. 13. OVERVIEW OF SIMULATORS COMBINATIONS FOR CAVS SIMULATIONS. ...................44

FIG. 14. WORKFLOW TO DEFINE THE APPROPRIATE SIMULATOR .....................................56

FIG. 15. WORKFLOWS TO VALETED A BASELINE SCENARIO AND ASSESSED THE RESULTS57

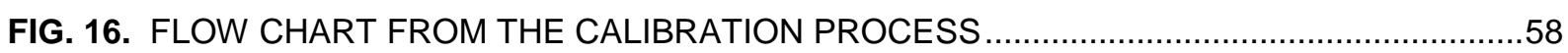

FIG. 17. DISTURBANCE ADDED TO THE MODEL ON SCENARIOS X.2 …....................................59

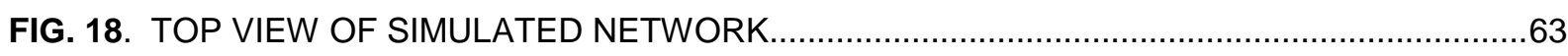

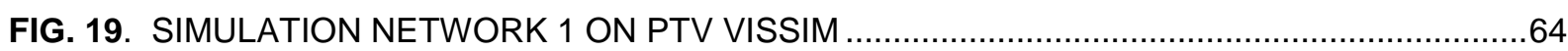

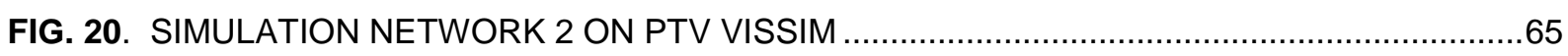

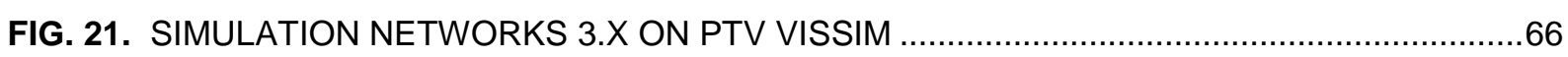

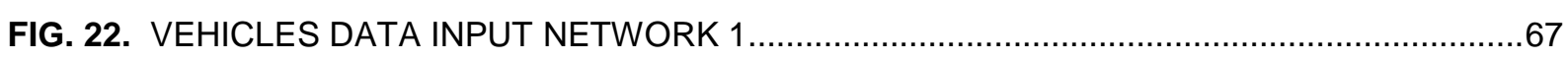

FIG. 23. RECOMMENDED PARAMETERS RELATED TO LANE CHANGE BEHAVIOR ..................68

FIG. 24. RECOMMENDED PARAMETERS RELATED TO LANE CHANGE FUNCTIONALITIES .....69

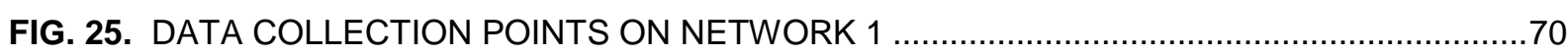

FIG. 26. DATA COLLECTION RESULTS EXAMPLE AT PTV VISSIM ….........................................

FIG. 27. TRAVEL TIME MEASUREMENTS FOR NETWORK 1 AT PTV VISSIM. ..............................71

FIG. 28. SIMULATION OF A BROKEN DOWN VEHICLE ON THE NETWORK …...............................71

FIG. 29. TRAVEL TIME RATIO CALCULATION BETWEEN W99 AND W74 ..................................72

FIG. 30. GRAPHIC FROM TRAVEL TIMES AND RELATION BETWEEN W99 AND W74

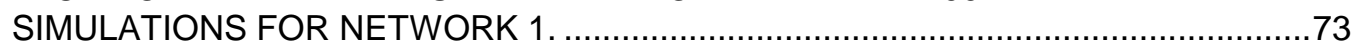

FIG. 31. GRAPHIC FOR TRAVEL TIME SCENARIOS COMPARISON FOR W74 MODEL ON NETWORK 1.

FIG. 32. GRAPHIC FOR TRAVEL TIME SCENARIOS COMPARISON FOR W74 MODEL ON NETWORK 2.

FIG. 33. GRAPHIC FOR TRAVEL TIME SCENARIOS COMPARISON FOR W99 MODEL ON NETWORK 1.

FIG. 34. GRAPHIC FOR TRAVEL TIME SCENARIOS COMPARISON FOR W99 MODEL ON NETWORK 2 .

FIG. 35. GRAPHIC FOR TRAVEL TIME VARIATION FOR A DIFFERENT MAXIMUM NUMBER OF VEHICLES IN A PLATOON ON SCENARIOS 6.X FOR NETWORK $1 \ldots \ldots \ldots \ldots \ldots \ldots \ldots . . . . . . . . . . . . .79$

FIG. 36. GRAPHIC FOR TRAVEL TIME VARIATION FOR A DIFFERENT MAXIMUM NUMBER OF VEHICLES IN A PLATOON ON SCENARIOS 6.X FOR NETWORK 2 .......................79

FIG. 37. GRAPHIC FOR TRAVEL TIME COMPARISON BETWEEN NAÇÕES UNIDAS AND

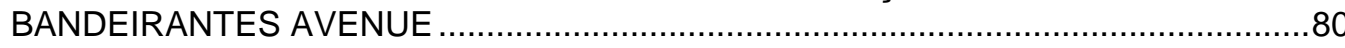

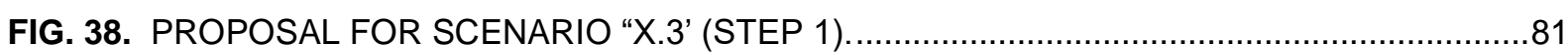


FIG. 39. PROPOSAL FOR SCENARIO "X.3 (STEP 2)" .82

FIG. 40. TRAVEL TIME COMPARISON AMONG THE SCENARIOS FOR NETWORKS 3.1, 3.2, AND 3.3. .83

FIG. 41. TRAVEL TIME RESULTS FOR NETWORK 3.1 ON SCENARIOS 4 AND 5 .86

FIG. 42. TRAVEL TIME RESULTS FOR NETWORK 3.2 ON SCENARIOS 4 AND 5 .87

FIG. 43. TRAVEL TIME RESULTS FOR NETWORK 3.3 ON SCENARIOS 4 AND 5. .87

FIG. 44. TRAVEL TIME RESULTS FOR NETWORK 3.1 ON SCENARIO 6 .88

FIG. 45. TRAVEL TIME RESULTS FOR NETWORK 3.2 ON SCENARIO 6 89

FIG. 46. TRAVEL TIME RESULTS FOR NETWORK 3.3 ON SCENARIOS 6 .89 


\section{LIST OF ABBREVIATIONS}

ABS - Anti-lock Brake System)

ACC - Adaptive Cruise Control

ADAS- Advanced Driver Assistant Systems

Al - Artificial Intelligence

AV - Autonomous Vehicles

CACC - Cooperative Adaptive Cruise Control

$\mathrm{CAH}$ - Constant Acceleration Heuristics

CASE - Connected, Autonomous, Shared, Electric

CAV - Connected Autonomous Vehicles

COM - Component Object Model

CV - Connected Vehicles

CVIC - Cooperative Vehicle Intersection Control

$\mathrm{C} 2 \mathrm{C}$ - Car to Car

C2X - Car to "X" (everything)

DSRC - Dedicated Short Range Communication

EDBM - External Driver Behavior Model

ESP - Electronic Stability Program

EIDM - Enhanced Intelligent Driver Model

FOT - Field Operational Trials

GLOSA - Green Light Optimized Advisory

HDV - Human Driven Vehicle

IBGE - Brazilian Institute of Geography and Statistics

ICV - Intelligent and Connected Vehicle

IDM - Intelligent Driver Model

IoT - Internet of Things

ITS - Intelligent Transportation Systems

LTE - Long Term Evolution

MHT - Multi-lane Hybrid Theory

NCAP - New Car Assessment Programs

OEM - Original Equipment Manufacturer

PNAD - National Household Sample Survey

RSU - Road Side Units

SAE - Society of Automotive Engineers

SDM - Smart Driver Model 
SIM - Subscriber Identity Module

SPTRANS - São Paulo Transportation

SSD - Stopping Side Distance

UMTRI - University of Michigan Transportation Research institute

USDOT - United States Department of Transportation

USP - Unique Selling Point

VANETs- Vehicular Ad Hoc Networks

VDOT- Virginia Department of Transportation

V2V - Vehicle to Vehicle

V2I - Vehicle to Infrastructure

V2X -- Vehicle to Everything

V2N - Vehicle to Network

WAVE - Wireless Acess in Vehicular Environments

W74 - Wiedemann 74

W99 - Wiedemann 99

WHO - World Health Organization 


\section{Table of contents}

RESUMO

ABSTRACT

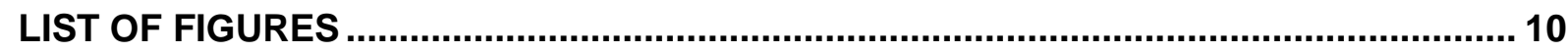

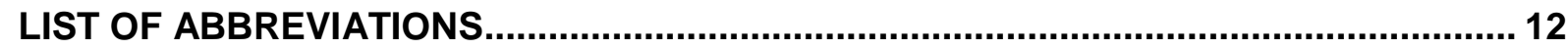

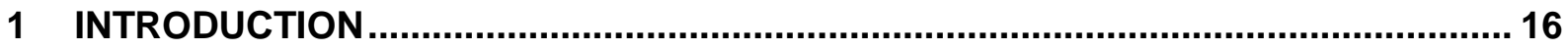

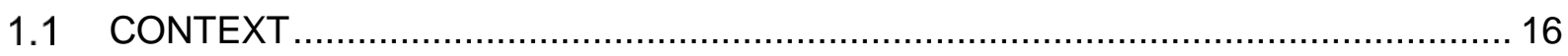

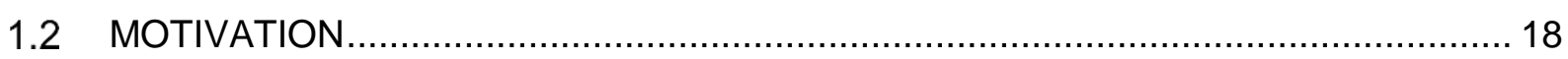

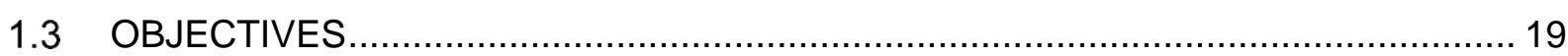

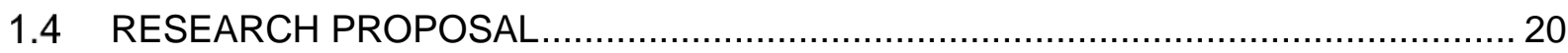

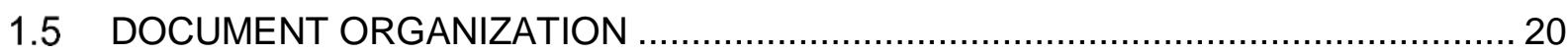

2 KEY CONCEPTS OF CONNECTED AND AUTONOMOUS VEHICLES AND TRAFFIC

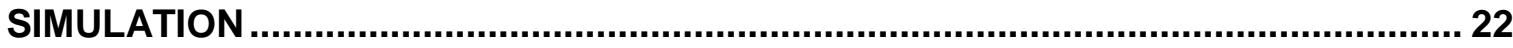

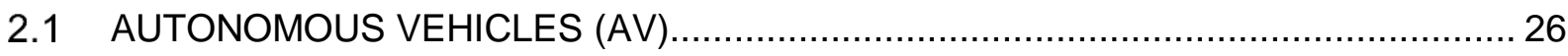

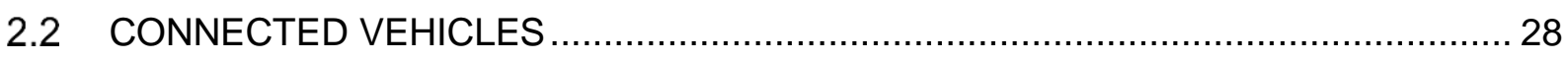

2.3 CONNECTED AND AUTONOMOUS VEHICLES (CAV) ……................................... 29

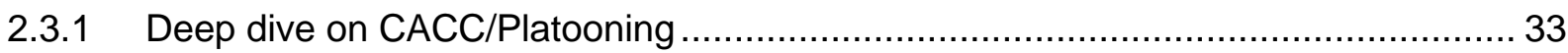

2.4 VEHICLE AUTOMATION FIELD OPERATIONAL TRIALS (FOT) ………................... 36

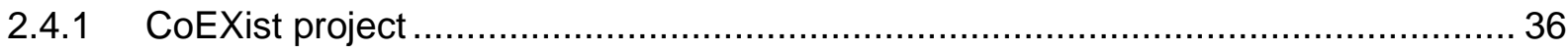

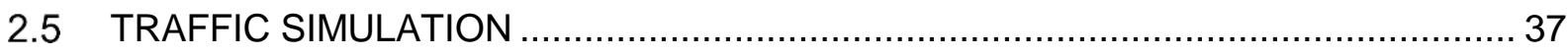

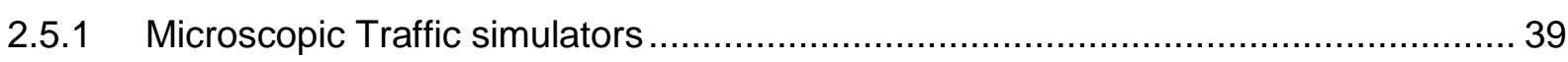

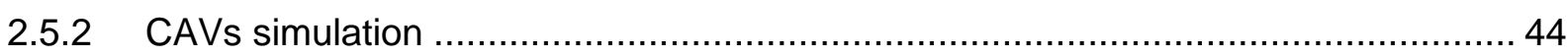

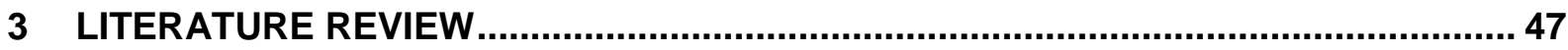

4 METHODOLOGY

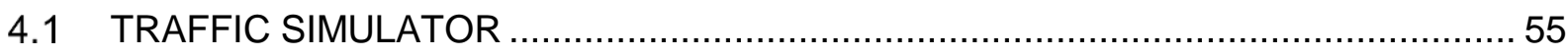

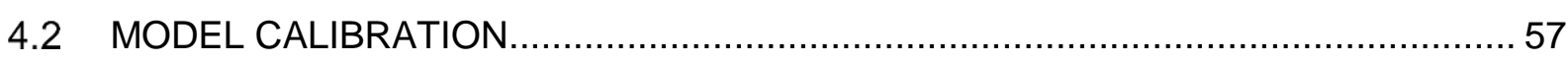

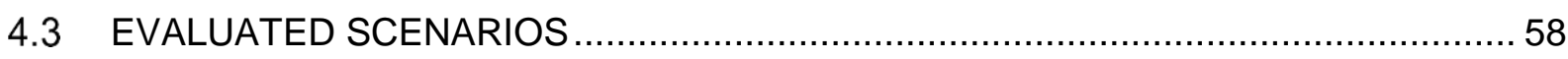

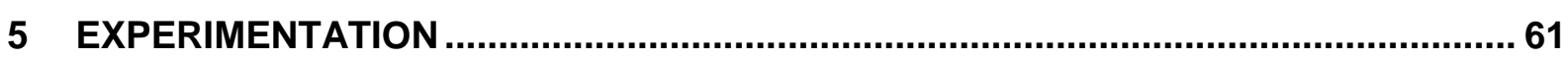

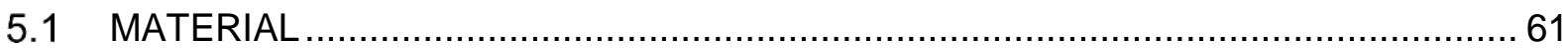

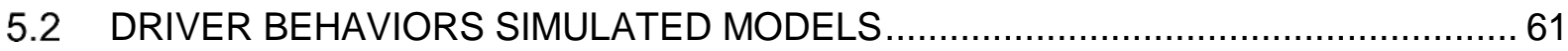

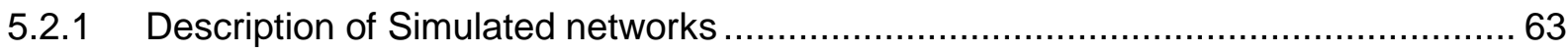

5.2.1.1 Network 1: São Paulo city (Bandeirantes x Nações Unidas ave.) …………….... 63

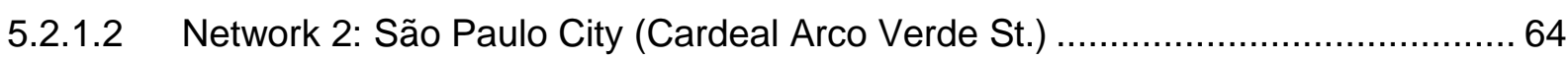

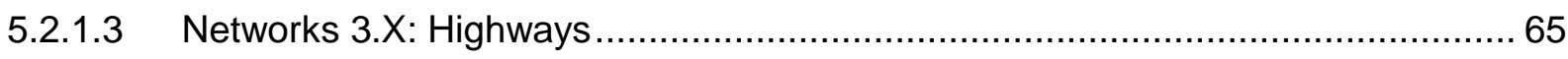

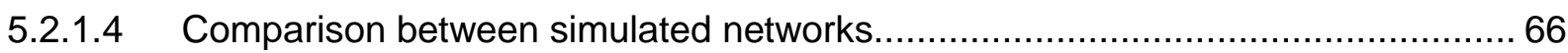




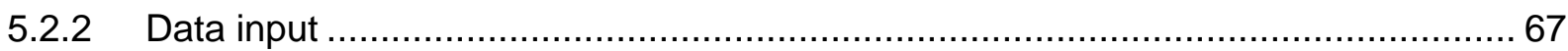

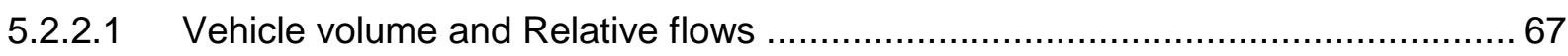

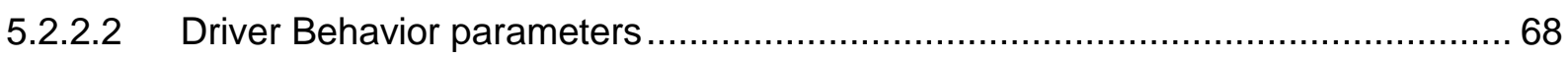

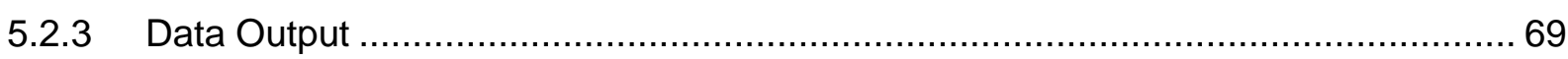

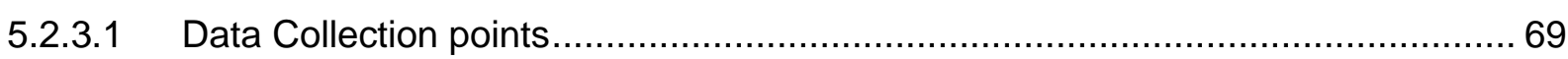

5.2.3.2 Travel time measurement ............................................................................. 70

5.3 ADDITIONAL MODEL ELEMENT: VEHICLE BREAK DOWN ................................ 71

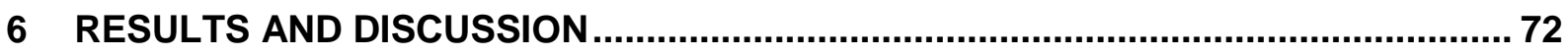

6.1 WIEDEMANN 74 X WIEDEMANN 99 COMPARISON............................................ 72

6.2 NETWORKS 1 AND 2 (URBAN): COMPARISON BETWEEN SCENARIOS .............. 73

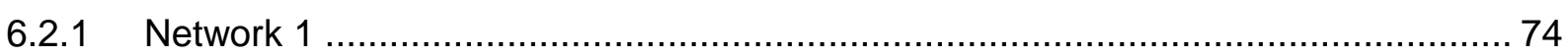

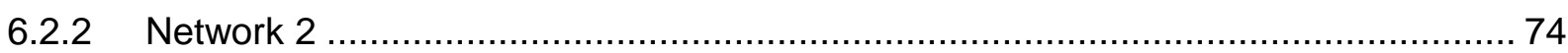

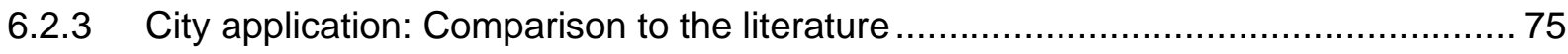

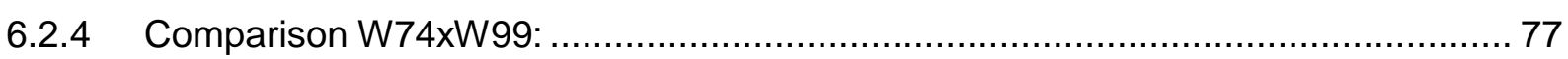

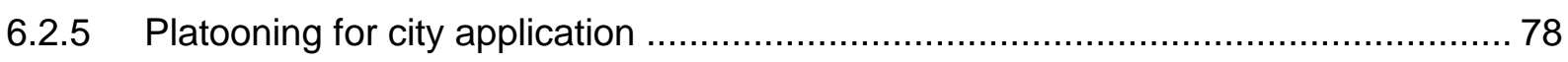

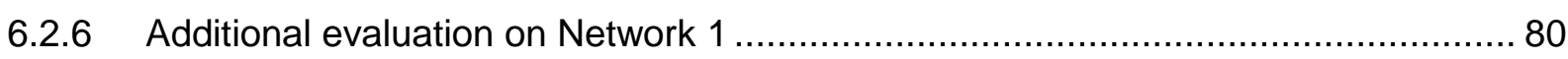

6.2.7 The proposition to faster overcome a disturbance ............................................... 80

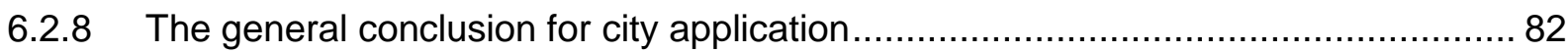

6.3 NETWORK 3 (HIGHWAYS): COMPARISON AMONG SCENARIOS ........................ 83

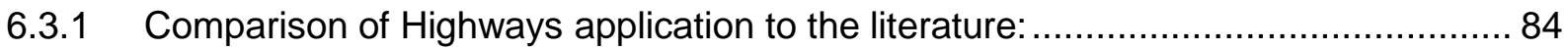

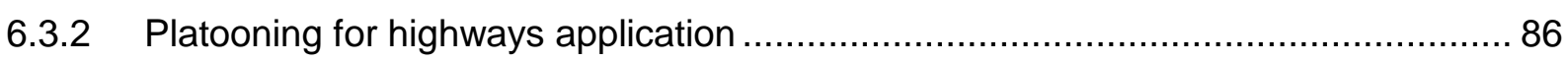

6.4 GENERAL PLATOONING EVALUATION ON TRAVEL TIME PERFORMANCE........90

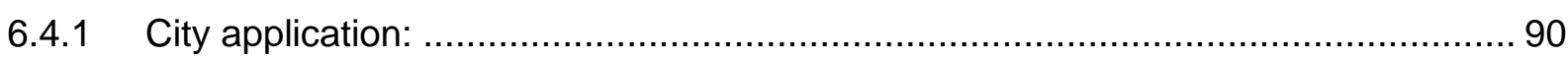

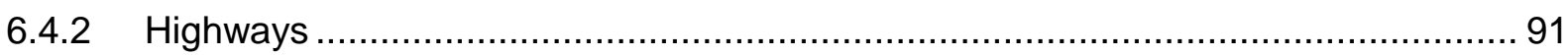

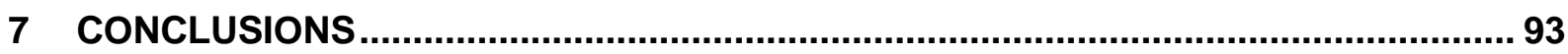

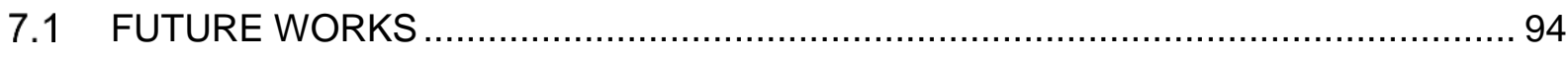

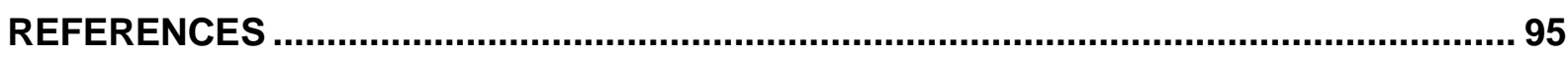

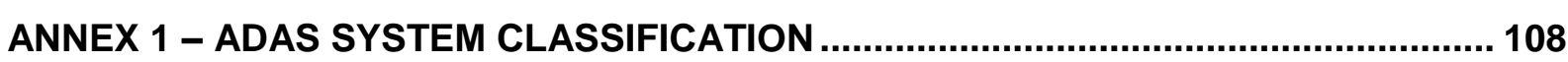

ANNEX 2 - LIST OF C-ITS PRIORITY SERVICES ...................................................... 109

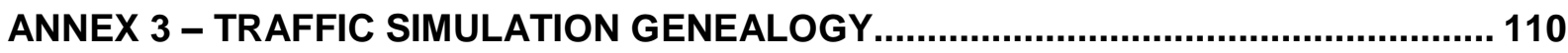

ANNEX 4- WIEDEMANN 99 ADJUSTABLE PARAMETERS....................................... 111

ANNEX 5- DATA INPUT FOR SIMULATED NETWORKS ......................................... 112 


\section{INTRODUCTION}

\subsection{CONTEXT}

Humans are almost 7.8 billion people globally, and United Nations estimates that this number will be nearly 10 billion in 2050 (UNITED NATIONS 2, 2019). The world urbanization prospects from the United Nations show that big cities will continue to re (UNITED NATIONS 2, 2019) despite the pace reducing. Simultaneously, Brazil's vehicle fleet almost doubled in the last ten years, from 54.5 million in 2008 to 100.7 million in 2018 (IBGE, 2019). In the same period, road infrastructure remained at the same level (CNT, 2020). These prospects reinforce the relevance of studies on Smart Cities and Intelligent Transportation Systems (ITS) context to keep the cities sustainable.

Mobility is a basic human need, and the demand is growing mainly in metropolitan areas (MEYER and SHAHEEN 2017). The decisions on how to go from "a" to "b" when you have several mobility options involve four main factors: 1) distance and time to achieve the destination, 2) cost, 3) safety, and 4) comfort (MADHUWANTHI et al., 2015). To match all those factors, including the environment, European Commission, in 2018, delivered a communication with the directives to the sustainable mobility for Europe, which they are: safe, connected, and clean c. This directive drives the main topics for overcoming current transportation challenges of reducing traffic jams and air pollution, improve energy efficiency and accessibility for all citizens (including the elderly and disabled). At the same time, changes in lifestyle, demographic changes, and the rise of the "Mobility-as-a-Service" (MaaS) concept are paving the way for a new mobility ecosystem in urban multimodal planning (MEYER \& SHAHEEN, 2017).

Following this path, the traditional Original Equipment Manufacturers (OEMs) as Audi and Daimler group in the last years have set a vision for the future of mobility based on four technology pillars: connected, autonomous, shared, and electric (AUDI, 2019; DAIMLER, 2019). The automotive business will change drastically, mainly for passenger cars. Owning a completely driverless vehicle as a personal car will not be possible for most of the population due to its cost (BANSAL \& KOCKELMAN, 2017). Buying a car will be much more related to an investment where during the time one is not using it, one could offer this availability as part of the mobility service. The most interested in being large fleet owners will be experts in some core aspects of vehicles or transportation as specialists on high-tech cars maintenance or logistics, energy supply/storage companies, owners of parking places, multimodal transportations companies, among others (JIA \& NGODUY, 2016).

A transition period is ongoing where the traditional OEMs and new high-tech players as Uber, Tesla, and Google frequently announce their progress on public roadside testing on 
autonomous vehicles. In this situation, it is clear that heterogeneous traffic will provoke a complex interaction between Human Driven Vehicles (HDV) and the driverless cars that have them from different automakers (including different systems providers) merging on the same road (GE et al., 2018).

This ecosystem will make our roads a mix of different car technologies for many years. For traffic agencies, this heterogeneous environment brings new challenges widely discussed on the legislation, legal responsibilities, cybersecurity, infrastructure, and road construction (dedicated lanes, ITS corridors) aspects.

The driverless car will require the merging o many technologies. At first, the driver assistance systems replace many technologies by perceiving the environment around and acting higher performance, reliability, and safety to take the passenger to the desired destination, known as Advanced Driver Assistant Systems (ADAS). The communication technologies complement with additional features that enable the data sharing from vehicle sensors and actuators, positioning, and routes with other vehicles, infrastructure, pedestrians, or any relevant elements. It leads to the so-called Vehicle-to-Everything communication (V2X), in close relationship with the Internet-of-Things (IoT) concept (SBD, 2018; FROST \& SULLIVAN, 2017; BAILEY, 2016; AISSIOUI et al., 2018).

Vehicle-to-vehicle communication (V2V) is part of V2X using a dedicated communication protocol to enable vehicles to exchange data with each other. It can develop new features as the Cooperative Cruise Control (also called platooning or automatic convoy). It brings new possibilities to improve traffic flow. The communication between is possible due to the development of Vehicular Ad Hoc Networks (VANETs) and 5G complying with low latencies, high reliability, safety, and data security requirements (FROST \& SULLIVAN, 2017; CHAI et al., 2017; AISSIOUI et al., 2018; 5G Automotive Association, 2019). The communication from the Vehicle-to-Infrastructure (V2I) brings additional possibilities for merging much real-time relevant information for improving traffic efficiency. Traffic lights timing, road signs, traffic jams, road accidents, bus service management, modals integration, and weather forecast, as well as historical data, are examples of relevant traffic-related data. These are the critical interfaces between the ITS and the Smart Cities (NETO et al., 2016; C-ITS, 2017; (CHEHRI et al., 2020). The joint of ADAS and V2X leads to Connected and Autonomous Vehicles (CAVs).

This complex combination of technologies raises many questions about validation and homologation aspects and data security robustness. Either way, vehicular field testing is essential in this process, but it is important to note that it is time-consuming and expensive. $A$ wide variety of traffic simulators are available to support this development, playing an important role in technology assessment, either individually or in their combination (SONGCHITRUKSA et al., 2016). 
The traffic simulators bring relevant outputs that can clarify different actors such as the government, industries, legal entities, and the population the real benefits that CAVs can bring to the mobility ecosystem. Therefore, traffic simulation can provide a more accurate estimation of these technologies' impact on traffic flow, test varied scenarios, and evaluate the most appropriate traffic behaviors to achieve the proposed goals (ZHANG et al., 2018).

The context where many characteristics of autonomous vehicles are required to improve traffic flow and reduce accidents will demand three pillars: the components smart cities, intelligent transportation systems leading, and automotive/technology industries. The use of traffic simulators is crucial to test hypotheses and speed up development. All these components and subcomponents were used in this research, and their interaction is described in Fig. 1.

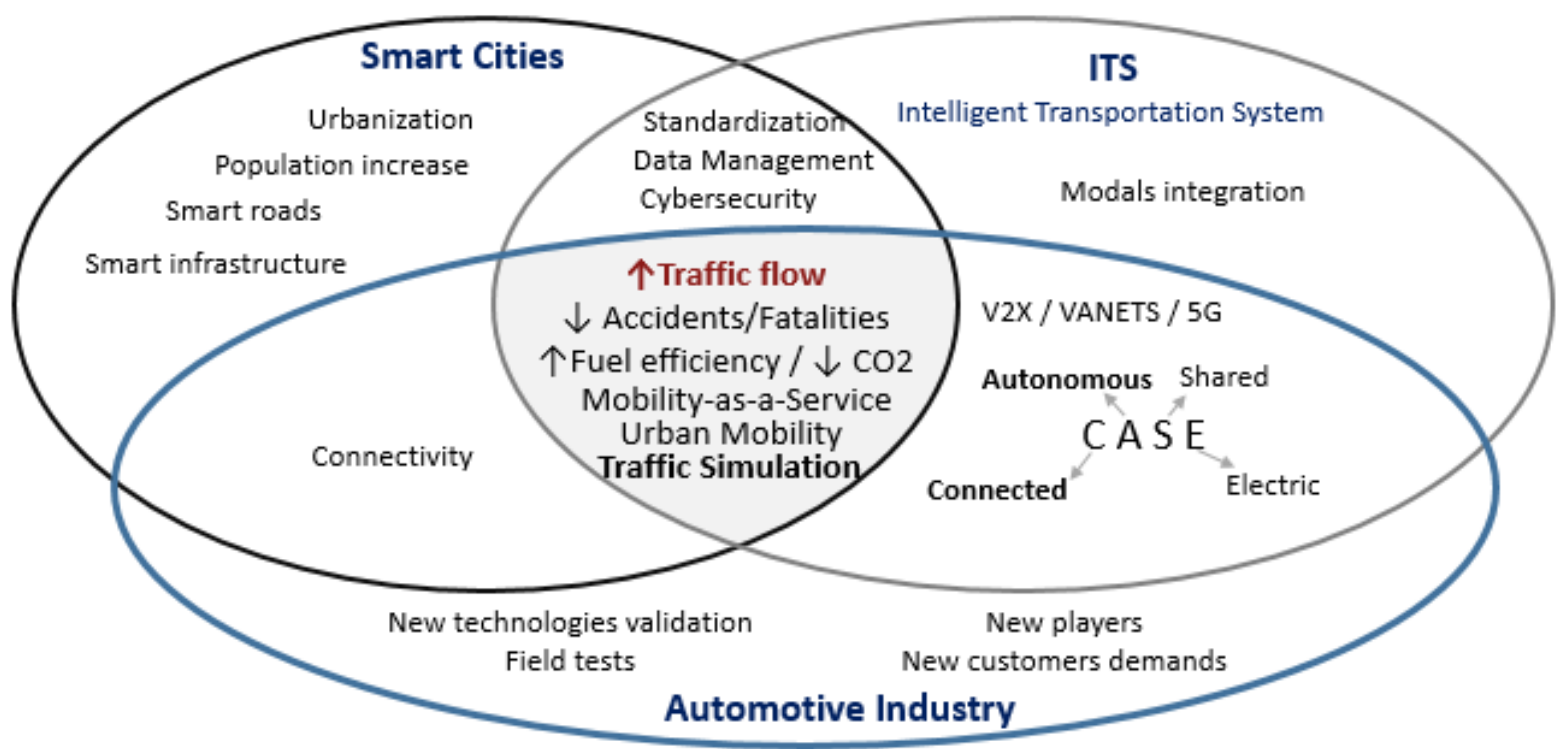

Source: Author.

Fig. 1. Context and fields in which the research localizes.

\subsection{MOTIVATION}

According to the Brazilian Institute of Geography and Statistics (IBGE) over National Household Sample Survey (PNAD) data from 2018 (PNAD, 2018), the average time spent from home to work in São Paulo city is around 45 minutes. More than $25 \%$ of the population spend more than 1 hour on this route. It directly affects the population's health and the economy.

CAVs bring new possibilities to reduce travel time significantly. Delivering reliable data from CAVs benefits to Brazilian cities' context can support these technologies' deployment and speed up their introduction on the roads.

In general, the traffic behavior impacts of AVs and CAVs technologies for cities and highways are the most valuable contributions from this research. It is essential to highlight one 
of the key topics was to evaluate one attention point from CAVs introduction: the transitions phases. Many different aspects will occur when roads have human-driven vehicles (HDV) and vehicles with varying automation levels defined by the SAE J3016 norm (SAE, 2018).

Besides, this research can be part of a set of studies that support Brazilian government decisions to accelerate the current path on approving regulations to make safety features mandatory, as airbag and Anti-lock Brake System (ABS) in 2014 and Electronic Stability Program (ESP) that will start in 2022. It can also support the approval of regulations to allow autonomous vehicle testing on a public road.

One important topic to mention is that measuring the benefits of CAVs on traffic conditions in Brazil is a topic still few explored. A few kinds of research were released with a focus on traffic performance on national universities.

The overall motivation comes from the possibility to contribute to an emerging and trend topic that can play a critical transformation role in society.

\subsection{OBJECTIVES}

This research aims to analyze, identify, and quantify the benefits of traffic flow from AVs and CAVs technologies for cities and highway applications. The analysis was also extended to the heterogeneous environment where autonomous and human-driven vehicles will coexist.

The specific objectives of this research are the following.

- To understand the characteristics of traffic microsimulation and choose one that suits the model and objectives proposed in the research.

- To use a traffic microsimulation to build a model with the following characteristics:

- High-density flow city roads in a big city in Brazil, including bus stops and the high number of motorcycles, and to measure the impacts of disturbances such as road accidents on traffic flow from that ecosystem.

- Highway application, including merging areas and exits for mixed fleets (passenger cars, trucks, and busses).

- To assess models that describe driver behaviors: the software object of the study uses the microscopic traffic models.

- To understand which features of autonomous vehicles distinguish from those human-driven and how these characteristics interfere with traffic microsimulation models.

- To assess the impact of autonomous vehicles on travel time.

- To assess the platooning/automated convoys impact on traffic flow for city and highway traffic characteristics, including the evaluation of optimal platooning size. 


\subsection{RESEARCH PROPOSAL}

This research looks for measuring the impacts of $A V s$ and $C A V s$ on the travel time for the mentioned mixed traffic environment considering big Brazilian cities' traffic characteristics. To bring new contributions, this research will evaluate for different scenarios how a disturbance (e.g., break down vehicle) affects traffic performance and proposes a rescue vehicle shared model to fasten attenuate the disturbance effects. Moreover, platooning features were evaluated to simulate CAVs characteristics. It was recently integrated into PTV VISSIM in September 2019. Fig. 2 illustrates the research gap.

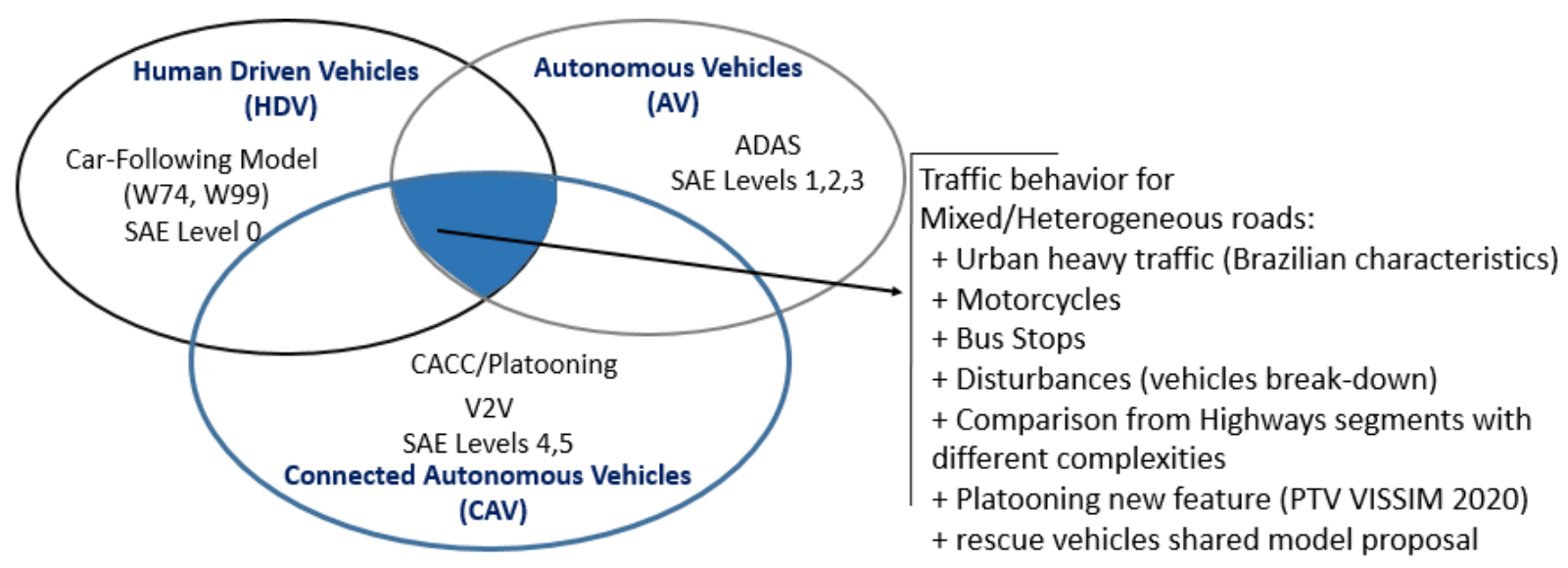

Source: Author.

Fig. 2. The research gaps.

Considering this research gap and topics that will be handled, this research aims to answer the following question:

- How will the CAVs influence traffic travel times for big cities and highways scenarios, including the transition phases?

\subsection{DOCUMENT ORGANIZATION}

The rest of this document is organized as follows.

Chapter 2 gives an overview of the key concepts from the automotive industry's future that drives this research, including the idea of CAVs and the tool used to develop this research: traffic microsimulation.

Chapter 3 describes and discusses the literature review from CAVs traffic simulation and the measured benefits on traffic flow.

Chapter 4 formally states the problem and the methodology to study the issue. 
Chapter 5 describes the methods, materials, scenarios evaluated, and software setups to validate the study.

Chapter 6 presents experimental results, the comparison between scenarios, and the discussions.

Finally, chapter 7 describes the conclusions of this research and suggestions for further investigations. 


\section{KEY CONCEPTS OF CONNECTED AND AUTONOMOUS VEHICLES AND TRAFFIC SIMULATION}

Connected and autonomous vehicle (CAV) research and developments are mainly focused on the following aspects: to reduce accidents, to increase fuel efficiency, to reduce emissions, and to improve traffic flow. To achieve that target, the vehicles need to be equipped with proper systems and technologies (PENDLETON, et al., 2017).

The most central concept when it comes to autonomous vehicles is to understand their classification. After many years of divergence, SAE International (Society of Automotive Engineers) released the first worldwide-adopted taxonomy and definitions for terms related to driving automation. The standard J3016 was first released in 2014 with two additional revisions in 2016 and 2018 (SAE, 2018). Fig. 3 shows a timeline with the evolution of this definition.

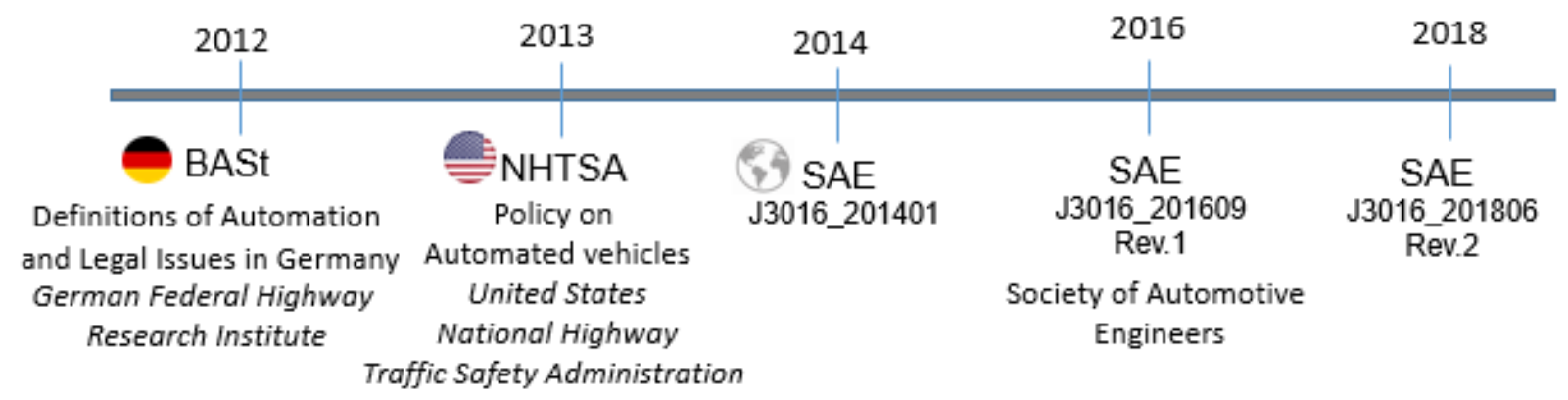
Source: Author.

Fig. 3. Taxonomy timeline of vehicle automation level standardization.

The standard classifies six different levels, from no automation to full automation. The higher the automation level is, the lower is the driver inputs dependency. Nevertheless, the higher the automation, the higher the Advanced Driver Assistance Systems (ADAS) dependency requires an incremental combination of sensors (ultrasonic, camera and LiDAR), the control of active drivability systems vehicle communication features. In fact, on SAE Level 5 , the vehicles will not need a physical accelerator, brake pedals, or steering wheels; the driver will become a passenger (SAGIR \& UKKUSURI, 2018).

Fig. 4 shows the definition of each automation level and ADAS examples. 


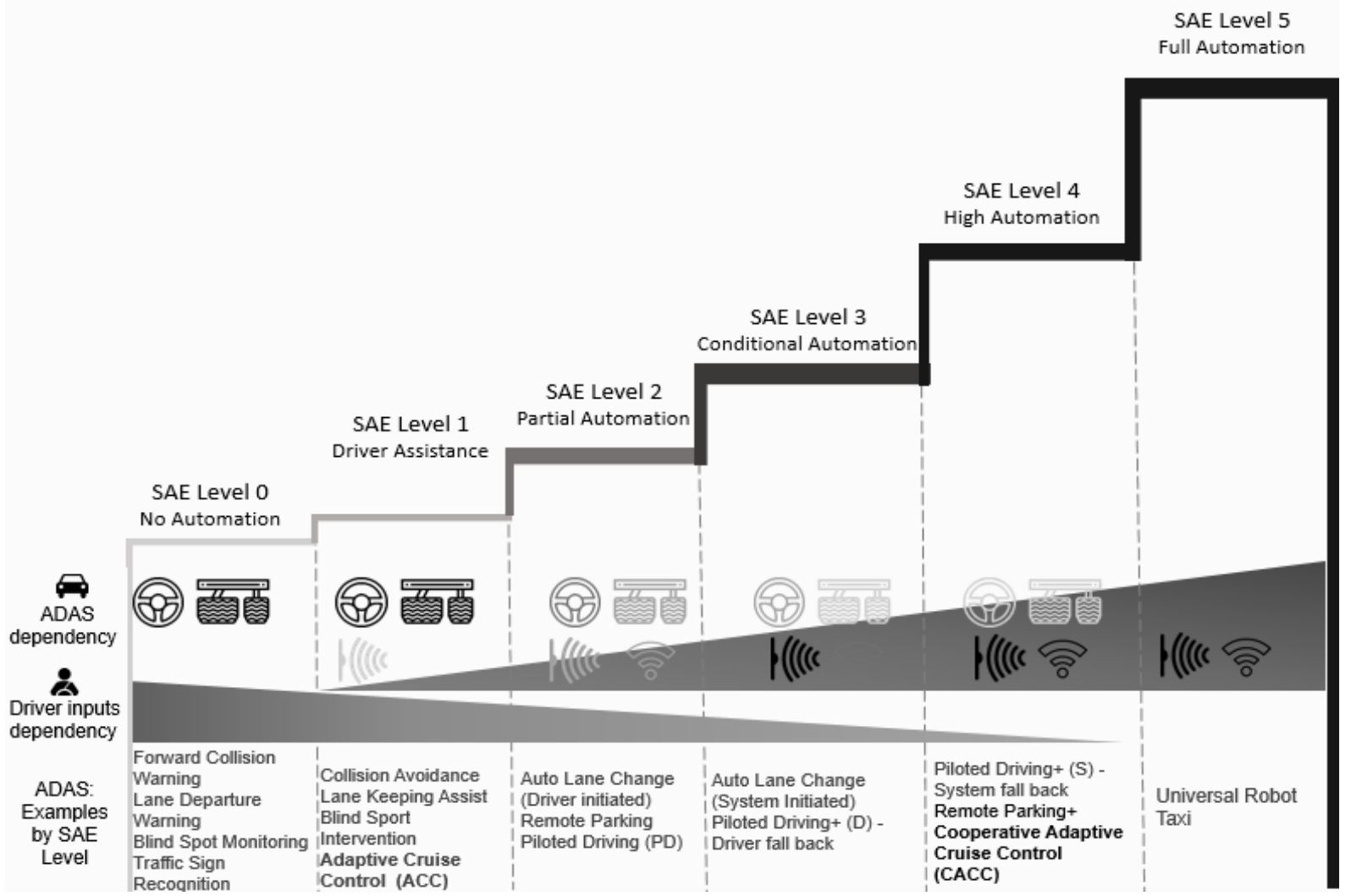

Fig. 4. SAE automation levels.

Source: Adapted from SAE J3016 (SAE, 2018).

To illustrate the path of automation level development, Audi A8 was the world's first production car to have achieved Level 3 (IEEE Spectrum, 2017). Companies are focused on Level 4 automation within geographical areas or weather conditions (ANDERSON, 2020). Waymo from the Alphabet group announced their first tests on level 4 vehicles on streets in October 2017 (WAYMO, 2020). In partnership with Torq Robotics, Mercedes-Benz started the first public road test of an autonomous truck, Level 4, in September 2019 in Virginia, USA, expanding this test to new public routes (DAIMLER TRUCKS, 2020).

To understand the autonomous vehicles' benefits on traffic performance, it is essential to explore some crucial concepts from vehicle dynamics, traffic engineering, and driver behavior. Let us consider Fig. 5 to illustrate traffic engineering parameters.

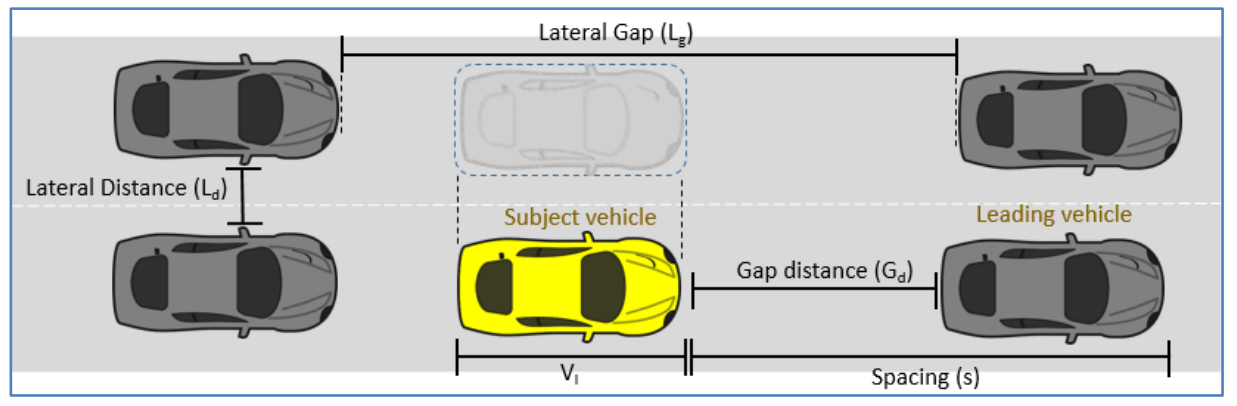

Source: Author.

Fig. 5. Traffic engineering parameters 
The following is a description of the parameters shown in Fig. 5.

- Spacing (s): is the distance between the front bumper of two consecutive vehicles.

- Gap distance $\left(\mathbf{G}_{\mathbf{d}}\right)$ : is the distance between the rear bumper of the leading vehicle and the subject vehicle's front bumper, where headway focuses on front-to-front spaces.

- Headway (h): a measure of the temporal space between two vehicles. The front bumpers of successive cars are used as a reference.

- Time Gap $\left(\mathrm{T}_{\mathrm{g}}\right)$ : a measure of the temporal space between two vehicles. Anyhow the references now are the rear bumper and front bumper of successive cars. The time gap is the ratio between spacing and speed. This concept is linked to driver behavior, socalled safety distance. The higher the speed, the higher the distance a human driver maintains from the vehicle forward. It is essential to mention that this safety distance is not proportional to human drivers' vehicle brake performance. It means that independent from the brake performance one individual in a determined vehicle speed will keep the same time distance.

- Lateral Gap $\left(\mathrm{L}_{g}\right)$ : is the front to rear bump distance between two vehicles placed at the subject vehicle's side lane. This distance affects the driver's behavior decision of lane changing. It also affects the possibility of traveling at a higher speed if the driving condition in the target lane is better than that in the current lane (YE \& YAMAMOTO, 2017). The perception of a proper lateral gap to perform the maneuver is also dependent on the speed.

- Lateral distance $\left(L_{d}\right)$ : is the distance between side-by-side vehicles. The lateral mirrors or cameras are used as a reference. This concept is especially relevant for traffic jams.

- Driver reaction time $\left(\mathbf{R}_{\mathrm{T}}\right)$ : usually defined on simulations as the time lag that the follower uses to react to the leader's change in driving behavior during a car following. In real traffic, it corresponds to the time delay between the brake lights lit from the leading vehicle and the brake pedals touch in the pursuing car. It is affected by several factors on a human-driven vehicle, from the driver distraction to the driver experience (ZHANG \& BHAM, 2007; WERF, SLADOVER, MILLER, \& KOURJANSKAIA, 2002).

- Stopping Side Distance (SSD): is the distance a vehicle needs to a full stop. It is a consolidated formula used in the transportation engineering field (FHWA, 1997) which the mathematical model is described as: 


$$
S S D=1,47 V(R T)+\frac{V^{2}}{2 g\left[f \pm\left(\frac{G}{100}\right)\right]}
$$

where $S S D$ is the Stopping Side Distance $(\mathrm{m}), V$ is the vehicle speed $(\mathrm{km} / \mathrm{h}), R_{T}$ is the driver Reaction Time (s), $g$ is the gravity, $f$ is the friction coefficient, and $G$ the inclination or slope (\%).

In Table 1, it is presented as a numerical example from equation 1. The human driver's reaction time is around $0,8 \mathrm{~s}$ to $1 \mathrm{~s}$, considering an experienced driver, with no distractions or fatigue. It means that if an autonomous vehicle has a faster reaction time, the SSD can be considerably reduced.

Table 1: (a) Values used on the calculation of SSD numerical example. (b) A numerical example of SSD parameter

\begin{tabular}{lcc} 
Variable & Unit & $\begin{array}{c}\text { Value used on the } \\
\text { example }\end{array}$ \\
\hline$S S D:$ stop distance & $m$ & $\rightarrow$ \\
\hline$V:$ Speed & $\mathrm{m} / \mathrm{s}$ & $25=90 \mathrm{~km} / \mathrm{h}$ \\
\hline$R_{T}:$ Reaction Time & $\mathrm{s}$ & $\rightarrow$ \\
\hline$g:$ gravity & $\mathrm{m} / \mathrm{s}^{2}$ & $9.8 \mathrm{~m}$ \\
\hline : friction coefficient & & 0.8 \\
\hline G: inclination/slope & $(\%)$ & $0 \%$ \\
\hline
\end{tabular}

Source: Author

\begin{tabular}{cc}
\hline$R_{T}(\mathrm{~s})$ & (b) \\
& \\
\hline 2 & 104.13 \\
\hline 1 & 67.38 \\
\hline 0.8 & 60.03 \\
\hline 0.6 & 52.68 \\
\hline 0.4 & 45.33 \\
\hline 0.2 & 37.98 \\
\hline 0 & 30.63 \\
\hline
\end{tabular}

- Safe Speed: the highest speed a vehicle can drive on an accident-free model where the subject vehicle can stop even on sudden braking from the leading vehicle (TREIBER \& KESTING, 2013). The safe speed is defined as

$$
v_{\text {Safe }}=-b R_{T}+\sqrt{b^{2} R_{T}^{2}+V_{l}^{2}+2 b\left(s-s_{0}\right)}
$$

where $R_{T}$ is the driver reaction time (s), $b$ is the constant braking deceleration $\left(\mathrm{m} / \mathrm{s}^{2}\right)$, is $V_{l}$ the leading vehicle speed $(\mathrm{m} / \mathrm{s})$ and $\left(s-s_{0}\right)=\mathrm{Gd}$ as gap distance $(\mathrm{m})$.

In Table 2, it is presented as a numerical example from equation 2. Considering a harsh deceleration $\left(-5 \mathrm{~m} / \mathrm{s}^{2}\right)$, a human driver can drive at $97.26 \mathrm{~km} / \mathrm{h}$ on accident-free mode on a highway at $100 \mathrm{~m}$ distance from the leading vehicle and reaction time around 1s. For lower reaction times, this speed can be $15 \%$ higher. In an urban environment, at a $10 \mathrm{~m}$ distance from the leading vehicle, the safe speed difference can be above $50 \%$ from a usual human driver to a system with a slower reaction time. It means that it is possible to correlate a lower reaction time with higher safe speeds that could benefit the traffic flow.

This group of traffic engineering parameters presents the aspects involved in traffic, vehicle dynamics, and driver behaviors that characterize human-driven vehicles. They are the basis to discuss how CAVs technologies will affect traffic conditions. 
Table 2: (a) Values used on the calculation of Safe Speed numerical example. (b) Results from the numerical example from the Safe Speed parameter.

(a)

\begin{tabular}{lcc}
\hline Variable & Unit & $\begin{array}{l}\text { Value used } \\
\text { on example }\end{array}$ \\
\hline $\begin{array}{l}b: \text { braking constant } \\
\text { deceleration }\end{array}$ & $\mathrm{m} / \mathrm{s}^{2}$ & 5 \\
\hline$R_{T}:$ Reaction Time $(\mathrm{s})$ & $\mathrm{s}$ & $\rightarrow$ \\
\hline $\begin{array}{l}V_{1}: \text { Leading vehicle } \\
\text { speed }\end{array}$ & $\mathrm{m} / \mathrm{s}$ & 0 \\
$\begin{array}{l}\text { (s-so): Gd - gap } \\
\text { distance }\end{array}$ & $\mathrm{m}$ & $\rightarrow$ \\
\hline
\end{tabular}

Source: Author

\begin{tabular}{ccc}
\hline & (b) & \\
\hline RT $(\mathbf{s})$ & $\begin{array}{c}\text { Gd=100m } \\
\text { Safe Speed } \\
(\mathbf{k m} / \mathbf{h})\end{array}$ & $\begin{array}{c}\text { Sd= } 10 \mathrm{~m} \\
\text { Safe Speed } \\
(\mathbf{k m} / \mathbf{h})\end{array}$ \\
\hline 2 & 83.4 & 14.91 \\
\hline 1 & 97.26 & 22.25 \\
\hline 0.8 & 100.35 & 24.37 \\
\hline 0.6 & 103.55 & 26.79 \\
\hline 0.4 & 106.87 & 29.51 \\
\hline 0.2 & 110.3 & 32.58 \\
\hline 0 & 113.84 & 36 \\
\hline & & \\
\hline
\end{tabular}

\subsection{AUTONOMOUS VEHICLES}

The first definitions of Autonomous Vehicles (AVs) were usually related to a composition of different ADAS systems that would perform the core vehicle dynamics behaviors independent from the driver (RAJESH, 2006). Anyhow, this definition became limited when the target is to transfer completely to the vehicle the responsibility to autonomously accelerate and brake and execute longitudinal and lateral movements and maneuvers. These activities are under development based on how humans perceive, plan and act over the environment during driving, replacing it with an extensive range of sensors, actuators, and artificial intelligence (PENDLETON et al., 2017; FROST \& SULLIVAN, 2017; HE et al. 2019).

The subject vehicle can continually monitor vehicles surrounding, leading to deterministic behavior compared to human drivers and almost instantaneous reaction time when relevant changes in the driving environment are assessed (MAHMASSANI, 2016). AVs are in continuous development to a broader application, including covering the limits of driving domains. Humans' capabilities are limited due to environmental, geographical, time-of-day restrictions. The Operational Design Domains (ODD) is defined as the conditions a human driver or an autonomous vehicle can operate (SAGIR \& UKKUSURI, 2018).

The Adaptive Cruise Control (ACC) was the first ADAS to control longitudinal vehicle motion, also referred to as the first step on AVs roadmap (RAJESH, 2006). The Intelligent Driver Model (IDM) has been developed and enhanced for several kinds of research over the years to model ACC and other aspects from AV (TREIBER et al., 2000; KESTING et al., 2010; SCHAKEL et al., 2010; SHLADOVER et al., 2012; TREIBER \& KESTING, 2013; DERBEL et al., 2013; 
MAHMASSANI, 2016; ZHOU et al.,2017; XIE et al., 2019). IDM considers some aspects as no exact reaction time or destabilizing effects on acceleration and braking caused by human imperfections (DO et al., 2019).

IDM specifies a subject vehicle acceleration as a continuous function of its current speed, the ratio between the current spacing to the desired spacing, and the vehicle speed difference between the leading and the subject vehicle as

$$
\alpha_{I D M}=a\left[1-\left(\frac{v}{v_{o}}\right)^{\delta}-\left(\frac{G_{d}{ }^{*}(v, \Delta v)}{G_{d}}\right)^{2}\right]
$$

where $a$ is the comfortable acceleration rate $\left(\mathrm{m} / \mathrm{s}^{2}\right), G_{d}$ are the distance from the subject and leading vehicle $(\mathrm{m}), v$ is the subject current vehicle speed $(\mathrm{m} / \mathrm{s}), v_{o}$ is the desired (safety) speed $(\mathrm{m} / \mathrm{s}), \Delta v$ is the speed difference between the subject vehicle and the leading vehicle $(\mathrm{m} / \mathrm{s}), \delta$ is the parameter that decides the magnitude of acceleration decrease depending on the vehicle speed, $G_{d} *$ is the desired distance (safety gap) described as

$$
G_{d}{ }^{*}(v, \Delta v)=G_{d_{o}}+\max \left[0, v T+\left(\frac{v \Delta v}{2 \sqrt{a b}}\right)^{2}\right]
$$

Where $G_{d_{o}}$ is the minimum gap (m),T is a constant value representing the desired gap (m), $a$ is the comfortable acceleration rate, and $b$ is the deceleration rate (TREIBER \& KESTING, 2013; DO et al., 2019).

IDM acceleration and deceleration rates are plausible for most situations other than when the gap between the subject vehicle and the leading vehicle is significantly lower than the desired interval or gap. TREIBER \& KESTING (2013) combined the IDM and the Constant Acceleration Heuristics (CAH) to avoid unrealistic deceleration rates. The frameworks of $\mathrm{CAH}$ matches with some assumptions from CAVs, as:

i. The leading vehicle will not change its acceleration suddenly in the following seconds.

ii. Safe time headway or minimum distance do not need to be considered.

iii. Drivers reaction time is zero (no delays).

Considering the gap $G_{d}$, the subject vehicle speed $v$, the leading vehicle speed $v_{l}$ and constant acceleration of both vehicles $\dot{v}$ and $\dot{v}_{1}$, the maximum acceleration max $(\dot{v})=\alpha_{\mathrm{CAH}}$ that prevents accidents is described as

$$
\alpha_{C A H}\left(G_{d}, v, v_{l}, \dot{v}_{l}\right)=\left\{\begin{array}{c}
\frac{v^{2} \bar{a}_{l}}{v_{l}-2 G_{d} \bar{a}_{l}}, \text { if } v_{l}\left(v-v_{l}\right) \leq-2 G_{d} \bar{a}_{l} \\
\bar{a}_{l}-\frac{\left(v-v_{l}\right)^{2} \theta\left(v-v_{l}\right)}{2 G_{d}}, \text { otherwise }
\end{array}\right.
$$

where $\bar{a}_{l}\left(\dot{v}_{l}\right)=\min \left(\dot{v}_{l}, a\right)$ is the adequate acceleration used to outline the situation where the leading vehicle acceleration capability is higher than the subject vehicle acceleration. The condition $v_{l}\left(v-v_{l}\right) \leq-2 G_{d} \bar{a}_{l}$ is valid if the vehicles stop until the minimum gap $G_{d}=0$ is 
achieved. It means that negative approaching rates make no sense, and it is handled by Heaviside step function $\theta(x)$ (with $\theta(x)=1$ if $x \geq 0$ and zero, otherwise).

IDM and the CAH acceleration models combined lead to the ACC model formulated as (TREIBER \& KESTING, 2013):

$$
\alpha_{A C C}=\left\{\begin{array}{lr}
\alpha_{I D M}, & \text { if } \alpha_{I D M}>\alpha_{C A H} \\
(1-c) \alpha_{I D M}+c_{l}\left[\alpha_{C A H}+b \tanh \left(\frac{\alpha_{I D M}-\alpha_{C A H}}{b}\right),\right. & \text { otherwise }
\end{array}\right.
$$

Where $c$ is the coolness factor, for $c=0$, the ACC model comes to IDM, while $c=1$ means no speed difference exists. TREIBER \& KESTING, 2013, had assumed c =0.99.

\subsection{CONNECTED VEHICLES}

Connected Vehicles (CV) will bring additional capabilities that humans are not able to. It will carry a complete assessment to perceive directly and instantly beyond the sensor range, as illustrated in Fig. 6. It will be enabled mainly by vehicle to everything communication (V2X) technology together with high-definition (HD) online mapping, analytics, and stored big data (JIA \& NGODUY, 2016; FROST \& SULLIVAN, 2017; UHLEMANN, 2016; SBD, 2018). CVs are based on the Cooperative Intelligent Transportation Systems (C-ITS) strategy defined by the European Commission to improve road safety and traffic efficiency (C-ITS, 2017; SINGH et al.., 2019).

The framework from connected vehicles is the ability to exchange information. For that, V2X capabilities include (for additional applications, see Annex 2):

- Vehicle-to-Vehicle (V2V): this technology enables each vehicle to be a gateway from its information and the whole ecosystem connected to it. It allows features as Cooperative Adaptive Cruise Control (C-ACC) or platooning (MAHMASSANI, 2016; DOLLAR \& VAHIDI, 2017; Ll et al., 2020).

- Vehicle-to-Infrastructure (V2I): this technology enables the vehicle to broadcast information with infrastructure over the Roadside Units (RSU), telecom infrastructure, radars, or traffic signs. It allows accessing and sharing real-time data from the weather forecast, road conditions, online traffic information, historical data, and traffic signals timing (GUO \& BAN, 2019; SINGH et al., 2019).

- Other V2X technologies: Vehicle-to-Pedestrian (V2P), Vehicle-to-Network (V2N), Vehicle-to-Home (V2H) (CHEHRI et al., 2020), and additional connectivity that matches with the Internet of Thing (IoT) concepts (MIR \& FITALI, 2016).

Fig. 6 shows examples of V2X capabilities. 


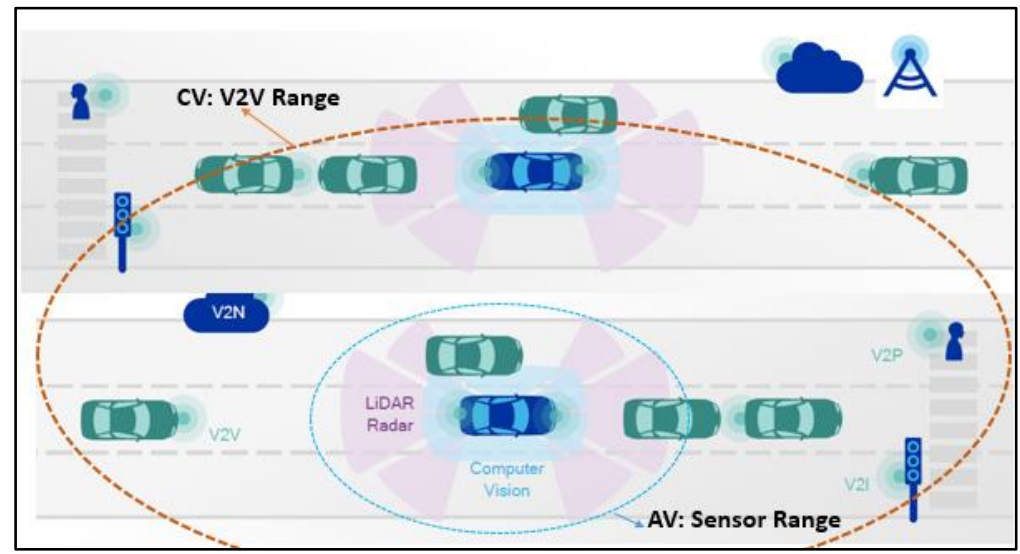

Fig. 6. V2V allows CAV vehicles to scan a broader vehicle ecosystem beyond the sensors range Source: adapted from Qualcomm (2016).

V2X network infrastructure and requirements were standardized over IEEE.802.11p/DSRC (IEEE, 2010) allows the data exchange with wireless Access's characteristics in Vehicular Environments (WAVE). It includes multiple propagation paths, high node dynamism, high bandwidth, and low latency (PENDLETON et al., 2017; VUKADINOVIC et al., 2018; HE et al., 2019).

However, in the last five years, the development of $5 G$ brought new discussions opportunities, as it was conceived to fulfil V2X requirements (Trafic Technology International, 2017; 5G Automotive Association, 2019; LUCERO, 2016; AISSIOUI et al., 2018; HUSSAIN, HUSSAIN, \& ZEADALLY, 2019; SINGH et al., 2019).

The current picture is that there is no convergent decision about adopting DSRC or $5 \mathrm{G}$. Pros and cons of technologies application, time to market, and costs are under discussion (AISSIOUI et al., 2018; LUCERO, 2016; SBD, 2018).

\subsection{CONNECTED AND AUTONOMOUS VEHICLES (CAV)}

To achieve high dependability for higher automation levels, including reliability and safety, the interface between a connected and autonomous vehicle will merge. CAV is a terminology adopted in the last few years to vehicle clustering features as Cooperative Adaptive Cruise Control (CACC) will require the full integration between sensors and communication technologies to control the vehicle's dynamics considering overall predictability from the road environment (CALVERT et al., 2020). CAVs will merge the technologies to enable the broad application of Artificial Intelligence (Al), including being adaptive, self-learning and foresight of future events on the road (uptime), and making a historical analysis based on big data analytics.

Fig. 7 illustrates the convergent point between AV and CV technologies. 


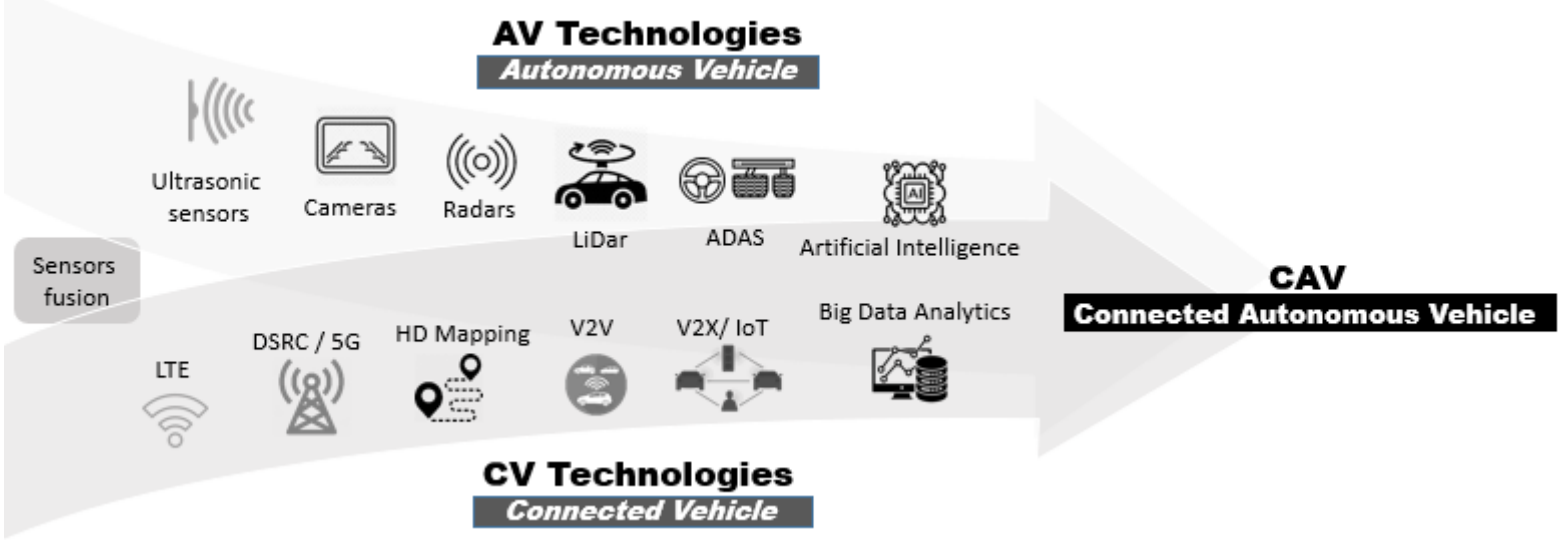

Source: Author.

Fig. 7. CAV technologies roadmap

CAVs will enable cooperative driving features that allow lower gap distances, shorter lateral distances, and optimized merging conditions. It will process a considerable amount of real-time data from vehicles around that. Simultaneously, it will make useless the former mandatory components on the human driver environment (e.g., brake lights, turn indicators, and horns). On the other hand, Al algorithms together with big data analytics will be essential players to replace distinctive human capabilities as context-sensitivity (memory effect of present and past overall traffic conditions), courtesy, and cooperation (particularly relevant for merging and lane changes situation) (TREIBER et al., 2000; DO et al., 2019, HE, et al. 2019).

The EU recently introduced legislation that requires OEMs to fit e-Call (Emergency Calls) as standard on all new vehicles. e-Call regulation could mean that all OEMs in the EU will have an embedded SIM-card (Subscriber Identity Module) in the future that enables as a fundamental feature the vehicles to send a warning to the authorities on an accident automatically. It was expected that around $60 \%$ of new cars sold in the EU and US would be equipped with embedded connectivity by 2020 (SBD, 2018). MEYER \& SHAHEEN (2017) states that fully CAVs, where a driver no longer must steer or adjust speed, could be commercially available within the next 1020 years.

Coming to the relevant concepts, CACC is frequently used to model CAVs, incorporating communication technologies into ACC (JIA \& NGODUY, 2016; MAHMASSANI, 2016; ZHOU et al., 2017; GE et al., 2018; DO et al., 2019). DO (2019) presents a survey of studies of CACC that highlight benefits on traffic flow considering shorter headway (i.e., 0.5 seconds) compared to the ACC (i.e., 1.4 seconds), mainly due to V2V technologies that bring a different approach to minimum safety distance. Field tests showed the same tendency to shorten time gaps due to faster response on changing behavior from the leading vehicle (SCHLADOVER et al., 2010).

ZHAO \& SUN (2013) based on previous studies by KESTIN et al. (2008), proposed acceleration equations for $\mathrm{ACC}$ and $\mathrm{CACC}$ acceleration. The acceleration model is a linear 
function between the subject vehicle and the leading vehicle and the current speed. The accelerations of vehicles are described by equations (7) and (8) for ACC vehicles and (9) and (10) for CACC (PARK et al., 2017) as

$$
\begin{gathered}
a_{c A C C}=k_{v} \cdot\left(v_{l}-v_{s}\right)+k_{s} \cdot\left(s-v \cdot t_{d}\right) \\
a=\max \left[a_{\min }, \min \left(a_{c}, a_{\max }\right)\right] \\
a_{c C A C C}=\boldsymbol{a}_{\boldsymbol{l}}+k_{v}\left(v_{l}-v_{s}\right)+k_{s} \cdot\left(s-v \cdot t_{d}\right) \\
a=\max \left[a_{\min }, \min \left(a_{c}, a_{\max }\right)\right]
\end{gathered}
$$

where $a$ is the acceleration in the next step of the subject vehicle, $\boldsymbol{a}_{\boldsymbol{l}}$ is the acceleration of the leading vehicle (the only additive variable added at CACC), $v_{s}$ and $v_{l}$ are the vehicle speed of the subject and leading vehicles, respectively, $a_{\max }$ is the maximum allowed acceleration, $a_{\min }$ is the maximum allowed deceleration, $k_{v}$ and $k_{s}$ are constant gains greater than zero.

On the other hand, Van AREM et al. (2006) developed the Microscopic Model for Simulation of Intelligent Cruise Control (MIXIC), which is compatible with CACC. The first focus of the study was to assess the throughput and stability impacts of the system. Results showed better stability and average speed increase on a freeway lane drop with increasing penetration of CACC. The model can incorporate V2V by sharing relevant information from leading vehicles to subject one, like vehicle speed, acceleration, and braking, assuming that the delay is zero (SHLADOVER et al., 2012; DO, et al., 2019).

On MIXIC basic model, the safe following distance is given by

$$
r_{\text {safe }}=\frac{v^{2}}{2} \cdot\left(\frac{1}{d_{p}}-\frac{1}{d}\right)=t_{\text {system }} \cdot v
$$

where $v$ is the subject vehicle speed, $d_{p}$ and $d$ are the deceleration capability of the leading and subject vehicles, respectively. $t_{\text {system }}$ is the time headway $(0.5$ seconds if the leading vehicle has CACC function and 1,4 seconds, otherwise). It means that for CACC equipped vehicles, the safe distance can be almost three times lower. SONGCHITRUKSA et al. (2016) stated that a proper time headway for CACC could be as small as 0.6 seconds. Fig. 9 illustrates it.

TELEBPOUR \& MAHMASSANI (2016) developed important concepts for CAVs based on MIXIC. The framework is that the speed of the CAV enables it to stop at the sensor detection range. The model that calculates safe speed considering it is

$$
\begin{gathered}
\Delta X_{n}=\left(X_{n-1}-X_{n}-l_{n-1}\right) v_{n} \tau+\frac{v_{n-1}^{2}}{a_{a n-1}^{\text {decc }}} \\
\Delta X_{n}=\min \left(\text { SensorDetectionRange, } \Delta X_{n}\right) \\
v_{\text {max }}=\sqrt{-2 a_{i}^{\text {decc }} \Delta X}
\end{gathered}
$$


where $n$ and $n-1$ are the subject and the leading vehicles, respectively. $X_{n}, I_{n}, V_{n}, \tau$, and $a_{n}^{\text {decc }}$ denotes the position, the length, the vehicle speed, the reaction time, and the maximum deceleration of the subject vehicle $n$, respectively.

The researchers defined the safe following distance $\left(\mathrm{s}_{\text {safe }}\right)$ and the following distance based on the reaction time $\left(\mathbf{s}_{\text {system }}\right)$ as

$$
\begin{gathered}
S_{\text {safe }}=\frac{v_{n-1}^{2}}{2} \cdot\left(\frac{1}{a_{n}^{\operatorname{decc}}}-\frac{1}{a_{n-1}^{\operatorname{dec} c}}\right) \\
S_{\text {sytem }}=v_{n} \tau
\end{gathered}
$$

It leads to the acceleration of CAV given by

$$
a_{n}(t)=\min \left[a_{n}^{d}(t), k\left(v_{\max }-v_{n}(t)\right]\right.
$$

$\mathrm{k}$ is a model parameter that is the same as the basic MIXIC (TELEBPOUR \& MAHMASSANI, 2016; DO, et al., 2019).

YE \& YAMAMOTO (2017) denotes the anticipation distance capability (based on the premise that CAVs can obtain the exact value of the distance gap). Equation 18 clearly shows the driver behavior difference when the leading vehicle is a CAV or an HDV (for mixed scenarios), given by

$$
d_{\text {anti }}^{C A V}=\left\{\begin{array}{c}
d+v_{\text {anti }}, \text { if } v_{l} \text { is a CAV } \\
d+v_{\text {anti }}-b_{\text {defense }}, \text { otherwise }
\end{array}\right.
$$

where $d$ is the distance gap between subject and leading vehicle, $V_{a n t i}$ is the leading vehicle's expected speed, and $b_{\text {defense }}$ is the randomization-deceleration rate under the defensive state. This equation is on the worst-case where a CAV is following an HDV. As HDV driving behavior is unpredictable, the CAV always needs to drive on the defensive.

YE \& YAMAMOTO (2017) incorporate the connectivity characteristics of V2V on the safe speed of a CAV as

$$
v_{\text {anti }}^{C A V}=\min \left(d_{l}, v_{l}+a, v_{\text {max }}, v_{l i}\right)
$$

where $v_{l i}$ is the average speed of leading $\mathrm{CV}$ within the communication distance range, $v_{l}$ and $d_{l}$ are the speed and gap distance from the leading vehicle, respectively.

Fig. 8 shows the evolution path of mathematical modeling of AVs, CVs, and CAVs expressed along with equations (3) (19). 


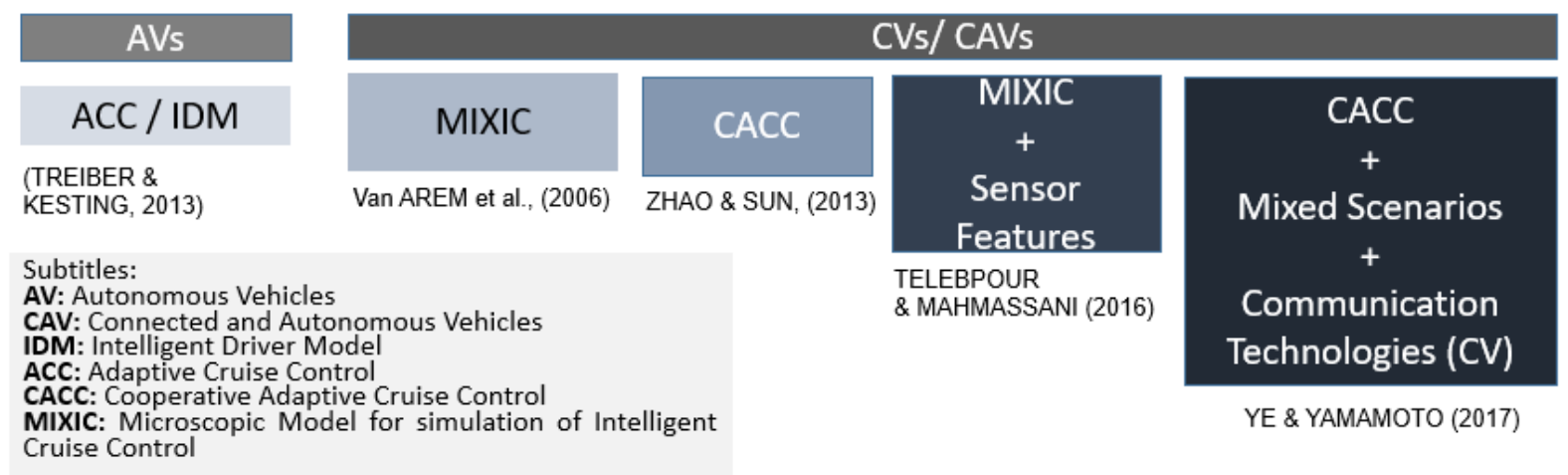

Source: Author.

Fig. 8. Mathematical models Evolution from AVs, CVs, and CAVs

\subsubsection{Deep dive on CACC/Platooning}

A sophisticated feature that CAVs enable is platooning, also called an automated convoy. The first public assessment of the technology dates from more than 20 years ago, in 1997 where the National Automated Highway Systems Consortium (NAHSC) conducted a public demonstration of eight fully automated cars driving in convoy in San Diego, California. The road was equipped with reference magnets for steering maneuvers, and the communication between vehicles was based on radio technologies (RAJESH, 2006).

The current approach for platooning is to use CACC as a framework. Its sensors and V2V communication technologies make it possible to create a group of vehicles electronic engaged. The first vehicle has responsibility for leading the convoy setting the speed, lane, and directions. The other vehicles act as slaves or followers (RAHMAN \& ABDEL-ATY, 2017).

The vehicles at the platoons use an Identification number (ID) to represents their sequential position on the convoy. The leader ID is zero, and the other vehicles have the ID number increased by one unit $(1,2,3 \ldots)$ sequentially until the maximum allowed platoon size. Suppose a vehicle is approaching the platoon, and the maximum platoon size is already achieved. In that case, this vehicle will start a new platoon where the inter platoon time headway should be considered. The maximum platoon size can depend on many different factors like the road type, maximum vehicle speed allowed, and vehicle models (SERAJ et al., 2018; GONG \& DU, 2018).

The relevant variables that will determine the platoon's performance are the number of vehicles and their distance. One additional primary feature that affects its performance is the capability to open gaps, accept new vehicles or allow vehicles to cut-in, and close gaps from vehicles that left the convoy (HU et al., 2017; YAO et al., 2020). Fig. 9 shows examples. 


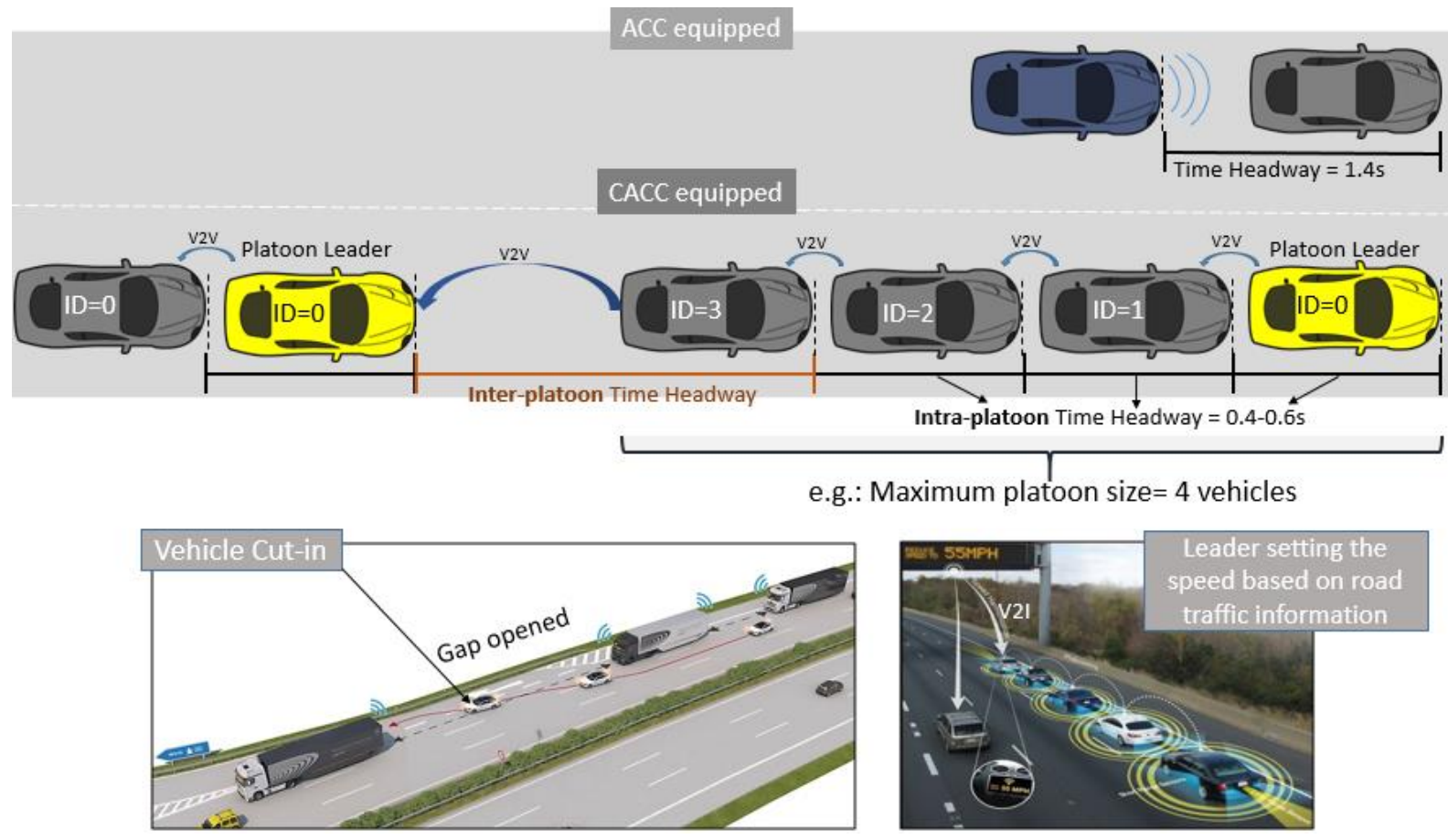

Fig. 9. Platooning/CACC key concepts Source: Author and adaptation from DIRT (2019) and DAIMLER CASE (2019).

SERAJ et al. (2018) bring the modeling of acceleration of the subject vehicle in a CACC system, similar to proposed by ZHAO \& SUN (2013) on equation (7) as

$$
v(t+\Delta t)=k_{1}\left(d(t)-v(t) \cdot T-s_{0}\right)+k_{2} \Delta v(t)
$$

where $k_{1}, k_{2}$ are control constants for relative distance and speed, respectively, higher than zero, $d$ is the distance gap between leading and subject vehicle, and $T$ is the reaction time.

The researchers simulated numerous scenarios with a stream of 20 vehicles following a platoon leader vehicle. The first analysis showed that creating platoons and HDV on mixed traffic configurations positively impacted the overall traffic flow (SERAJ, LI, \& QIU, 2018). SONG, CHEN \& MA (2019) results from numerical simulations also show positive effects of platooning on traffic flow by increasing the average speed and reducing lane change frequency. The best results were achieved for platooning dedicated lanes. The research shows that the positive effect is reduced gradually when traffic density increases. CALVERT, SCHAKEL, \& VAN AREM (2019) study focused on trucks platooning also concluded that its ability is better on noncongested traffic. On the other hand, they concluded that no positive effect was found on traffic flow performance and recommended focusing on improvements in emissions and energy consumption.

Different studies state the benefits of the group's fuel efficiency and emissions by reducing the overall air drag (ALAM et al., 2015). TSUGAWA (2014) delivered the results from the field test project that tested a platoon of 3 fully automated trucks, driving along an expressway at 80 $\mathrm{km} / \mathrm{h}$ with a preset distance of $10 \mathrm{~m}$ between them. The fuel consumption measurement showed 
a reduction of about 14\%. WANG et al. (2017) assessed an eco-friendly CACC system with cars car and got $2 \%$ higher fuel efficiency with 17\% emission reductions. ALMANNAA et al. (2019) field studies showed that the proposed Eco-CACC could achieve a $31 \%$ fuel consumption reduction. DE RANGO et al. (2020) performed simulations using MATLAB and Omnet++, showed that the platoons save energy and reduce fuel consumption. They used Grey Wolf Optimization to find the best platoon configuration, limiting to a maximum of five vehicles in each platoon.

The best platoon configurations are a high point of interest. One crucial aspect studied by Van Arem et al. (2006) was the intra-platoon gap time. They projected a value as low as $0.3 \mathrm{~s}$ for the future. SERAJ, LI, \& QIU (2018) found the best platoon configuration that gives the maximum benefits to the traffic was: intra-platoon headway $=0.5 \mathrm{~s}$, inter-platoon headway $=2 \mathrm{~s}$, and maximum platoon size $=5 / 6$ vehicles. CALVERT, SCHAKEL, \& VAN AREM (2019) stated a time gap between $0.3 \mathrm{~s}$ for $100 \%$ CAVs penetration rates until $0.7 \mathrm{~s}$ for lower ones.

Tsugawa et al. (2016) found that using dedicated lanes for trucks platooning with sizes up to 10 could double the capacity. JO et al. (2019) analyzed 160 scenarios. They noticed that the configuration that maximized the capacity was a platoon size of 2 trucks, $6 \mathrm{~m}$ intra-platoon, and $50 \mathrm{~m}$ inter-platoon gap size for $25 \%$ penetration rates.

Also, a literature review showed that currently, most of the studies for CACC/Platooning focus on trucks due to the hypothesis that a better aerodynamic performance can be achieved by grouping large vehicles. A platoon survey for trucks can be found at (BHOOPALAM et al., 2018).

Finally, considering that CAVs will enable a shorter gap and lateral distance between the vehicles, one additional relevant aspect that these technologies will bring to the society comes up: the throughput capability increases using the same road area or keeps the throughput decreasing the number of lanes. Adding it to the new approach that V2X can give to sharing mobility and multi-modal transportation can dramatically change the cities architecture, avoiding the continuous necessity of roads area increase as well as open spaces for sidewalks, bicycles lanes, parks, among others (NTOUSAKIS et al., 2015; ARIA et al., 2016; HAO et al., 2017).

It is essential to mention that the minor part of the research still focuses on the traffic performance potential of $\mathrm{CACC} /$ platooning, as the benefits of energy consumption and emissions seem to be more evident. This study brings a contribution to evaluate further this and other aspects of platooning. 


\subsection{VEHICLE AUTOMATION FIELD OPERATIONAL TRIALS (FOT)}

A Field Operational Trial (FOT), in terms of CAVs, is a private or government-funded project in which autonomous technologies are tested in a real-world environment. A key benefit of real-world trials is that the technology can be observed and monitored to evaluate how it reacts to random scenarios. The possibility of exposing the technology to public interaction is another positive aspect of making people aware and confirming innovations (SBD, 2018).

These CAVs field tests have many different targets as the assessment of operational systems, artificial intelligence, sensing, DSRC, 5G (MOTO et al., 2019), communication (LI et al., 2020), mobility, mapping, software and hardware development, simulation, transition phases (CALVERT et al., 2020) and coexistence between human-driven and CAVs as well as government certification and legislation relevant topics.

\subsubsection{CoEXist project}

Inside the FOT context, the CoEXist project must be highlighted and further explained. Some of its deliverables were used as core references for the traffic microsimulation phase developed inside this research. CoEXist was a European project (May 2017 - April 2020), aiming to prepare the transition phase where automated and conventional vehicles will co-exist on the roads. The mentioned deliverables were related to field tests in cooperation with the PTV company are described below:

- (Coexist D2.3, 2018) - Default behavioral parameter sets for Autonomous vehicles $(\mathrm{AV})$ : set of new features to make $\mathrm{AV}$ vehicles simulation more accurate (available from VISSIM 11), the numerical recommendation for the Wiedemann 74 (W74), and Wiedemann 99 (W99) following behavior, lane changing behavior, and signal control behavior.

- (Coexist D2.4, 2018) - PTV VISSIM extension new features and improvements: show the results of data evaluation in combination with the proposed concept of four different driving logics, which characteristics are:

i. Rail Safe: suggested parameters characterize a mostly closed environment (e.g., no lane changes allowed), similar to driver behavior on public transportation dedicated lanes;

ii. Cautious: driver that follow all rules straightly, keep a safe distance from the vehicle ahead, and change lanes when significant gaps are opened at the lateral lane; 
iii. Normal: suggested parameters mostly based on PTV VISSIM users manual. It will represent the driver's behavior that reproduces with more accuracy the actual human-driven vehicle;

iv. All-knowing: based on driver behavior and dynamic characteristics of CAV, as smaller front-rear gaps between vehicles, cooperative lane changes (vehicles at the lateral lane create the gaps), and slower reaction time. Anyhow just setting this behavior at VISSIM does not mean that any connected technology can be assessed.

- (Coexist D2.5, 2018) - Micro-simulation guide for automated vehicles: deep dive explanation on how to use the new features available at VISSIM 11, including "enforce absolute braking distance," "use implicit stochastic," "number of interaction vehicles," and "increased desired acceleration."

- (Coexist D2.6, 2018) - Technical report on data collection and validation process: details the validation process with the data collection process done in TASS international test network in Helmond Netherlands. The tests were performed using three vehicles equipped with CAVs Level 3 systems.

- (CoEXist D5.6, 2019) - Report from a CAV demonstration at ITS in European Conference 2019 (Helmond, Netherland). Simulations on PTV VISSIM and Prescan and a live demonstration showed that travel time could be reduced by $16 \%$ when V2V and V2I were used compared to scenarios with no communication.

The project results proved that using new features and adapted driver behavior parameters can simulate CAVs behavior with a satisfactory accuracy level.

\subsection{TRAFFIC SIMULATION}

The study of traffic for roads and urban environments is a complex science. It presents many variables and interactions that make it a challenge to find a formal general description. Researchers recognized the need to represent traffic flow in analytical terms and developed formulations, which simulation modelers could use.

That context triggered the traffic simulators that dates from the 1950s (Transportation Research Circular, 2015) . In Annex 3, a genealogy of traffic simulators is presented. They are software tools that support traffic engineers, transportation planners, system designers, authorities, and researchers to evaluate diverse traffic ecosystems and relevant topics with agility and low cost. They are used for many different purposes, from the design of sensors and algorithms to control driverless cars individually (DOSOVITSKIY et al., 2017) and evaluate the impacts of the overall traffic condition, supporting to find optimization opportunities during the 
design phase of new highways and urban pathways. They also can assess the effect of public transportation and pedestrian interactions (HELBING, 2002; SAIDALLAH et al., 2016). One more capability of traffic simulators was used in this research: to evaluate the impact of new technologies as V2X and CAVs vehicles on different traffic aspects.

As mentioned, the traffic complexity made it necessary to split the traffic simulators into four categories, from nanoscopic to macroscopic traffic models. The category selection depends on the focus of the study. Fig. 10 and Chart 1 describes the differences between these levels of simulations.

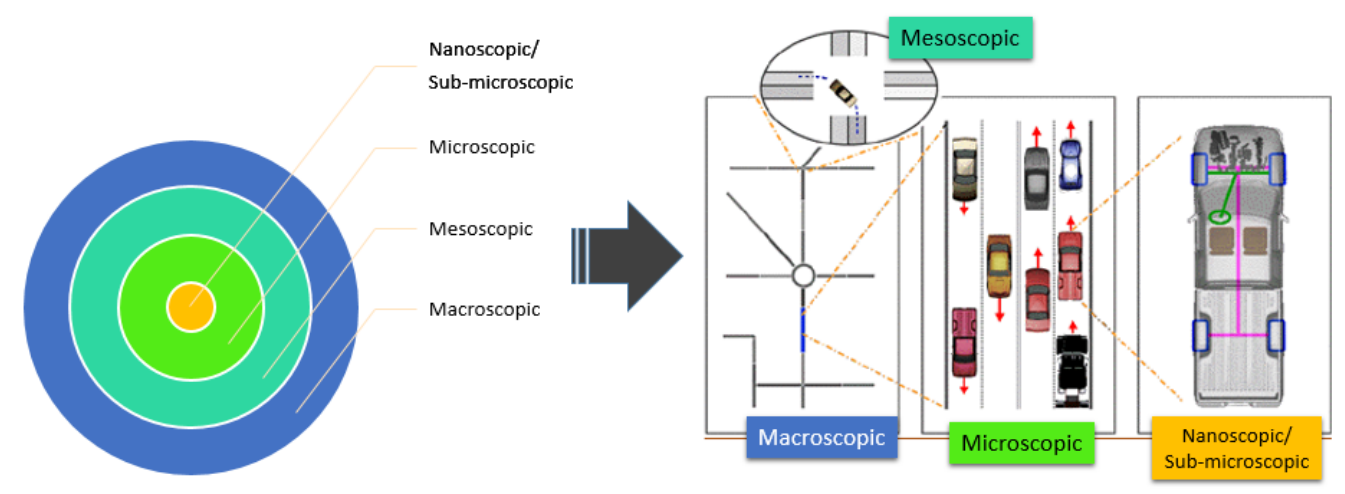

Source: Author.

Fig. 10. Traffic simulation categories

\begin{tabular}{|c|c|c|}
\hline $\begin{array}{l}\text { Traffic Simulator } \\
\text { Types }\end{array}$ & Main characteristics & Simulator Examples \\
\hline $\begin{array}{l}\text { Nanoscopic/ } \\
\text { Sub-microscopic }\end{array}$ & $\begin{array}{l}\text { - To control of engine, acceleration, brakes and steering from each individual vehicle; } \\
\text { - To evaluate driver assistance systems (CC, ACC) and sensors (Lidar, Radars, Cameras, GPS, } \\
\text { V2V); } \\
\text { - To evaluate ODD for individual vehicles based on its technologies and algorithms } \\
\text { (application limits depending environmental conditions, time of the day, road application, } \\
\text { etc.) } \\
\text { - Research groups are developing add-on to microscopic simulators to include nanoscopic } \\
\text { characteristics in the model. }\end{array}$ & $\begin{array}{l}\text { CARLA } \\
\text { PRESCAN } \\
\text { ULTraSIM } \\
\text { HutSIM } \\
\text { 2DSIM }\end{array}$ \\
\hline Microscopic & $\begin{array}{l}\text { - Focus on Traffic flow dynamics: car-following models (reaction time, time gap, } \\
\text { acceleration, deceleration and lane changing); } \\
\text { - Delineate the positions xa ( } t \text { ) and velocities va ( } t \text { ) of all interacting vehicles } \\
\text { - Focus on Driver Behaviour (car-following models); } \\
\text { - Most of traffic simulation available on the market focus on microsimulation; } \\
\text { - Pedestrian simulation possible. }\end{array}$ & $\begin{array}{l}\text { PTV VISSIM } \\
\text { SUMO } \\
\text { PARAMICS } \\
\text { AIMSUN }\end{array}$ \\
\hline Mesoscopic & $\begin{array}{l}\text { - City level analysis, cycle period of traffic lights, stop-and-go waves; } \\
\text { - Higher number of different routes; } \\
\text { - Simulated traffic must be distributed realistically among the available alternatives; }\end{array}$ & $\begin{array}{l}\text { PTV VISSIM } \\
\text { SUMO } \\
\text { AIMSUN } \\
\text { MEZZO }\end{array}$ \\
\hline Macroscopic & $\begin{array}{l}\text { - Remand side analysis (peak hour, daily demand pattern); } \\
\text { density } p(x, t) \text { and the average velocity } V(x, t) \text { as a function of the freeway location } x \text { and } \\
\text { time } t \text {. } \\
\text { - Focus on overall outputs from vehicles, pedestrians, public transportation interaction } \\
\text { (Kinetic-Gas models) }\end{array}$ & $\begin{array}{l}\text { PTV VISSUM } \\
\text { SUMO } \\
\text { AIMSUN }\end{array}$ \\
\hline
\end{tabular}

Source: Author. 
Due to the characteristics of this research, the microscopic model was chosen as detailed in chapter 4.1. The differences in driving behaviour between HDV and CAVs can be better explored in the microscopic environment.

\subsubsection{Microscopic Traffic simulators}

The Microscopic traffic simulation focuses on flow models from single vehicle drive units, where the dynamic parameters and variables represent their speed and position individually. Its models consist of several sub-models that are used to describe the driving behavior. These submodels are referred to by GAO (2008) as the "underlying logic" of a traffic simulation model. This logic consists of car-following, lane-changing, and gap-acceptance logics, all of which are highly relevant in driver behavior modeling.

A wide range of micro simulators is available for commercial and research applications (SAIDALLAH et al., 2016). On Chart 2, an overview of the most used is presented.

Chart 2: Overview of most used traffic microscopic traffic simulators.

\begin{tabular}{|c|c|c|c|}
\hline $\begin{array}{c}\text { Traffic } \\
\text { Microsimulator }\end{array}$ & $\begin{array}{l}\text { Car-following } \\
\text { model }\end{array}$ & $\begin{array}{c}\text { Application Software } \\
\text { License }\end{array}$ & Developer \\
\hline PTV VISSIM & $\begin{array}{c}\text { Wiedemann } 1974 \\
\text { (W74) and } \\
\text { Wiedemann } 1999 \\
\text { (W99) }\end{array}$ & Proprietary & $\begin{array}{c}\text { PTV (Planung } \\
\text { Transport Verkehr } \\
\text { AG) in Karlsruhe, } \\
\text { Germany. }\end{array}$ \\
\hline SUMO & Krauss (1997) & Open-source & $\begin{array}{c}\text { German Aerospace } \\
\text { Center (DLR), } \\
\text { Germany. }\end{array}$ \\
\hline AIMSUN & Gipps (1981) & Proprietary & $\begin{array}{l}\text { Transport Simulation } \\
\text { Systems (TSS), } \\
\text { Spain. Acquired by } \\
\text { Siemens in } 2018 .\end{array}$ \\
\hline CORSIM & $\begin{array}{l}\text { Pipes or GM } \\
\quad(1953)\end{array}$ & Proprietary & $\begin{array}{l}\text { Federal Highway } \\
\text { Administration } \\
\text { (FHWA), USA. }\end{array}$ \\
\hline PARAMICS & Fritzsche (1994) & Proprietary & $\begin{array}{c}\text { Quadstone Paramics, } \\
\text { UK. }\end{array}$ \\
\hline MOTUS & External models & Open source & $\begin{array}{c}\text { Delft University of } \\
\text { Technology, } \\
\text { Netherlands }\end{array}$ \\
\hline MovSim & $\begin{array}{c}\text { Gipps (1981) } \\
\text { Krauss (1997) }\end{array}$ & Open source & $\begin{array}{l}\text { CIVITAS initiative, } \\
\text { Europe }\end{array}$ \\
\hline MATsim & Vickery model & Open source & MATsim Communiity \\
\hline TransCAD & Not mentioned & Proprietary & $\begin{array}{c}\text { Caliper Corporation, } \\
\text { USA. }\end{array}$ \\
\hline SimTraffic & Not mentioned & Proprietary & $\begin{array}{c}\text { Trafficware (CUBISC } \\
\text { Company), USA. }\end{array}$ \\
\hline
\end{tabular}

Source: Author.

During the literature review phase of this research, VISSIM, SUMO, and AIMSUM are the most used simulators in studies by traffic planners and traffic planning researchers, as shown in 
Chart 5 from chapter 3. Many different studies worldwide were done based on that three software. Due to the characteristics of this research further explained in chapter 5 , VISSIM was the option chose.

PTV group headed by Rainer Wiedemann at Karlsruhe University in Germany VISSIM developed the microsimulation software called VISSIM. The backbone of the microscopic simulator is driving behavior (OLSTAM \& TAPANI, 2004). Fig. 11 shows the main components of the driver behavior model in VISSIM.

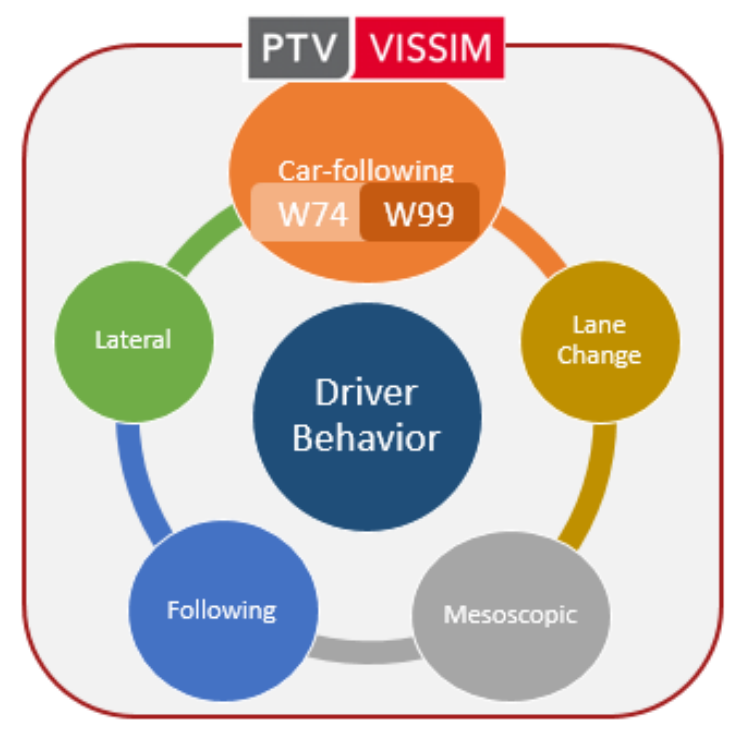

Source: Author.

Fig. 11. Driver behavior components in VISSIM.

The car-following behavior in VISSIM is based on a so-called psychophysical model. It combines human physiological restrictions as reaction times, estimation errors, perception thresholds (HIGGS, ABBAS, and MEDINA, 2011), and psychological aspects such as anticipation, context-sensitivity, and driving strategy. Wiedemann suggested this model in 1974 (WIEDEMANN, 1974) and 1999. This characteristic is why the distance a human driver keeps from the leading oscillates around a target time headway. This human driver behavior shall be adjusted to modeling the test vehicles' deterministic behavior (TREIBER \& KESTING, 2013).

GAO (2008) and HIGGS et al. (2011), the Wiedemann model assumes that a driver can be in four different driving regimes:

- Free driving: no obstacles or vehicles in front of the vehicle. The driver can proceed with its desired current speed.

- $\quad$ Approaching: the driver identifies the leading vehicle in lower vehicle speed and brakes until it achieves the desired gap.

- Following: the driver tries to keep the desired gap from the leading vehicle. For human drivers, the distance oscillates due to acceleration and brake patterns. 
- Braking: the leading vehicle applies the harsh brake, and the subject vehicle must also brake.

The four driving regimes are defined by the thresholds that represent the change in driver behavior. Fig. 12 shows a simplified representation of these transitions in the three-dimensional state space spanned by a gap (s), speed (v), and approaching rate ( $\Delta \mathrm{v}$ : speed difference between subject and leading vehicles). The blue line with an arrow shows the trajectory of a vehicle coming from a "free flow," changing to "approaching" and then to the "following" process where the leading vehicle is the reference. (TREIBER \& KESTING, 2013; FRANSSON, 2018).

As can be seen in Fig. 12, the transition thresholds for the regimes are as follows:

- SDV: it is where the driver recognizes he is driving is a higher speed than the leading vehicle and starts approaching).

- CLDV is where a driver recognizes minor differences in speed, decreasing distances);

- OPDV: it is where the driver recognizes he is driving is a lower speed than the leading vehicle and starts to accelerate to keep following).

- $A B X$ : it is minimum following distance).

- SDX: it is the maximum following distance during the same speed conditions as ABX.

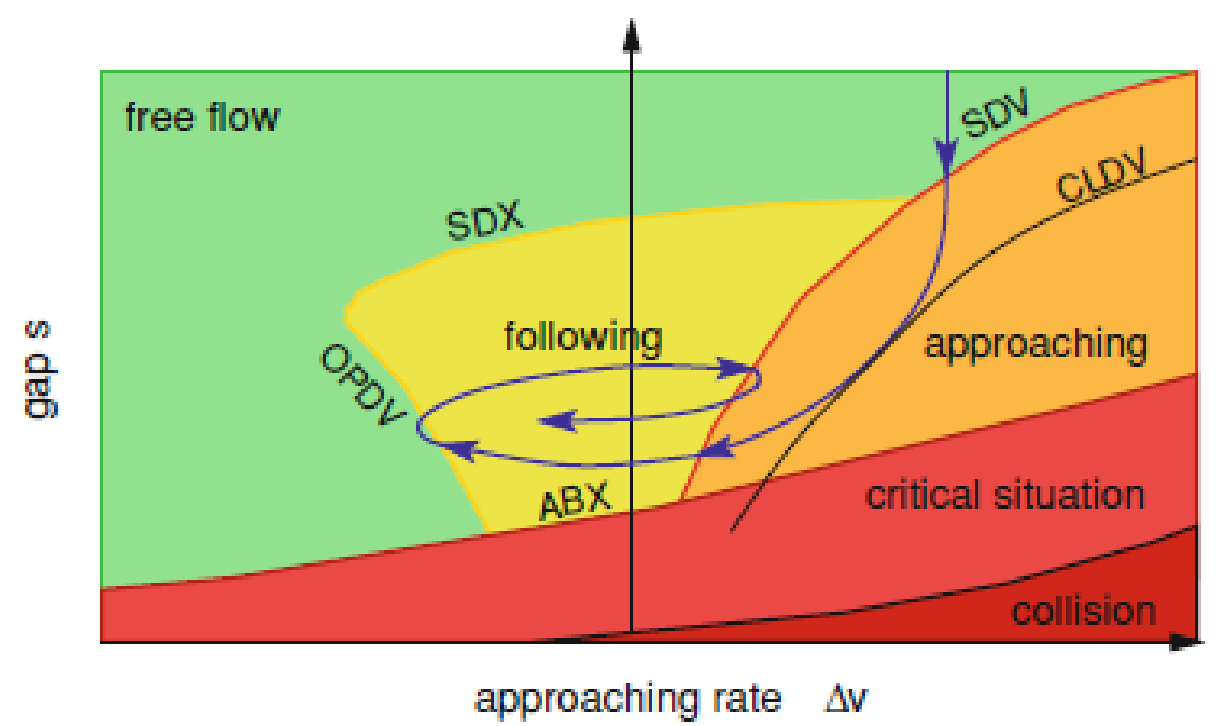

Fig. 12. Illustration of the driving regimes from the Wiedemann model.

Source: (WIEDEMANN, 1974)

According to GAO (2008) Wiedemann 74 (W74) model used in VISSIM is formulated as

$$
u_{n}(t+\Delta t)=\min \left\{\begin{array}{l}
3.6 \cdot\left(\frac{s_{n(t)-A X}}{B X}\right)^{2} \\
3.6 \cdot\left(\frac{s_{n(t)-A X}}{B X \cdot E X}\right)^{2}
\end{array}, u_{f}\right.
$$


where $u_{n}(t+\Delta t)$ is the speed update and $u_{f}$ is the space-mean traffic stream free-flow speed $(\mathrm{km} / \mathrm{h}) . \mathrm{AX}$ and $\mathrm{BX}$ are adjustable parameters expressed at

$$
d=A X+B X
$$

where $A X$ is the standstill distance $(m)$ and $B X$ the safety distance $(m)$ given by

$$
B X=\left(B X_{\text {add }}+B X_{\text {mult }} \cdot z\right) \cdot \sqrt{v}
$$

where $v$ is the vehicle speed $(\mathrm{m} / \mathrm{s}), B X_{a d d}$ is the additive part of the safety distance, $B X_{\text {mult }}$ the multiplicative part of the safety distance, and $z$ is a value from $0-1$, usually distributed around 0.5 with a standard deviation of 0.15 .

While Wiedemann 74 is usually applied for urban traffic interactions and merging areas, Wiedemann 99 (W99) is a refined and modified version to model the freeway traffic conditions (PARK et al., 2017; Vissim User Manual, 2019; LACERDA \& NETO, 2014; SONGCHITRUKSA et al., 2016). According to GAO (2008), the W99 model used in VISSIM is formulated as

$$
u_{n}(t+\Delta t)=\min \left\{\begin{array}{c}
u_{n}(t)+3.6 \cdot\left(C C 8+\frac{C C 8-C C 9}{80} u_{n}(t)\right) \Delta t \\
3.6 \cdot\left(\frac{\left.s_{n(t)-C C 0-L_{n-1}}\right)^{2}}{u_{n}(t)}\right)^{2}
\end{array}, u_{f}\right.
$$

where CCO is the standstill distance $(\mathrm{m}), \mathrm{CC} 8$ is the standstill acceleration (m/s), and CC9 is the desired acceleration $(\mathrm{m} / \mathrm{s})$ at a speed of $80 \mathrm{~km} / \mathrm{h}$. Besides CC0, CC8, and CC9, there are still additional adjustable parameters from W99 described in Annex 5 (FRANSSON, 2018).

The relation between W99 parameters and the thresholds described in Fig. 12 are the following (AGHABAYK et al., 2013):

$$
A X=L+C C 0
$$

where $L$ is the length of the leading vehicle

$$
B X=A X+C C 1 \cdot v
$$

Where $v$ is the subject vehicle speed if it's lower than the leading one, it is the same value from leading vehicles with random errors determined by multiplying the speed difference of them by a random number between -0.5 and 0.5 .

$$
\begin{gathered}
S D X=B X+C C 2 \\
(S D V)_{i}=\frac{\Delta x-(S D X)_{i}}{C C 3}-C C 4
\end{gathered}
$$

Where $\Delta x$ is the spacing from the subject and leading vehicle (bumper to bumper).

$$
C L D V=\frac{C C 6}{17000}(\Delta x-L)^{2}-C C 4
$$




$$
O P D V=\frac{C C 6}{17000} \cdot(\Delta x-L)^{2}-\zeta C C 5
$$

where $\zeta$ is a variable equal to 1 when the subject vehicle is higher than CC5, else 0 .

CC7, CC8, and CC9 are parameters not related to the threshold but to the acceleration progress that depends on the driving behavior limited to the vehicle's maximum performance. They are described in Chart 8.

Chart 3 shows manuals and research with reference values for each of those parameters.

Chart 3: References for VISSIM parameters set.

\begin{tabular}{|c|c|}
\hline Reference & Weblink \\
\hline VISSIM 11 Manual & Available inside the installation folders \\
\hline $\begin{array}{l}\text { Advanced Transportation Leadership and Safety Center } \\
\text { (ATLAS Center) from the University of Michigan and Texas } \\
\text { A\&M Transportation Institute: Incorporating Driver Behaviors } \\
\text { into Connected and Automated Vehicle Simulation (2016) }\end{array}$ & $\begin{array}{l}\text { https://www.atlas-center.org/wp- } \\
\text { content/uploads/2014/10/ATLAS- } \\
\text { Research-Report-Songchitruksa- } \\
\text { ATLAS-2016-13.pdf } \\
\text { Access: September } 2019\end{array}$ \\
\hline $\begin{array}{l}\text { Oregon Department of Transportation (ODT): Protocol for } \\
\text { VISSIM Calibration (2011) }\end{array}$ & $\begin{array}{l}\text { https://www.oregon.gov/ODOT/Plannin } \\
\text { g/Documents/APMv2 Add15A.pdf } \\
\text { Access: September } 2019\end{array}$ \\
\hline $\begin{array}{l}\text { Wisconsin Department of Transportation (WSDOT): Protocol } \\
\text { for VISSIM simulation (2014) }\end{array}$ & $\begin{array}{l}\text { https://www.wsdot.wa.gov/NR/rdonlyre } \\
\text { s/378BEAC9-FE26-4EDA-AA1F- } \\
\text { B3A55F9C532F/0/VISSIMProtocol.pdf } \\
\text { Access: September } 2019\end{array}$ \\
\hline $\begin{array}{l}\text { Wisconsin Department of Transportation (WSDOT): VISSIM } \\
\text { Calibration Settings (2018) }\end{array}$ & $\begin{array}{l}\text { https://wisconsindot.gov/dtsdManuals/t } \\
\text { raffic-ops/manuals-and- } \\
\text { standards/teops/16-20att6.3.pdf } \\
\text { Access: September } 2019\end{array}$ \\
\hline $\begin{array}{l}\text { Deliverable } 2.3 \text { CoEXISt: Default behavioral parameter sets } \\
\text { (2018) }\end{array}$ & $\begin{array}{l}\text { https://www.h2020-coexist.eu/wp- } \\
\text { content/uploads/2018/10/D2.3-default- } \\
\text { behavioural-parameter-sets final.pdf } \\
\text { Access: September } 2019\end{array}$ \\
\hline
\end{tabular}

Source: Author.

For CAVs simulation, a recommendation from the Coexist project is to use W99 even on freeway traffic conditions (Coexist D2.6, 2018). It is recommended mainly due to the availability of more parameters to control the behaviors. Also, on the W74 model, the vehicles keep their exact desired speed on the free driving mode, when W99 allows for changing many of the parameters used and assumes a linear relationship between speed and following distance (i.e., a constant time headway plus standstill distance). In conclusion, W99 demonstrates to be more suitable for simulating CAVs independent of road characteristics. 
Finally, apart from car-following parameters, more than forty-seven other parameters are available to define the driver behavior.

\subsubsection{CAVs simulation}

In the simulations involving CAVs, it is demanded to gather expertise in many different fields of knowledge. Including road traffic simulation, network simulation, and V2X application. According to (GOEBEL, 2017) simulating it in a single simulator would have many disadvantages of consuming a significant amount of time for planning, programming, and verifying the combined simulator. He states that the approach to couple well-established simulators of the different domains is much more promising. At least three sets of simulators need to be coupled to allow realistic simulations of V2X applications communicating via cellular networks:

i. Well-established road traffic simulator to simulate the traversal of vehicles on the road network.

ii. Network simulator with cellular network simulation capabilities (MUSSA et al., 2016);

iii. V2X application simulator.

Fig. 13 shows an overview of possible settings for CAVs simulation with SUMO and VISSIM. (GÁLVAN, 2016). Moreover, GOEBEL (2017) describes in detail the co-simulators compatible with SUMO. On the website from Open-Source Application Development Portal (OSADP) from USDOT, it is available some co-simulators developed to be compatible with VISSIM (e.g., for CACC feature) (ITS Forge, 2019). It is essential to mention that some tries to use OSADP co-simulators were performed unsuccessfully due to a lack of documentation.

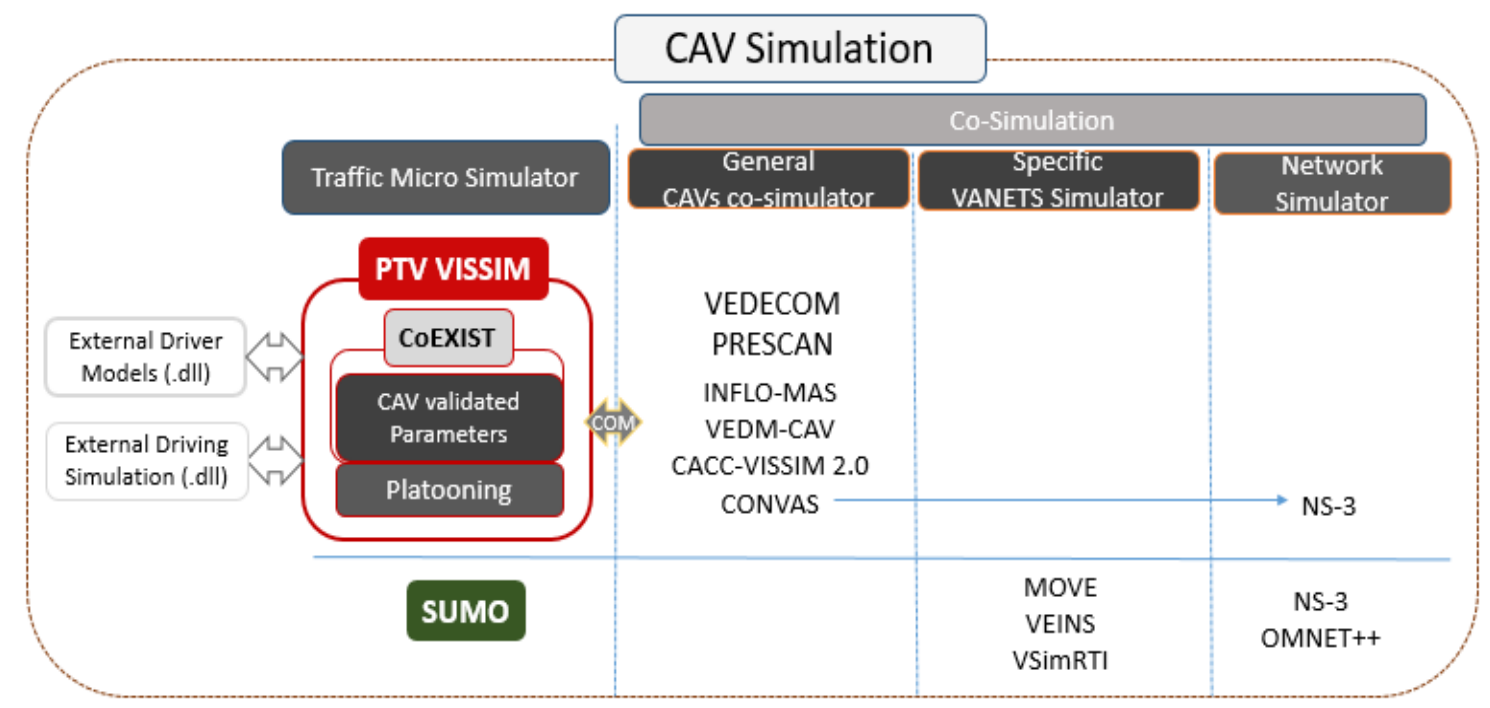

Source: Author.

Fig. 13. Overview of simulators combinations for CAVs simulations. 
On the VISSIM version 11, new features were added to support CAVs characteristics and mixed traffic situations, as described in Chart 4.

Chart 4: New features released at VISSIM to enable AVs and CAVs traffic simulation.

\begin{tabular}{|l|l|l|}
\hline \multicolumn{1}{|c|}{ Feature } & \multicolumn{1}{|c|}{$100 \%$ HDV environment } & \multicolumn{1}{c|}{ CAV/ mixed environment } \\
\hline $\begin{array}{l}\text { Use implicit } \\
\text { stochastics }\end{array}$ & $\begin{array}{l}\text { Stochastic: the imperfection of } \\
\text { human driving }\end{array}$ & Deterministic machines \& computers \\
\hline $\begin{array}{l}\text { Class dependent } \\
\text { safety distance in the } \\
\text { following behavior }\end{array}$ & $\begin{array}{l}\text { Headway is fixed for all vehicle } \\
\text { classes }\end{array}$ & $\begin{array}{l}\text { Headway dependent on followed vehicle } \\
\text { class: possible to set different following } \\
\text { distances to conventional vehicles, } \\
\text { automated vehicles, connected and } \\
\text { automated vehicles, and cyclists }\end{array}$ \\
\hline $\begin{array}{l}\text { Number of interaction } \\
\text { objects \& vehicles }\end{array}$ & $\begin{array}{l}\text { Humans can see many vehicles } \\
\text { ahead independent of sensors } \\
\text { but have limited capacity to } \\
\text { interact with many objects }\end{array}$ & $\begin{array}{l}\text { AVs can detect objects and interpret visual } \\
\text { information inside the sensor's range. } \\
\text { CAVs can interact with more objects due to } \\
\text { communication capabilities. }\end{array}$ \\
\hline $\begin{array}{l}\text { Increased } \\
\text { acceleration } \\
\text { following possible }\end{array}$ & $\begin{array}{l}\text { Humans have limited capacity } \\
\text { to keep following the leading } \\
\text { vehicle closely. During the } \\
\text { following behavior, the } \\
\text { acceleration rates are not highly } \\
\text { increased to keep the distance. }\end{array}$ & $\begin{array}{l}\text { Higher acceleration rates are necessary for } \\
\text { CAVs in a platoon formation to maintain the } \\
\text { headway even when the leading vehicle's } \\
\text { speed increases slightly. Therefore, to } \\
\text { simulate platoon behavior, the "Increased } \\
\text { acceleration" parameter must be set above } \\
\text { 100\%. }\end{array}$ \\
\hline Zero passengers & $\begin{array}{l}\text { It will be every time at least the } \\
\text { driver inside the vehicle }\end{array}$ & $\begin{array}{l}\text { It allows to setting vehicles with zero } \\
\text { passengers (for SAE J3016 Level 4 and 5) }\end{array}$ \\
\hline
\end{tabular}

Source: Adapted from PTV (2019) and Coexist D2.6 (2018).

VISSIM did the first try on having a connected vehicle integrated tool in September 2019. VISSIM 2020.00-0 beta version released the feature platooning (PTV, 2019). Before launching platooning, all the material that the PTV released for testing CAVs was done using external coding (python script and COM interface).

On VISSIM 2020, it is possible to set five different parameters related to platooning, as follows:

- Maximum number of platoon vehicles: maximum number of vehicles in a single platoon.

- Maximum platoon approach distance $(m)$ : a vehicle that intends to join a platoon should be at a smaller distance from behind than set in this parameter.

- Maximum platooning desired speed $(\mathrm{km} / \mathrm{h})$ : when a vehicle is inside a platoon, this becomes the new desired speed. When a vehicle leaves the platoon, its individual desired speed is automatically back. Reduced speed areas are considered and respected. 
- Maximum platooning clearance $(\mathrm{m})$ : minimum standstill distance between two vehicles in a platoon.

- Minimum gap (s): refers to the minimum time gap between two vehicles in a platoon (PTV VISSIM 2020 USER MANUAL, 2019).

This feature was developed inside the software to evaluate the effects on overall traffic, and it was modeled considering the following characteristics:

- The entire platoon uses the same lane. Vehicles inside a platoon do not change lanes.

- Only vehicles with the same driver behavior can form a platoon.

- A platoon can be split if a vehicle inside needs to take a different route. If the conditions are met, the split platoons can join again.

- To safely leave the platoon, the following vehicle must increase the distance downstream to its preceding vehicle and upstream to its following vehicle.

- A platoon can be split during a red traffic light if there is not enough time for the whole convoy to pass through.

- A platoon can be disabled depending on the link configuration; it is possible to set at the same network area where platoon is enabled or disabled.

- PTV VISSIM software running alone do not consider the communication between vehicles and their possible influence on driving behavior nor other platoon-internal dynamics (PTV VISSIM 2020 USER MANUAL, 2019).

As platooning is a new feature focusing on $\mathrm{V} 2 \mathrm{~V}$, and there are still few kinds of research worldwide that delivered results using that software capability, it will be used in that research on scenarios with CAVs. 


\section{LITERATURE REVIEW}

This chapter presents different aspects of the CAVs concept that evolved over the years, focusing on microscopic simulation. The review is presented chronologically with the most relevant studies related to the topic to explore the art state in that research field. This review aims to answer four central questions:

i. How will CAVs impact the traffic performance of the cities and roads,

ii. How will be the traffic performance and which are the most relevant aspects to be evaluated during transition phases where different vehicle automation levels will share the same road?

iii. Any of those studies cover Brazilian city traffic situations?

iv. Which technologies are more relevant? Bearing those questions in mind, this research its relevance can be further comprehended.

The literature about traffic microsimulation for CAVs is mostly condensed in the last four years due to the topic's increasing prominence. Simultaneously, the simulator's capabilities to model the characteristics of this environment have been improved. RIOS-TORRES \& MALIKOPOULOS (2017) brings a collection of studies starting from the end of the 1960s with different approaches to achieve safe and efficient vehicle coordination to improve the traffic flow. TIAN et al. (2018) and DO et al. (2019) published surveys with many different research types related to the simulation of CAVs. Those surveys and a further active literature search on leading journals, books, and congress proceedings are presented in the following.

Along with the $90 \mathrm{~s}$, the first system on the roadmap to the AV's most used terminology was Autonomous Intelligent Cruise Control (AICC). It was defined as a vehicle-installed system that automatically adapts the speed to keep a safe distance from the vehicle ahead. The vehicle's communication technologies were still not part of those research. KING et al. (1993) and BJORNBERG (1994) presented the control algorithm's description to define the system that years later would be so-called ACC. CHIEN \& IOANNOU (1993) showed that the AICC system outperformed the human driver model due to its faster and better transient response, resulting in smoother traffic and faster traffic flow. CARREA \& SAROLDI (1993) explored in a testing vehicle the integration between AICC and anti-collision systems. Other studies, as ERIKSSON \& AS (1995) and AOYAGI et al. (1997), had the focus on radar development for AICC systems.

After the 2000s, the terminology ACC and CACC become more used. WERF et al. (2002) developed a simulation based on the Monte Carlo algorithm to estimate ACC's impacts in different proportions and HDVs. AREM et al. (2006) developed a microsimulation model dedicated to studying the impact of CACC on traffic flow. The authors evaluated its impacts on a highway scenario, focusing on merging spots compared to non-equipped vehicles. They 
reported an improvement in traffic flow stability. Anyhow, it was not found relevant improvements on travel times. On the other hand, KESTING et al. (2008) developed a microscopic traffic simulator and used the IDM to propose an ACC with an active jam-avoidance system. They noticed that a proportion of $5 \%$ of ACC vehicles already improved the traffic flow, and $25 \%$ of ACC reduced the cumulated travel time by approximately $75 \%$, mainly because ACC avoided the breakdown of traffic flow in the model.

Many research types focused on ACC, IDM models, and CACC impact on traffic performance in the current decade. SCHAKEL et al. (2010) used a modified version of IDM, socalled IDM+ and CACC algorithms, to evaluate traffic flow stability on field tests with 50 vehicles (FOT). In mixed traffic scenarios with $50 \%$ of CACC equipped vehicles, the shockwave duration was five times lower than 100\% HDVs. KESTING et al. (2010) proposed an Extended IDM (EIDM) using a constant-acceleration heuristic $(\mathrm{CAH})$ as a performance index. They found a direct relation between ACC penetration rate on traffic performance: each $1 \%$ more ACCs increased road capacity by about $0.3 \%$. (LIU et al., 2018) also developed a variation of Extended IDM that considers V2V technologies. A stability analysis is performed where EIDM shows a broader stability region when compared to IDM. LU et al. (2019) proposed a model for CAVs in a platoon based on an ecological control strategy so-called Ecological Smart Driver Model (EcoSDM), considering IDM as the base model (100\% HDVs). The simulation results show that the model is superior in fuel efficiency (at fully CAVs scenarios, EcoSDM was $10 \%$ better for the platoon than EIDM) and stabilization effects compared to SDM and EIDM. A topic to highlight in this study is that the platoon's position has interference on fuel consumption as expected. A nontrivial output was that the platoon leader was almost $2 \%$ better fuel efficiency than the base scenario, and the vehicle on position 16 of the platoon was near to $0 \%$.

In parallel, several researchers used microsimulation tools to assess their studies in the same fields. PLOEG et al. (2011) simulated CACC systems and showed evidence that the smaller gaps achieved with the vehicles' platoon increased the road throughput. PARK et al. (2011) used VISSIM to explore a lane change advisory algorithm for CAVs on-road merge conflicts, considering V2V capabilities. As the vehicles on the road open gaps for vehicles entering the merging areas, they measured a 6,4\% higher average vehicle speed in the freeway and a $5.2 \%$ reduction in emissions with $100 \%$ of CAVs compared to the merging area with $100 \%$ HDVs. On the other hand, SHLADOVER et Al. (2012) simulated ACC and CACC with AIMSUM traffic simulation. They tested different market penetrations, and results showed that ACC has low impacts on increasing road capacity (veh/h), even in higher penetration rates. Although CACC showed a low penetration of $20 \%$ already increased the capacity by $7 \%$, it doubled the lane capacity for $100 \%$ of CACC. It is essential to mention that the better results came with CACC penetration rates above $80 \%$. (ZHAO \& SUN, 2013) used VISSIM to simulate a mixed 
freeway with vehicles with no ADAS together with vehicles equipped with $A C C$ and $C A C C$ (platoon mode). ACC and CACC were simulated using the External Driver Behavior Model (EDBM) coded in $\mathrm{C} / \mathrm{C}++$ coding. Results showed that traffic capacity almost doubled from $0 \%$ CACC market to $100 \%$. One relevant outcome was that the platoon's size (from 2 to 6 vehicles) did not significantly impact traffic capacity.

Other research had a focus on the interface between vehicles and infrastructure. Their studies were assessed on micro simulators. LEE \& PARK (2012) developed a V2I system for Cooperative Vehicle Intersection Control (CVIC), and simulation results revealed a reduction of $99 \%$ of stop delays and travel time, which impacted on $44 \%$ reduction of fuel consumption when compared to the same intersection with $0 \%$ vehicles equipped with V2I technology. KATSAROS et al. (2011) reported a $7 \%$ reduction in fuel consumption in a scenario with $100 \%$ of vehicles equipped with Green Light Optimized Advisory (GLOSA) when compared to standard vehicles. STEFANOVIC et AI. (2013) also evaluated GLOSA with high penetration rates that presented a reduction of $52 \%$ vehicle stop delay, a $46 \%$ reduction on vehicles stop, although just $0,5 \%$ higher fuel efficiency. A few years later, GLOSA focused on CHOUDHURY et al. (2016) that developed a simulation setup with VISSIM, MATLAB, and NS-3 (network simulator) to test this application. The authors obtained a $7.4 \%$ reduction in fuel consumption and a $20 \%$ higher network throughput in the scenario where GLOSA was applied to $100 \%$ of vehicles. An extensive report from FROST \& SULLIVAN (2017) shows that intelligent traffic system applications can reduce travel time by $23 \%$ for emergency vehicles (hospital ambulances, fire engines) and $27 \%$ for other vehicles.

Studies with mixed or heterogeneous traffic topics got attention from the researchers during the last few years. When human-driven AVs and CAVs coexist on the same road, YANG et al. (2016) further explore the aspect. Simulations resulted in an evident decrease in the total number of stops and delays when using an algorithm for $C V$ s relative flows above $50 \%$. BAILEY (2016) modeled a mixed flow with autonomous, based on modifications on IDM (presented in chapter 2, so-called Enhanced Intelligent Driver Model (EIDM). ZHOU et al. (2017) also proposed modifications on IDM, so-called Cooperative IDM (CIDM), and evaluated the average travel time for $\mathrm{AVs}$ percentage from $0-25 \%$. Results showed that for safe time gaps between $0.4 \mathrm{~s}$ to $0.8 \mathrm{~s}$, the average travel was reduced by $15 \%$ when a $25 \%$ percentage of AVs was achieved. It was also concluded that an increase in urban traffic network capacity and a decrease in average delay as CVs penetration rate is increased (on $100 \%$ and $20 \%$ CVs penetration a reduction in travel time of $80 \%$ and $53 \%$, respectively, was achieved). RIOSTORRES \& MALIKOPOULOS (2017) made a comparison with an optimal control scenario considering $100 \%$ of CAVs penetration and reached a $60 \%$-time reduction for heavy traffic. 
ARIA et al. (2016) used VISSIM (W99 model) to simulate AVs based on parameter adjustments. At the simulated autobahn with $100 \%$ of $A V s$, the authors reported improvement by $9 \%$ on travel times and $8.48 \%$ higher average vehicle speed when compared to the base scenario (0\% AVs). PARK et al. (2016) used VISSIM running with the COM (Component Object Model) interface that makes it possible to anticipate the information from the next step of the simulation. They concluded that the $\mathrm{CV}$ environment reduces the congestion in proper traffic volume because of eliminating the perception-reaction time gap. YE \& YAMAMOTO (2017) focus was also on heterogeneous traffic flows, showing more significant improvement when the penetration rate o CAVs is above $30 \%$. DOLLAR and VAHIDI (2017) show different algorithms to compare platooning performance and reports a potentially significant fuel efficiency benefit when the proposed Model Predictive Control (MPC) algorithms are used. HAAS \& FRIEDRICH (2017) developed a microscopic simulation with SUMO and Plexe (extension for SUMO to implement platoon functionality) for CAVs platoons, used in city logistics with the focus on the travel time issue. The main results show that an increase in the number of vehicles per platoon (from 2 to 6 ) decreases the travel time. This result was achieved mainly during peak hours (network crowded).

The pace of studies on the related kept increasing in the last two years. RIOS-TORRES \& MALIKOPOULOS (2018) simulated based on Gipps car-following model and optimal control, including V2V and V2I, to evaluate its impacts CAVs on fuel consumption and a traffic flow from $0 \%$ to $100 \%$ penetration. The results for low traffic volumes were the fuel-saving achieved $55 \%$ increasing proportionally from 0 to $100 \%$ CAVs. One conclusion was that for medium and high traffic demand, a significant fuel saving was achieved just near $100 \%$ CAVs penetration. BAZ (2018) used VISSIM and game theory concepts to propose improving delay times on roundabouts and intersections. The results show that the proposed system reduces the total delay by more than $65 \%$ on the roundabout and about $85 \%$ percent on a signalized intersection. TILG et al. (2018) developed a variation of the multi-class hybrid model (MHT) based on multiple vehicle classes for CAVs mixing traffic in weaving sections. The model was developed using MATLAB and calibrated with field data from the city of Basel, Switzerland. Results show that growing shares of CAVs can increase up to 15\% traffic flow capacity by optimizing the spatial lane change distribution compared to scenarios with no CAVs. OLIA et al. (2018) simulated the CAVs under mixed-traffic conditions with the assumption of increasing a $10 \%$ gap of CAVs. The result shows that a $100 \%$ penetration rate of CAVs could increase road capacity from 2,046 to 6,450 vehicles/hour/lane. LIU et al. (2018) simulated the impacts of a CACC multi-lane freeway with mixed traffic highway simulations by increasing CACCs' gap by $20 \%$. The results show that the freeway capacity could be approximately $90 \%$ higher with a $100 \%$ CACC penetration rate, compared to $0 \%$. 
CHEN et al. (2019) simulated with VISSIM to assess the impact of ACC and CACC increasing penetration rates among HDVs. For both ACC and CACC increasing penetration rates, the most significant impacts were found on travel time. For a $90 \%$ penetration rate, there was a $9 \%$ and $11 \%$ reduction of travel time ACC and CACC, respectively. XIE et al. (2019) propose a generic car-following model for HDVs and CAVs. Results shoes that increasing penetration of CAVs can suppress traffic waves (using information from ADAS for penetration above $80 \%$, the variation on vehicle speed could be almost neglected) stabilize traffic, therefore, increasing the traffic flow. ZHOU et al. (2019) modeled four-lane cellular automata traffic on mixed traffic with $A C C / C A C C$ and manual vehicles. The numerical results indicated that the CACC strings presented considerable stability while the ACC strings show instability. The CACC penetration rate evaluation showed that the capacity per lane almost doubled from $2000 \mathrm{veh} / \mathrm{hr}$ (0\% CACC) to approximately $3900 \mathrm{veh} / \mathrm{hr}(100 \%$ CACC), where the higher impacts came from penetration rates above $60 \%$. GHIASI (2019) presented a speed harmonization algorithm to harmonize traffic for HDVs and CAVs in mixed traffic situations. The numerical experiment results indicate that the algorithm could smooth CAV movements and harmonize the following human-driven traffic.

CALVERT et al. (2019) simulated platoons for trucks in congested highways using PTV VISSIM. They considered an extreme scenario with no maximum platoon size and intra-platoon time headway of $0,3 \mathrm{~s}$, where they found a small benefit of $2,9 \%$ travel time reduction for penetration rates above $80 \%$. In general, the authors justified the results because longer platoons outperformed the lane changed from vehicles around and suggested the application of platoons in non-congested traffic, then larger platoons with short time headways can perform better. The following year, CALVERT et al. (2020) released a new study from an FOT and simulation experiment of CACC for city environments. The authors found important savings in travel time on heavy traffic, mainly when applied to the V2I feature (traffic lights green extension). For penetration rates smaller than $50 \%$, no positive effects were found because CACC vehicles turned to normal ACC when the following vehicle does not have the technology. The results for a $100 \%$ penetration rate were a $5 \%$ reduction in travel time that was increased to $11 \%$ when V2I was applied. Their settings for CACC were time headway of $0,6 \mathrm{~s}$ plus $5 \mathrm{~m}$, considering no communication delays, and $0.8 \mathrm{~s}$ plus $5 \mathrm{~m}$ for ACC. One important contribution was to release the calibrated W99 most relevant parameters for HDVs after field tests presented also on Chart 8: $\mathrm{CC} 1=0.9 \mathrm{~s}, \mathrm{CC} 7=1.0 \mathrm{~m} / \mathrm{s}^{2}, \mathrm{CC} 8=4.5 \mathrm{~m} / \mathrm{s}^{2}$ and $\mathrm{CC} 9=1.5 \mathrm{~m} / \mathrm{s}^{2}$. For CACC, CC1 was considered as $0.6 \mathrm{~s}$.

CHANG et al. (2020) studied the platoons (CACC) for their alternative taxonomy to CAVs, so-called Intelligent and Connected Vehicles (ICVs), keeping the focus on mixed traffic flows. Their assessments were done based on IDM and CACC described in equation 20. The first 
analysis was on time headways for $100 \%$ CAVs penetration, where the traffic capacity decreased by $26 \%$ comparing time headways from 0,6 s to 1,1 s. For a $50 \%$ penetration rate, the reduction in traffic flow was much lower, by 7\%, comparing headways. The second analysis kept the time headway in $0.6 \mathrm{~s}$, where the capacity increased by $64 \%$ from $10 \%$ to $100 \%$ CAVs penetration rates and increased by $45 \%$ from $50 \%$ to $100 \%$ penetration rates. Their third analysis was changing platoon size from 2 to 8 vehicles. For CAVs penetration rates up to $30 \%$, the impacts on capacity were insignificant, independent of platoon size. When it comes to $50 \%$ or higher, the capacity is increased by $7 \%$ comparing 2 to 8 vehicles platoon size and $55 \%$ for a $100 \%$ penetration rate compared to the same platoon sizes. Collating the worst to the better results means a $10 \%$ penetration rate with two vehicles platoon size to $100 \%$ penetration rate and eight vehicles platoon size, the capacity increased by $75 \%$. Therefore, they concluded that CAVs could effectively improve the throughput of existing road traffic systems. The increase in the maximum platoon size is advantageous for improving the mixed flow capacity.

YAO et al. (2020) used SUMO and OMNET++ to simulate a simple urban network. In their model, even on $100 \%$ CAVs penetration rates, all the vehicles could be driven by a human, where only platoon followers were considered to be autonomously driven. The results showed a reduction of $19 \%$ and $27 \%$ in travel delays for $60 \%$ and $100 \%$ CAVs penetration rates compared to $0 \%$, respectively. One other remarkable result was that the merging requests for joining platoons increased up to $31 \%$ and $70 \%$ compared with $60 \%$ to $80 \%$ and $100 \%$ CAVs penetration rates, respectively.

Chart 5 shows a summary table with the major studies on CAVs microscopic simulation research that presented numerical results related to its impacts on traffic flow, fuel efficiency, and emissions. As the impacts on traffic flow focus on this research, those results are used to assess the results found during the simulation scenarios proposed.

Besides the mentioned CAVs impacts, it worth mentioning additional studies on road safety focus. VALIDI et al. (2017) use SUMO and "Scene Suit" to show the impact of CAVs on road safety. For the scenarios evaluated, the overall results show that even the lowest penetration rate $(40 \%)$ of $\mathrm{V} 2 \mathrm{~V}$ resulted in a dramatic improvement in road safety by preventing all types of accidents. One additional valuable reference from GE et al. (2018) shows an experimental validation done with retrofitted vehicles equipped with V2X devices at the University of Michigan Mobility Transformation Center. The experiments demonstrate that both safety and fuel efficiency can be significantly improved for CAVs and nearby human-driven vehicles. They conclude that CAV may bring additional societal benefits by mitigating traffic waves. 
Chart 5: Summary table with results comparison between references and author

\begin{tabular}{|c|c|c|c|}
\hline Reference & Simulator & Application & Results \\
\hline $\begin{array}{l}\text { H. PARK et al. } \\
\text { (2011) }\end{array}$ & VISSIM & $\begin{array}{l}\text { Merging } \\
\text { Highway }\end{array}$ & $\begin{array}{l}\uparrow 6,4 \% \text { average vehicle speed } \\
\downarrow 5,2 \% \text { emissions }\end{array}$ \\
\hline $\begin{array}{l}\text { KATSAROS et al. } \\
(2011)\end{array}$ & SUMO & City & $\begin{array}{l}100 \% \text { GLOSA equipped vehicles } \rightarrow \downarrow 7 \% \\
\text { fuel consumption }\end{array}$ \\
\hline $\begin{array}{l}\text { STEVANOVIK et } \\
\text { al. (2011) }\end{array}$ & VISSIM & City & $\begin{array}{l}100 \% \text { GLOSA equipped vehicles } \rightarrow \downarrow 50 \% \\
\text { stop delays }\end{array}$ \\
\hline $\begin{array}{l}\text { SHALODER et al. } \\
(2012)\end{array}$ & AIMSUM & Highway & $100 \%$ CACC $\rightarrow 2 x$ lane capacity \\
\hline $\begin{array}{l}\text { ZHAO \& SUN } \\
(2013)\end{array}$ & $\begin{array}{l}\text { VISSIM + C++ } \\
\text { DLL }\end{array}$ & Highway & $100 \%$ CACC $\rightarrow \uparrow 95 \%$ traffic capacity \\
\hline ARIA et al. (2016) & VISSIM & Highway & $\begin{array}{l}\uparrow 8.48 \% \text { : average vehicle speed } \\
\downarrow 9.00 \% \text { : travel time }\end{array}$ \\
\hline $\begin{array}{l}\text { CHOUDHURY et } \\
\text { al. (2016) }\end{array}$ & $\begin{array}{l}\text { VISSIM } \\
\text { NS-3/Matlab }\end{array}$ & City & $\begin{array}{l}100 \% \text { CACC } \rightarrow \downarrow 7,4 \% \text { fuel consumption } \\
100 \% \text { CACC } \rightarrow \downarrow 7 \% \text { emissions }\end{array}$ \\
\hline BAILEY (2016) & AIMSUM & City & $\begin{array}{l}20 \% \text { AVs } \rightarrow \downarrow 53 \% \text { travel time } \\
100 \% \text { AVs } \rightarrow \downarrow 80 \% \text { travel time }\end{array}$ \\
\hline $\begin{array}{l}\text { RIOS-TORRES et } \\
\text { al. (2017) }\end{array}$ & AIMSUM & City & $100 \% \mathrm{AVs} \rightarrow \downarrow 60 \%$ travel time \\
\hline EVANSON (2017) & $\begin{array}{l}\text { VISSIM + } \\
\text { Platooning } \\
\text { (external) }\end{array}$ & Highway & $100 \% \mathrm{CAVs} \rightarrow \downarrow 11 \%$ travel time \\
\hline BAZ (2018) & VISSIM & City & $\begin{array}{l}\downarrow 65 \% \text { total delays in roundabouts } \\
\downarrow 85 \% \text { total delays on signalized intersections }\end{array}$ \\
\hline OLIA et al. (2018) & Not mentioned & Highway & $100 \%$ CAVs $\rightarrow \uparrow 315 \%$ veh $/ \mathrm{hr} /$ lane capacity \\
\hline TILG et al. (2018) & $\begin{array}{l}\text { MATLAB + } \\
\text { Not mentioned }\end{array}$ & Highway & $100 \%$ AVs $\rightarrow \uparrow 15 \%$ traffic capacity \\
\hline LU et al. (2019) & Not mentioned & Highway & $100 \%$ AVs $\rightarrow \downarrow 16 \%$ fuel consumption \\
\hline ZHOU et al. (2019) & Not mentioned & Highway & $100 \%$ CACC $\rightarrow \uparrow 95 \%$ lane capacity \\
\hline $\begin{array}{l}\text { GOÑI-ROS et al. } \\
\text { (2019) }\end{array}$ & Not mentioned & Highway & $\begin{aligned} 50 \% \text { CACC } \rightarrow & \downarrow 15 \% \text { travel time } \\
& \downarrow 55 \% \text { average veh delay } \\
100 \% \text { CACC } \rightarrow & \downarrow 20 \% \text { travel time } \\
\downarrow & \downarrow 4 \% \text { average veh delay }\end{aligned}$ \\
\hline CHEN et al. (2019) & VISSIM & Highway & $\begin{array}{l}90 \% \text { ACC } \rightarrow \downarrow 9 \% \text { travel time } \\
90 \% \text { CACC } \rightarrow \downarrow 11 \% \text { travel time. }\end{array}$ \\
\hline $\begin{array}{l}\text { CALVERT et al. } \\
(2019)\end{array}$ & Not mentioned & $\begin{array}{l}\text { Highway } \\
\text { (Trucks) }\end{array}$ & $\begin{array}{l}\leq 80 \% \text { CACC } \rightarrow \text { no positive effect } \\
100 \% \text { CACC } \rightarrow 2.9 \% \text { travel time reduction }\end{array}$ \\
\hline $\begin{array}{l}\text { CHANG et al. } \\
(2020)\end{array}$ & Not Mentioned & Highway & $\begin{array}{l}\text { Platoon size }=8 \text {; Time Headway }=0,6 \mathrm{~s} \text { : } \\
50 \% \text { CACC } \rightarrow \downarrow 13 \% \text { travel delays } \\
100 \% \text { CACC } \rightarrow \downarrow 75 \% \text { travel delays }\end{array}$ \\
\hline YAO et al. (2020) & $\begin{array}{l}\text { SUMO/ } \\
\text { OMNET++ }\end{array}$ & City & $\begin{array}{l}60 \% \text { CACC } \rightarrow \downarrow 19 \% \text { travel delays } \\
100 \% \text { CACC } \rightarrow \downarrow 27 \% \text { travel delays }\end{array}$ \\
\hline $\begin{array}{l}\text { CALVERT et al. } \\
(2020)\end{array}$ & VISSIM & City & $\begin{array}{l}\leq 50 \% \text { CACC } \rightarrow \text { no positive effect } \\
100 \% \text { CACC } \rightarrow \downarrow 11 \% \text { travel time. }\end{array}$ \\
\hline
\end{tabular}

Source: Author. 
Other critical aspects for CAVs evaluated by FERNANDES \& NUNES (2012); OSMAN \& ISHAK (2015), BIDÓIA (2015), MIR \& FITALI (2016), CHAl et al. (2017), HE, et al. (2017), NANAJl et al. (2017) and TAKAHASHI, (2018), NAUFAL et al. (2018) and HUSSAIN et al., (2019), are the connectivity robustness, cyber/data security, network performance and functional safety (ISO 26262, adapted for the automotive industry from IEC61508). They discuss topics related to the effects of the position error, communication delay, received signal strength, packet delivery ratio, number of nodes, and reliable communication range for the given data rate settings.

Besides, apart from the already mentioned BIDOIA (2015), it is essential to cite other research in Brazil related to CAVs. It was not found studies related explicitly to CAVs traffic microsimulation impacts on traffic flow; anyhow, other essential topics from their ecosystems were on the scope. MATEUS (2010) provided new directions to design efficient routing protocols performance for vehicular networks. CARIANHA (2011) also focused on vehicle networks assessing a cryptographic "mix-zones" model to improve location privacy information. GÁLVAN (2016) used the combination of SUMO and OMNET++ to study the vehicle's wave propagation modes from VANETs in the urban environment.

In conclusion, a wide range of research in CAVs, from simulation to field tests, shows that these technologies positively impact highway traffic flow, lane capacity, and fuel efficiency and emissions. On many different studies based on microscopic traffic simulation among different assumptions about car-following behavior, lane changing behavior, and connectivity, there is a common trend showing that increased penetration of autonomous vehicles leads to increased capacity and flow. The increasing penetration of technologies enabled by CAVs (as CACC/platooning, GLOSA, and modified version of IDM) impacted better results from all the aspects evaluated on the challenging mixed traffic conditions. It shows that the technologies should continue to be developed, and the implementation path accelerated.

The gaps found to be explored in this research are: The simulation research explores highways or city conditions with aspects that do not cover Brazilian metropolitan areas' roads and streets reality as the high number of motorcycles, buses, and trucks, non-dedicated public transportation lanes. Another topic that is not explored in many types of research is to add disturbance as vehicle breakdown and how to recover the normal traffic conditions in less time. Also, for highways, a gap was found on comparing, based on the same inputs data, variations of baseline network adding complexity as new entrances and exits. In this study, a different approach was made on highway networks, splitting them into segments to analyze individually the impacts of platoons being enabled or not for distinct vehicle interaction characteristics. 


\section{METHODOLOGY}

This research aims to develop a methodology that makes it possible to carry out studies to assess the impacts of AVs and CAVs on traffic. The simulation or an FOT (Field Operational Trial) can be used as the framework, making the following methodology steps different. If the simulation is the option, then the proper traffic simulator's choice takes the central role. In this research, the possibility the simulation was chosen to make it possible to assess and compare many different scenarios and features from HDVs, AVs, and CAVs, including the interaction among a considerable quantity of vehicles from different autonomous levels.

So, the simulation network model should be built. The input data and proper parameters should be collected according to the tool characteristics leading to a crucial phase: the calibration and complete definition of the baseline model. The scenarios derived from the baseline can be developed according to the simulator features and the research targets. When the collection of scenarios is defined, many different outputs can be used to compare the relevant aspects assessed during the research leading to the conclusions. The detailed steps are described as follows.

\subsection{TRAFFIC SIMULATOR}

The first step of the methodology is to define the research targets clearly (step "a" from Fig. 14). The second step is to define the desired outputs to find the appropriate conclusions (step "b). Then, the level of details that the simulation network requires, and the demanded features will support to define of the simulator category from nanoscopic to macroscopic (step "c" described in). Each simulator has its characteristics: features capabilities, co-simulation compatibility, required skills from the user who builds up the model, and minimum computer processing capacity to run the simulation. An exhaustive search on the simulators and a first contact considering tutorials is essential to assure the proper choice (step "d"). At that point, it is crucial to evaluate the question from (step "e"). If the research targets cannot be covered with the current choice, including co-simulators, it is necessary to go some steps to ensure the proper choice.

In this research, the driver behavior comparison among HDVs, AVs, and CAVs took the central role of microscopic simulation. The simulator defined for this research was PTV VISSIM due to the more straightforward configuration of different scenarios than other simulators, and the built-in platooning feature enabled the assessment of the same algorithm framework for the different convoys configuration. It Included the possibility to apply the convoys in specific segments of the road, lanes, or vehicle types. Even though it is commercial software, PTV Group 
offers a thesis license to students. PTV provided VISSIM 11 student licenses for ten months and VISSIM 2020 for additional six months. It is also available at the university labs.

Fig. 14 shows a workflow with the steps to define the appropriate simulator.

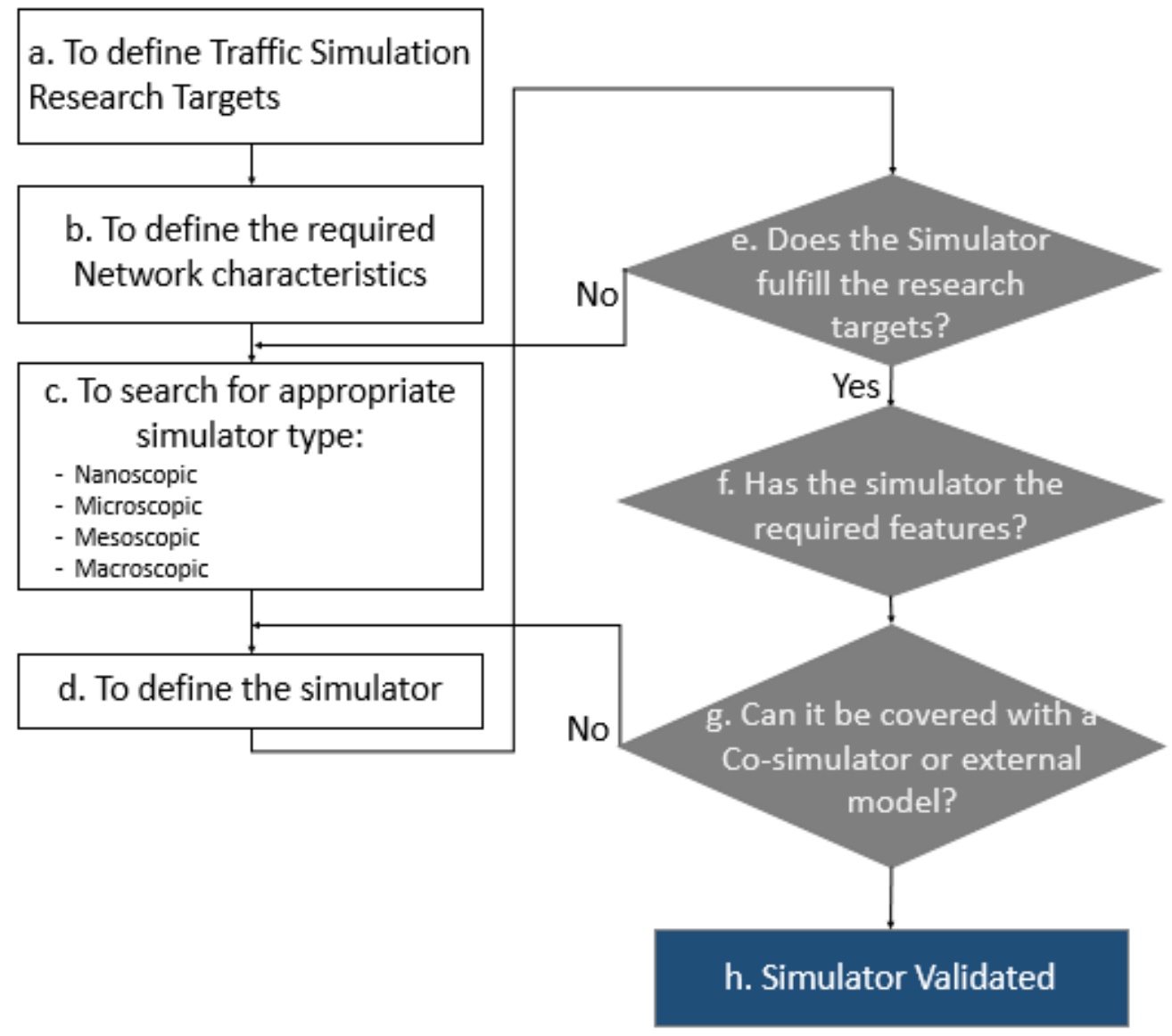

Fig. 14. Workflow to define the appropriate simulator.

Source: Author.

Once the simulator is defined, a new phase starts by building up the simulation network model, including all the required details to reproduce the base scenario described in step I from Fig. 15. Broad research to find all the required input data is demanded. It can include field studies, transportation entities report, or web-based data (step II). The most important part of this new phase is to perform the correct calibration to make the simulation valid. Usually, the calibration is an interactive process that is refined until the point that the result compared to a reference is acceptable (step IV). When it is finished, real-world networks with $100 \%$ of HDVs in São Paulo city, including the specific day's traffic characteristics. Besides that, three more networks were built and calibrated to assess the segment of highways.

As the purpose is to evaluate the AVs and CAV's introduction, a proper model of each automation level needs to be built. It includes the driver behavior models, parameters, and demanded features that reproduce AVs and CAVs, including how they interact with others (step 
$\mathrm{VI})$. Finally, all the demanded inputs to the simulator are ready. They can be used in different combinations to generate the results and use them according to the research objectives (step VII). In this research, the travel time comparison (step VIII) among the different scenarios and sub scenarios (step IX) was the primary output assessed to come to the conclusions. Fig. 15 shows the workflows to validate a baseline scenario and to assess the results based on a comparison.
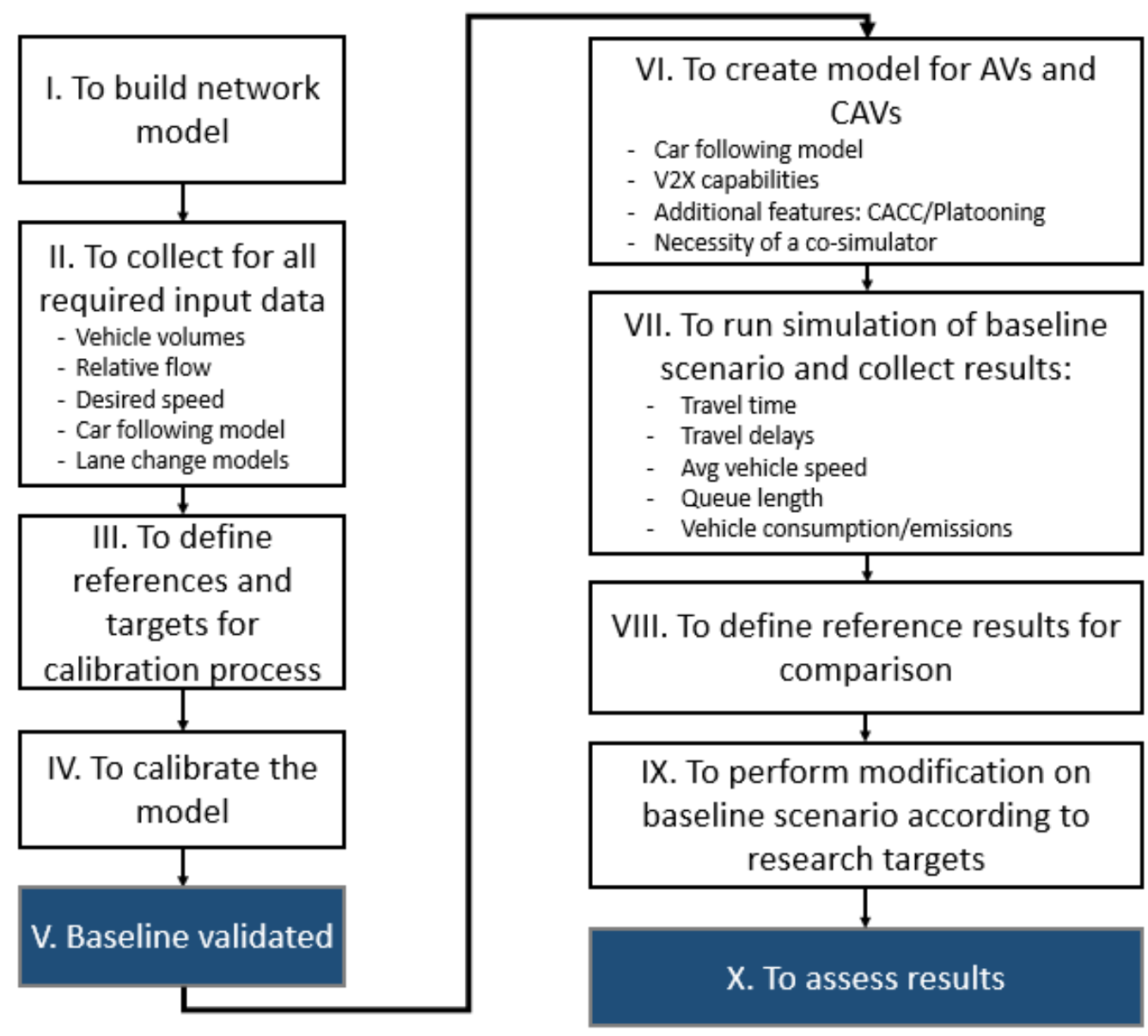

Fig. 15. Workflows to validate a baseline scenario and assessed the results Source: Author.

\subsection{MODEL CALIBRATION}

The model calibration is crucial for establishing a reliable framework that makes the data assessment scientifically valid. The theory of traffic model calibration is addressed in section 2.5. The main characteristics used to the calibration from all the networks in this research are listed below: 
- The base scenario 1.1 was used to calibrate the simulation model.

- Simulation time 1800 s (30 minutes).

- Starting of valid data from 300s simulation time on recommended waiting time for simulation traffic loading.

- All the parameters described in section 0 were fixed: CoExist's "Normal" driving logic.

The primary output data used as a reference was the average vehicle speed. This is the only scientifically validated data found on that specific network. Fig. 16 shows a flow chart with the calibration process.

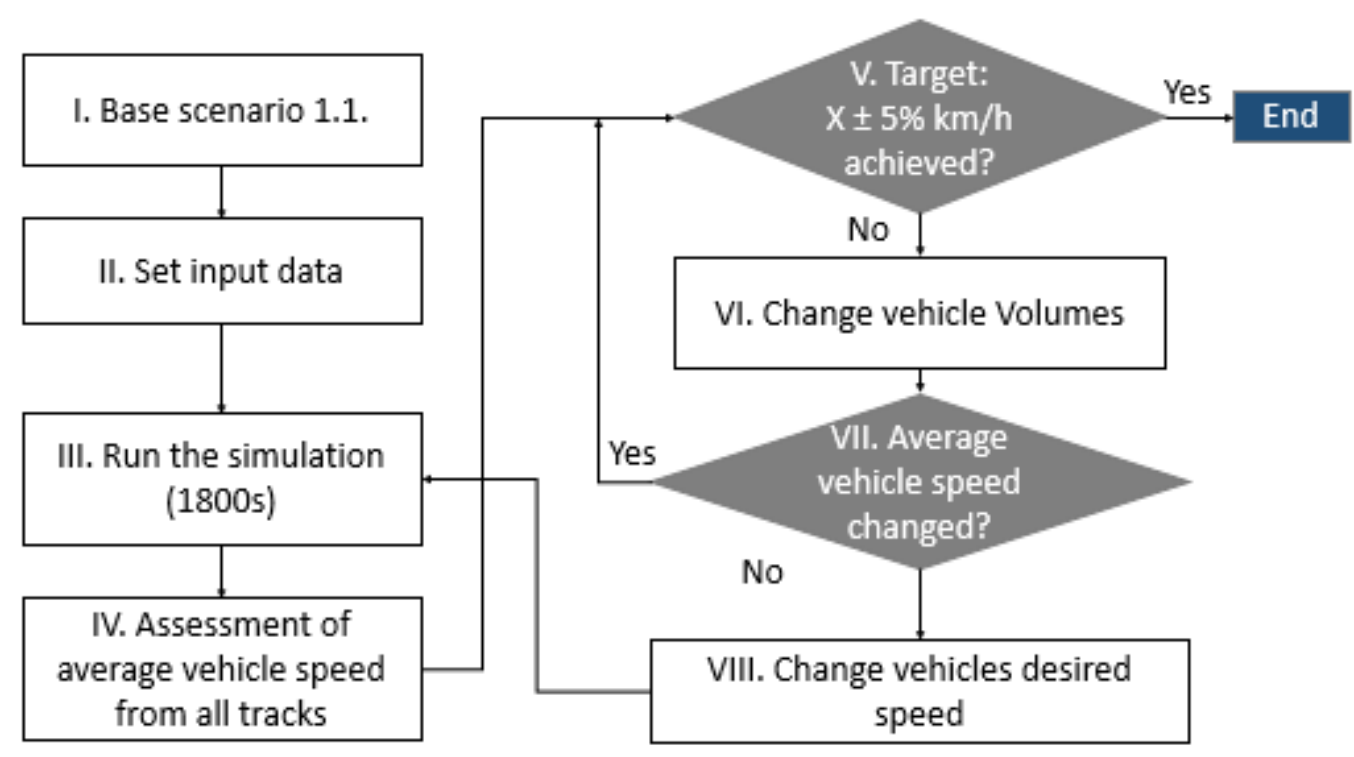

Source: Author.

Fig. 16. Flow chart from the calibration process

This interactive process was performed to define the baseline scenario for all three networks. Annex 5 is listed the vehicle's desired speed and volumes for each vehicle model after calibration.

\subsection{EVALUATED SCENARIOS}

Seventeen scenarios were built combining different elements as driver behaviors, external disturbance, and an additional new proposal. For every scenario, each driver's behavior's penetration rate was predefined to make it possible to measure the benefits of the incremental introduction of the autonomous and connected vehicle. Chart 6 shows the overview. 
Chart 6: Evaluated scenarios overview

\begin{tabular}{cccc}
\hline Scenarios & Subcenarios & Driver Behavior Model & Pen Rate \\
\hline 1.1 (Baseline) & 1.2 (Baseline) & Human Driven (HDV) & $100 \%$ \\
\hline 2.1 & 2.2 & Human Driven $(H D V)$ & $50 \%$ \\
& & $A V$ & $50 \%$ \\
\hline 3.1 & 3.2 & $A V$ & $100 \%$ \\
\hline 4.1 & 4.1 .1 and 4.2 & Human Driven $(H D V)$ & $33 \%$ \\
& & $A V$ & $33 \%$ \\
& & CAV & $33 \%$ \\
\hline 5.1 & 5.1 .1 and 5.2 & $A V$ & $50 \%$ \\
& & $C A V$ & $50 \%$ \\
\hline 6.1 & $6.1 .1 ; 6.1 .2 ; 6.1 .3$ and 6.2 & $C A V$ & $100 \%$ \\
\hline
\end{tabular}

Source: Author.

Details from scenarios composition:

- Scenarios X.1: base scenarios reproduce real-world models from the modeled network. Scenario 1.1 is the baseline, and its calibration process is described in chapter 4.2 . These scenarios do not include disturbances.

- Scenarios X.2 $\rightarrow$ adding a disturbance: they vary from scenarios X.1, including an external disturbance. The disturbance is a vehicle break down a situation that is always placed in the same position on the network, and it starts at the same simulation time step. To simulate the broken vehicle, it was inserted a bus stop and the open-door time was defined with a value higher than the total simulation time. Fig. 17 shows how the disturbance was added to the simulation.

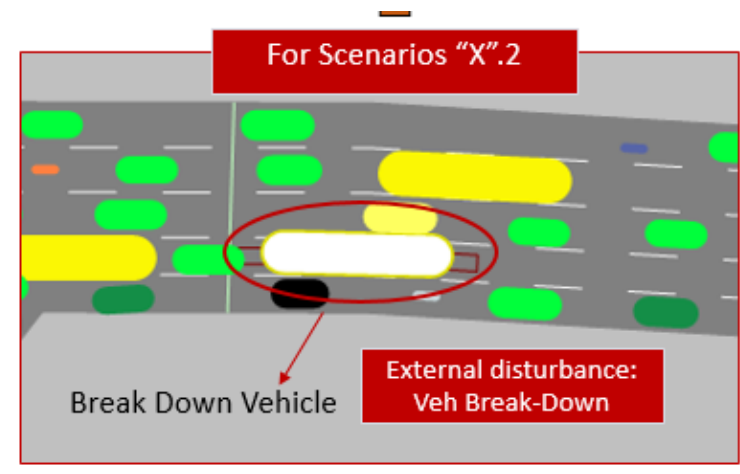

Source: Author.

Fig. 17. The disturbance was added to the model on scenarios X.2.

During the highway's simulations with platooning features, there was a need to create sub scenarios based on Scenarios X.1. They were created to support additional evaluations as described below: 
- Sub scenarios X.1.1: they differ from X.1 as just vehicles with similar dynamic behavior can perform a platoon, i.e., a passenger car cannot join a platoon with trucks and busses. It was assessed for scenarios 4.1, 5.1, and 6.1.

- Sub scenario 6.1.2: the target was to enable setting different driver behaviors along with the same network. The highways from network 3.2 and 3.3 were split into segments where platooning was allowed or not. The details of these networks are in item 5.2.1.3. It was assessed only for scenario 6.1.

- Sub scenario 6.1.3: a combination of X.1.1 and X.1.2. It was assessed only for scenario 6.1 .

The following sections will detail the simulated networks model, data input, data output, and calibration. Three different networks were selected to evaluate the aspects involved in vehicle automation for city and highway applications. Combining those networks could bring a wide range of simulations leading to a comprehensive evaluation of travel time impacts from CVs and CAVs. 


\section{EXPERIMENTATION}

In this chapter, it is presented the methods and materials used during the research development. The input data and simulator calibrations are described as soon as the description and background of the scenarios.

\subsection{MATERIAL}

As this research was done based on computer simulations, the details of the materials used are described in Chart 7.

\begin{tabular}{|c|c|c|c|}
\hline \multicolumn{4}{|c|}{ Chart 7 - List of materials } \\
\hline Item & Hardware and Software & Destination & Specification \\
\hline 1 & Ultrabook LG & \begin{tabular}{lll} 
Used on & \multicolumn{2}{c}{ scenarios } \\
configurations and first \\
simulations
\end{tabular} & $\begin{array}{l}\text { Model U46 } \\
\text { Processor: Core i5 } \\
\text { RAM: } 4 \mathrm{~GB} \\
\text { HD: } 512 \mathrm{~GB} \\
\text { Dedicated graphics board: no }\end{array}$ \\
\hline 2 & Desktop Computer & $\begin{array}{l}\text { Used for multiple parallel } \\
\text { simulations }\end{array}$ & $\begin{array}{l}\text { Intel i7 Processor 3.2GHz } \\
\text { SSD 480GB DATA 6GB } \\
\text { Memory DDR } \$ 16 G B \\
2400 \mathrm{MHz} \\
\text { Video card (GPU) Geforce } \\
\text { RTX2070 } \\
\text { HD 2TB }\end{array}$ \\
\hline 3 & PTV VISSIM Software & Simulation & $\begin{array}{l}\text { Thesis license } \\
\text { Versions: } \\
11.00-06 \text { to }-10 \text { ( } 64 \text { bits) } \\
2020.00 .00 \text { to }-09 \text { ( } 64 \text { bits) }\end{array}$ \\
\hline
\end{tabular}

Source: Author.

It is important to remark that for all simulated networks, it was possible to run the traffic simulator used in this research properly even with a medium performance computer without a dedicated graphics board (item 1, Chart 7).

\subsection{DRIVER BEHAVIORS SIMULATED MODELS}

The research's main goal was to investigate vehicle automation's benefits on different networks for both city and highway applications.

Some scenarios were built based on three different driver behaviors to achieve the goal. Mind that two of them (HDV and AV) were based on the CoEXist project model validated in partnership with PTV mentioned in chapter 2.4.1. CAV driver behavior was modeled based on AVs-based settings adding the platooning feature.

The parameters validated for each driver's simulation during the CoEXist project (Coexist D2.3, 2018) are presented in Chart 8. Specific platooning related parameters available on VISSIM 2020 are listed. The comparison to default parameters recommended at the VISSIM user manual (PTV VISSIM 2020 USER MANUAL, 2019) is presented on column denominated 
"def" as well as the comparison to studies from TIBLJAS et al. (2018) and CALVERT et al. (2020).

Chart 8: Parameters for following behavior validated inside CoEXist project

\begin{tabular}{|c|c|c|c|c|c|c|c|}
\hline & & $\begin{array}{l}\text { Human } \\
\text { Driven } \\
\text { (HD) }\end{array}$ & $\begin{array}{l}\text { Autonomous } \\
\text { Vehicle } \\
\text { (AV) }\end{array}$ & $\begin{array}{c}\text { Connected } \\
\text { Autonomous } \\
\text { Vehicle (CAV) }\end{array}$ & $\begin{array}{l}\text { Default } \\
\text { PTV } \\
\text { VISSIM }\end{array}$ & $\begin{array}{l}\text { TIBLJAS } \\
\text { et al. } \\
(2018)\end{array}$ & $\begin{array}{l}\text { CALVERT } \\
\text { et al. } \\
(2020)\end{array}$ \\
\hline \multirow{3}{*}{ W74 } & $\begin{array}{l}\text { Ax-Average Standstill } \\
\text { Distance }\end{array}$ & 2 & 1 & 1 & 2 & - & - \\
\hline & $\begin{array}{l}\text { Bxadd - Additive part of } \\
\text { Safety Distance }\end{array}$ & 2 & 1,5 & 1,5 & 2 & - & - \\
\hline & $\begin{array}{l}\text { Bxmult - Multiplicative } \\
\text { part of Safety Distance }\end{array}$ & 3 & 2 & 2 & 3 & - & - \\
\hline \multirow{10}{*}{ W99 } & $\begin{array}{l}\text { CCO - Standstill } \\
\text { distance }(\mathrm{m})\end{array}$ & 1,5 & 1 & 1 & 1,5 & 1 & 8 \\
\hline & CC1 - Spacing time (s) & 0,9 & 0,6 & 0,3 & 0,9 & 0,5 & $\begin{array}{l}\text { HDV:0,9 } \\
\text { CAV: } 0,6\end{array}$ \\
\hline & $\begin{array}{l}\text { CC2 - Following } \\
\text { variation }(\mathrm{m})\end{array}$ & 0 & 0 & 0 & 4 & 1 & $\begin{array}{l}\text { Not } \\
\text { mentioned }\end{array}$ \\
\hline & $\begin{array}{l}\text { CC3 - Threshold for } \\
\text { entering "following" (s) }\end{array}$ & -8 & -6 & -6 & -8 & -8 & $\begin{array}{c}\text { Not } \\
\text { mentioned }\end{array}$ \\
\hline & $\begin{array}{l}\text { CC4 - Negative } \\
\text { „following" threshold } \\
(\mathrm{m} / \mathrm{s})\end{array}$ & $-0,1$ & $-0,1$ & $-0,1$ & $-0,35$ & $-0,1$ & $\begin{array}{c}\text { Not } \\
\text { mentioned }\end{array}$ \\
\hline & $\begin{array}{l}\text { CC5 - Positive } \\
\text { „following" threshold } \\
(\mathrm{m} / \mathrm{s})\end{array}$ & 0,1 & 0,1 & 0,1 & 0,35 & 0,1 & $\begin{array}{c}\text { Not } \\
\text { mentioned }\end{array}$ \\
\hline & $\begin{array}{l}\text { CC6 - Speed } \\
\text { dependency of } \\
\text { oscillation }\left(10^{-4} \mathrm{rad} / \mathrm{s}\right)\end{array}$ & 0 & 0 & 0 & 11,44 & 0 & $\begin{array}{c}\text { Not } \\
\text { mentioned }\end{array}$ \\
\hline & $\begin{array}{l}\text { CC7 - Oscillation } \\
\text { acceleration }\left(\mathrm{m} / \mathrm{s}^{2}\right)\end{array}$ & 0,1 & 0,1 & 0,1 & 0,25 & 0,4 & HDV:1 \\
\hline & $\begin{array}{l}\text { CC8 - Standstill } \\
\text { acceleration }\left(\mathrm{m} / \mathrm{s}^{2}\right)\end{array}$ & 3,5 & 4 & 4 & 3,5 & 4 & HDV:4,5 \\
\hline & $\begin{array}{l}\text { CC9 - Acceleration at } \\
80 \mathrm{~km} / \mathrm{h}\left(\mathrm{m} / \mathrm{s}^{2}\right)\end{array}$ & 1,5 & 2 & 2 & 1,5 & 2 & HDV:1,5 \\
\hline \multirow{2}{*}{$\begin{array}{l}\text { Add } \\
\text { relev. } \\
\text { parame } \\
\text { ters }\end{array}$} & Inc Acc & $100 \%$ & $110 \%$ & $110 \%$ & $100 \%$ & $\begin{array}{c}\text { Not } \\
\text { mentioned }\end{array}$ & $\begin{array}{c}\text { Not } \\
\text { mentioned }\end{array}$ \\
\hline & $\begin{array}{l}\text { Safety Distance } \\
\text { Reduction factor (m) }\end{array}$ & 0,6 & 0,5 & 0,5 & 0,6 & $\begin{array}{c}\text { Not } \\
\text { mentioned }\end{array}$ & HDV: 0,2 \\
\hline \multirow{5}{*}{$\begin{array}{l}\text { Platoon } \\
\text { ing }\end{array}$} & $\begin{array}{l}\text { Max Number of } \\
\text { Vehicles }\end{array}$ & - & - & Not fixed & 7 & $\begin{array}{c}\text { Not } \\
\text { mentioned }\end{array}$ & $\begin{array}{l}\text { Not } \\
\text { mentioned }\end{array}$ \\
\hline & $\begin{array}{l}\text { Max Desired Speed } \\
(\mathrm{km} / \mathrm{h})\end{array}$ & - & - & 90 & 80 & $\begin{array}{c}\text { Not } \\
\text { mentioned }\end{array}$ & $\begin{array}{c}\text { Not } \\
\text { mentioned }\end{array}$ \\
\hline & $\begin{array}{l}\text { Max distance for } \\
\text { catching up to a } \\
\text { platoon }(\mathrm{m})\end{array}$ & - & - & 250 & 250 & $\begin{array}{c}\text { Not } \\
\text { mentioned }\end{array}$ & $\begin{array}{l}\text { Not } \\
\text { mentioned }\end{array}$ \\
\hline & $\begin{array}{l}\text { Gap Time [Similar do } \\
\text { CC1] (s) }\end{array}$ & - & - & $\begin{array}{l}0,6 \mathrm{~s} \text { (Sc. } 4 \text { and } 5) \\
0,3 \mathrm{~s} \text { (Sc.6) }\end{array}$ & 0,6 & $\begin{array}{c}\text { Not } \\
\text { mentioned }\end{array}$ & $\begin{array}{c}\text { Not } \\
\text { mentioned }\end{array}$ \\
\hline & Minimum Clearance (m) & - & - & $\begin{array}{l}2 \mathrm{~m}(\mathrm{Sc} 4 \text { and } 5) \\
0,5 \mathrm{~m} \text { (for Sc.6) }\end{array}$ & 2 & $\begin{array}{c}\text { Not } \\
\text { mentioned }\end{array}$ & $\begin{array}{c}\text { Not } \\
\text { mentioned }\end{array}$ \\
\hline
\end{tabular}

Source: adapted from (Coexist D2.3(2018); PTV VISSIM 2020 USER MANUAL (2019); TIBLJAS et al. (2018); CALVERT et al. (2020)). 


\subsubsection{Description of Simulated networks}

5.2.1.1 Network 1: São Paulo city (Bandeirantes x Nações Unidas ave.)

To select a proper network for the simulation, extensive research was performed. The target city was São Paulo in Brazil due to the well-known traffic jam issues and the proximity to the university, and the possibility to do evaluations "in loco."

The starting point was to find trustworthy and scientific information from the traffic situation to be a robust framework. Then it was found the annual Mobility Road System report was released for CET (abbreviation in Portuguese to Traffic Engineer Company) (CET, 2018). This report delivers information from traffic volumes and average vehicle speed from distinct main roads in the city. It is a reference used by public and private traffic management entities to report the networks' improvements and critical points requiring further attention. This report presents a robust statistics and measurement methodology to acquire data and a complete set of detailed results.

From the CET's report, a particular network was chosen. It is the intersection between Bandeirantes Avenue and Nações Unidas Avenue, as shown in Fig. 18.

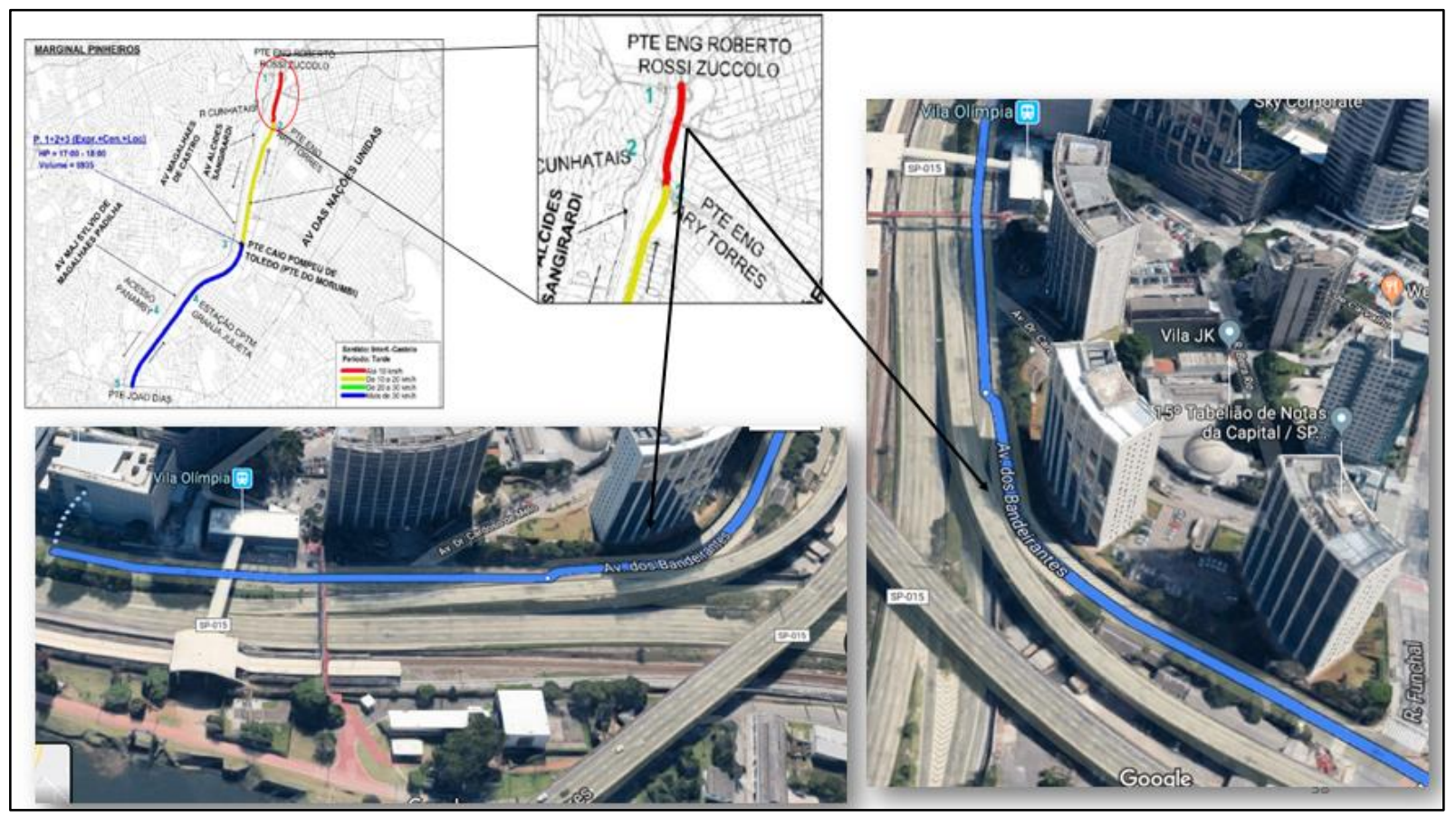

Fig. 18. Top view of simulated network Source: Adapted from CET (2018) and Google Maps.

This network was chosen between the options due to the following reasons:

- The Highly congested area on rush time: $<10 \mathrm{~km} / \mathrm{h}$ average speed.

- Intersection from two large traffic flow roads (pointed as I and II on Fig. 18).

- The Bus stop with several lines: two busses together at the bus stop most of the time leading almost to a lane blocking. 
- Higher than 10\% motorcycles relative flow: typical from large avenues in São Paulo city.

After choosing the network, the first step was to reproduce the streets inside PTV VISSIM software. It offers many resources to make the network as near as possible to reality. The primary resources and the ones used in the model in this research are in italic. They are: Number of lanes and the total length; Intersections; Reduced speed areas; Bus Stops; Priority rules; Sidewalks and crosswalks; Lane marks and road signs; Traffic sign.

It is important to remark that the HERE® mapping source company's background is an additional resource to make it easier to draw the network. On Fig. 19, it is shown the simulation test Network 1 built inside PTV VISSIM.

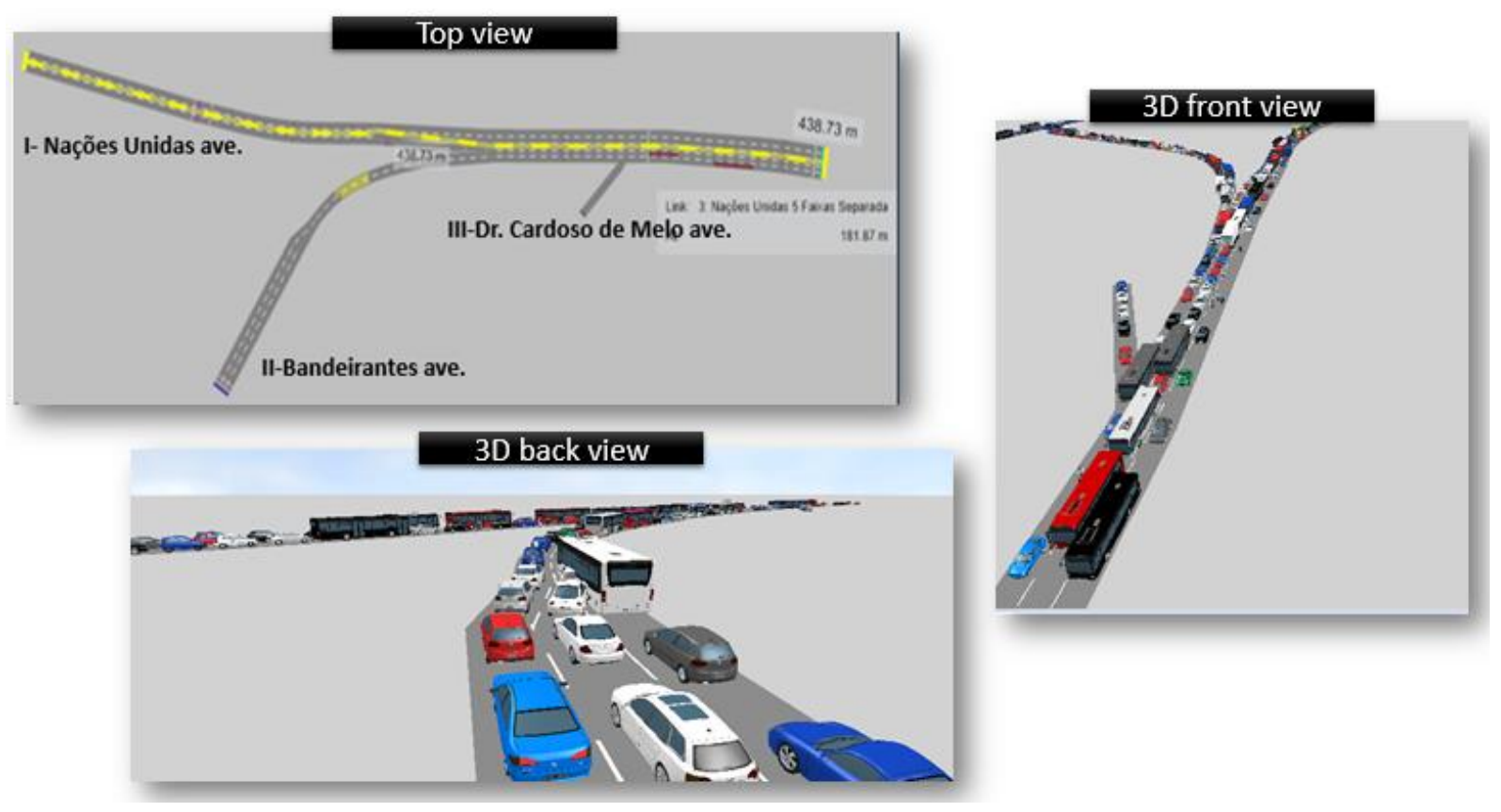

Source: Author.

Fig. 19. Simulation Network 1 on PTV VISSIM

\subsubsection{Network 2: São Paulo City (Cardeal Arco Verde St.)}

Network 2 is also in São Paulo city. Anyhow, the main characteristics are significantly different from Network 1, as:

- The high density of traffic lights: in total, three signal heads in $520 \mathrm{~m}$. No communication with traffic lights (V2I) considered.

- Lower volumes of vehicles: better traffic conditions.

- No relevant volume of motorcycles.

These differences are relevant to understand better the autonomous vehicle's impacts on the city environment's traffic performance. As in Network 1, the calibration was also done based on the Mobility Road System report (CET, 2018), and traffic light times were measured. 
Empirically in place. On Fig. 20, it is shown the simulation test Network 2 built inside PTV VISSIM.

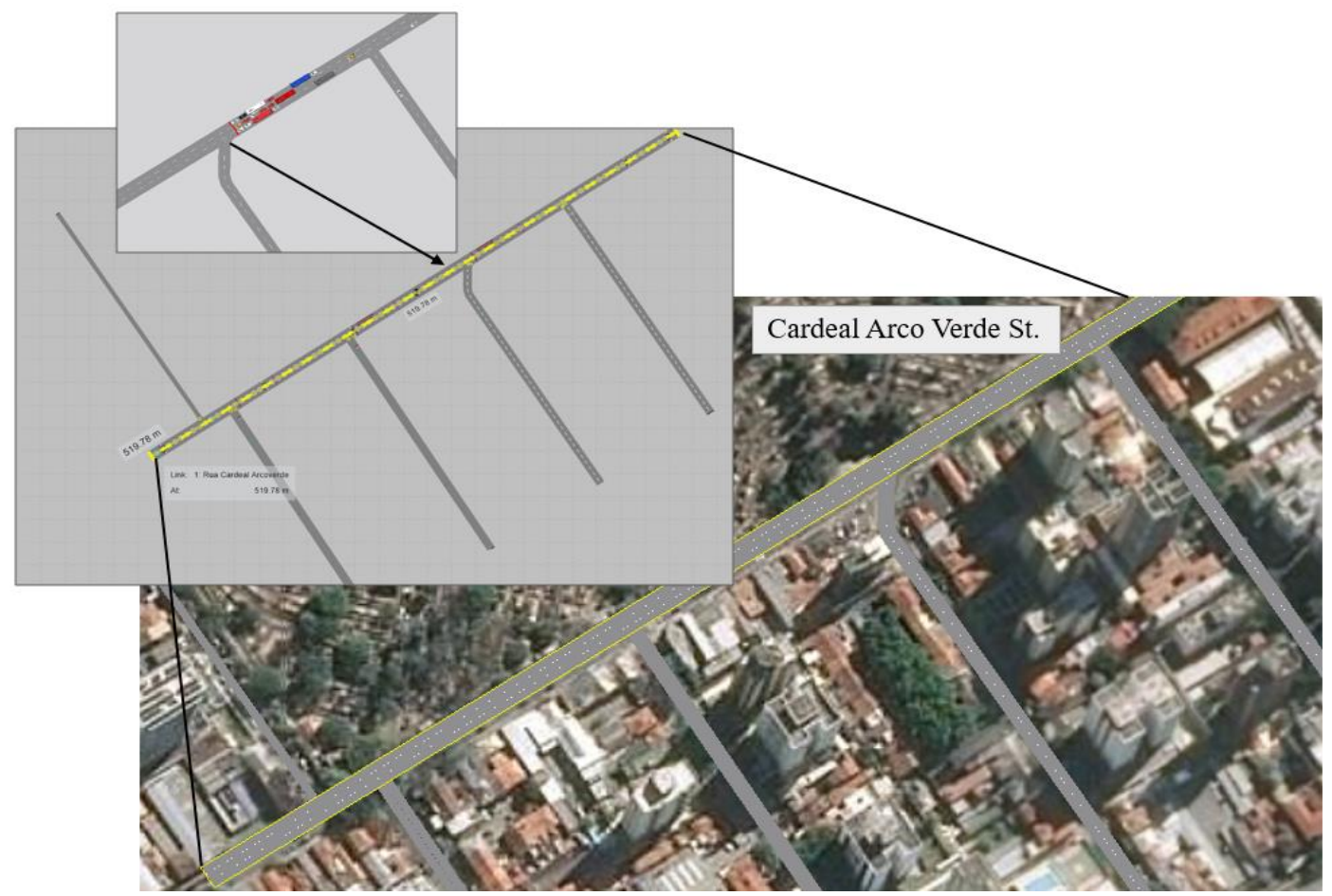

Source: Author.

Fig. 20. Simulation Network 2 on PTV VISSIM

\subsubsection{Networks 3.X: Highways}

Networks 3.X was not built based on a specific highway, but they have a combination of their main characteristics. The target was to evaluate the autonomous vehicles on a highway's different segments and mainly study the platooning feature.

At first, Network 3.1 is a straight segment from a highway without an entrance or exit. To make it comparable, Networks 3.2 and 3.3 have the same length; however, they have more complex interaction among vehicles, as they have exits that obligate cars to change lanes.

On Networks 3.2 and 3.3, 15\% of vehicles leave the highway over exit one and more $10 \%$ on exit 2. Specifically, on 3.3, one additional entrance was added to increase vehicle volumes and enhance vehicle interactions.

Some essential characteristics from Brazilian highways were used as:

- High penetration rates of trucks.

- Trucks and busses maximum allowed speed of $80 \mathrm{~km} / \mathrm{h}$, passenger cars $100 \mathrm{~km} / \mathrm{h}$;

- Trucks and busses can drive only on the last two lanes.

In Fig. 21, it is shown the simulation test Networks 3.X built inside PTV VISSIM. 


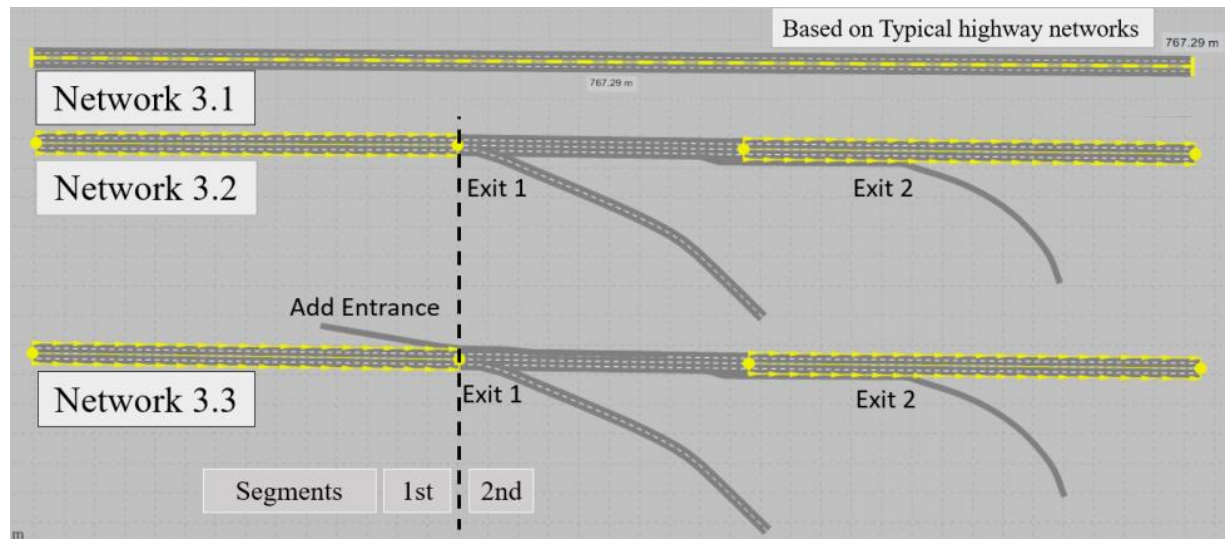

Source: Author.

Fig. 21. Simulation Networks 3.X on PTV VISSIM

\subsubsection{Comparison between simulated networks}

Chart 9 presents the overview and comparison among the simulated networks.

Chart 9: General networks comparison

\begin{tabular}{|c|c|c|c|}
\hline & Network 1 & Network 2 & Networks 3.X \\
\hline $\begin{array}{l}\text { Simulation } \\
\text { Top view }\end{array}$ & & & Nectort 3.1 \\
\hline Application & City (marginal areas) & City (central area) & Highway \\
\hline Framework & São Paulo City & São Paulo City & $\begin{array}{l}\text { Combination of highways } \\
\text { main characteristics }\end{array}$ \\
\hline $\begin{array}{l}\text { Assessed } \\
\text { Driver } \\
\text { Behaviors }\end{array}$ & W74 and W99 & W74 and W99 & (2) \\
\hline $\begin{array}{l}\text { Main } \\
\text { Characteristi } \\
\text { cs }\end{array}$ & $\begin{array}{l}\text { - The highly congested } \\
\text { area on rush time: }<10 \mathrm{~km} / \mathrm{h} \\
\text { average speed. } \\
\text { - Intersection from two } \\
\text { large traffic flow avenues } \\
\text { - A bus stop with several } \\
\text { lines: two busses together } \\
\text { at the bus stop most of the } \\
\text { time leading almost to a } \\
\text { lane blocking. } \\
\text { - >10\% motorcycles } \\
\text { relative flow: typical from } \\
\text { large avenues in São Paulo } \\
\text { city. }\end{array}$ & $\begin{array}{l}\text { - The high density of } \\
\text { Traffic lights: in total, } \\
\text { three signal heads in } \\
520 \mathrm{~m} \text {. } \\
\text { - Lower volumes of } \\
\text { vehicles: better traffic } \\
\text { conditions. } \\
\text { - No relevant volume of } \\
\text { motorcycles. } \\
\text { - One dedicated lane for } \\
\text { busses. }\end{array}$ & $\begin{array}{l}\text { - A high percentage of } \\
\text { Trucks } \\
\text { - Trucks and busses } \\
\text { maximum allowed speed } \\
\text { of } 80 \mathrm{~km} / \mathrm{h} \text {, passenger cars } \\
100 \mathrm{~km} / \mathrm{h} \text {. } \\
\text { - Trucks and busses can } \\
\text { drive only on the last two } \\
\text { lanes. }\end{array}$ \\
\hline $\begin{array}{l}\text { Evaluation } \\
\text { targets }\end{array}$ & $\begin{array}{l}\text { Impacts of autonomous } \\
\text { vehicles different } \\
\text { penetration rates on cities } \\
\text { with high-density traffic } \\
\text { conditions }\end{array}$ & $\begin{array}{l}\text { Comparison to network } \\
\text { one on cities with lower } \\
\text { traffic jams considering } \\
\text { traffic lights }\end{array}$ & $\begin{array}{l}\text { Impacts of autonomous } \\
\text { vehicles different } \\
\text { penetration rates on } \\
\text { Highways with focus on } \\
\text { Platooning }\end{array}$ \\
\hline
\end{tabular}

Source: Author. 


\subsubsection{Data input}

Many different data are required to input in a microscopic traffic simulator to have a robust simulation. The most important are:

i. Vehicle volume by time interval: number of vehicles in volume/hour for each avenue/street.

ii. Vehicles relative flow by model: percentage split between passengers cars, trucks, buses, bikes/motorcycles a train.

iii. Desired vehicle speed for each vehicle model.

iv. Driver behavior parameters.

v. Bus stops: bus lines, volumes, number of passenger and parameters related to the time the bus stay in a standstill at the bus stop.

In the following sections, it is described how these data were obtained.

\subsubsection{Vehicle volume and Relative flows}

There are different ways to get information about volumes of relative flows for the calibration process. In a city like São Paulo, the most usual ways used by traffic planners are official reports from government traffic agencies, e.g., from CET (CET, 2018), real-time public buses with networking system data available on public APIs from the government, e.g., from SPTrans (SPTrans, 2019), and empirical measurements and even google traffic information.

The specific part of the city chosen to build Network 1 was part of the CET report's measured data (CET, 2018), as it presents a clear and robust data collection methodology. In the simulation model, there are three avenues. For each one, a vehicle input (vehicle volume by time interval) was added, as illustrated in Fig. 22.

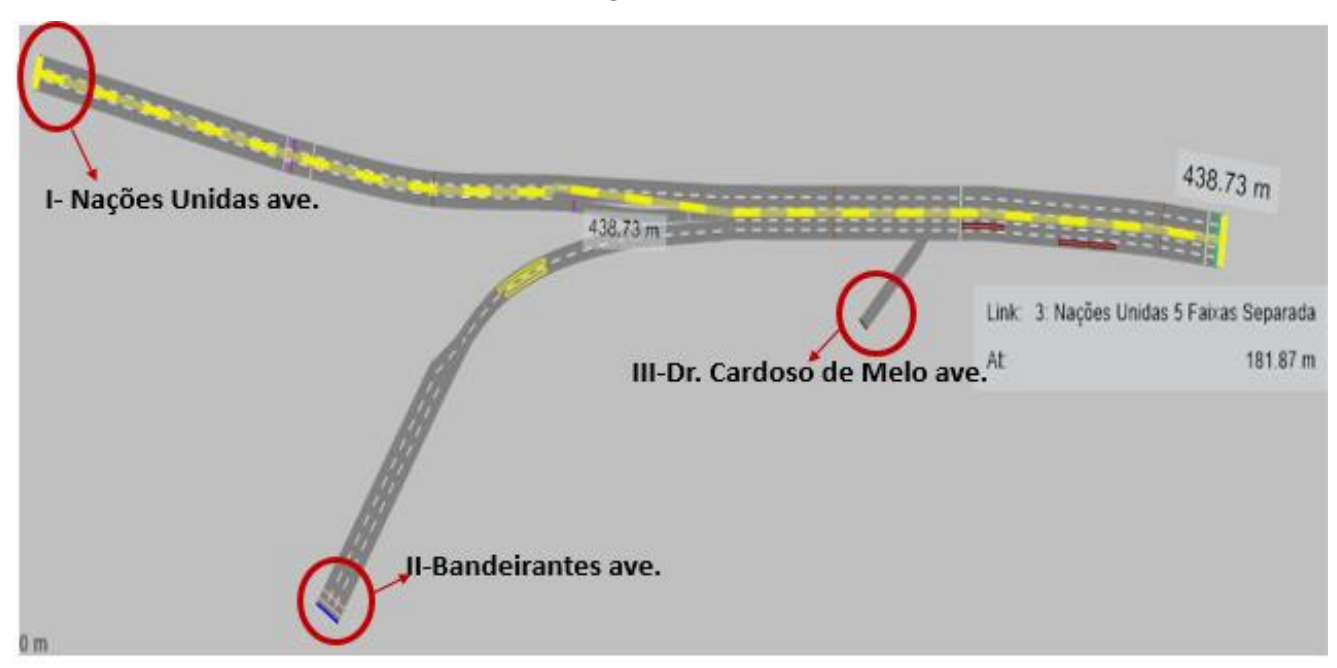

Source: Author.

Fig. 22. Vehicles data input Network 1 
On Network 2, the volumes and relatives' flows were empirically measured by students from Civil Engineer (graduate course at the Universidade de São Paulo).

On both Networks 1 and 2, the bus lines' inputs were based on SPTRANS itinerary plan (SPTans 2, 2019).

On Network 3, the inputs were done interactively based on observation and average vehicle speed until the highways achieved the desired traffic flow, enough to study the driver behavior phenomena and the platoon formation.

The volumes, relative flows, and desired vehicle speeds used for the calibration process are detailed for all networks on Annex 5.

\subsubsection{Driver Behavior parameters}

In this research, Wiedemann's parameters for driver behaviors are in Chart 8. Lane change-related parameters and their driver logic are described in Fig. 23 and Fig. 24 following CoEXist references.

\begin{tabular}{|c|c|c|c|c|c|c|c|c|c|c|}
\hline \multirow[b]{3}{*}{$\begin{array}{l}\text { parameter for } \\
\text { necessary lane } \\
\text { change* }\end{array}$} & \multicolumn{10}{|c|}{ driving logic } \\
\hline & \multicolumn{3}{|c|}{ rail safe } & \multicolumn{2}{|c|}{ cautious** } & \multicolumn{3}{|c|}{ normal } & \multicolumn{2}{|c|}{ all knowing } \\
\hline & own & \multicolumn{2}{|c|}{$\begin{array}{l}\text { trailing } \\
\text { vehicle }\end{array}$} & own & $\begin{array}{l}\text { trailing } \\
\text { vehicle }\end{array}$ & own & \multicolumn{2}{|c|}{$\begin{array}{l}\text { trailing } \\
\text { vehicle }\end{array}$} & own & $\begin{array}{l}\text { trailing } \\
\text { vehicle }\end{array}$ \\
\hline $\begin{array}{l}\text { maximum } \\
\text { deceleration }\end{array}$ & n.a. & \multicolumn{2}{|c|}{ n.a. } & $\begin{array}{c}\text { smaller/ } \\
\text { def }\end{array}$ & $\begin{array}{c}\text { smaller/ } \\
\text { def }\end{array}$ & def & \multicolumn{2}{|c|}{$\begin{array}{c}\text { smaller/ } \\
\text { def }\end{array}$} & def & $\begin{array}{c}\text { higher/ } \\
\text { def }\end{array}$ \\
\hline $\begin{array}{l}-1 \mathrm{~m} / \mathrm{s} \text { per } \\
\text { distance }\end{array}$ & n.a. & \multicolumn{2}{|c|}{ n.a. } & $\begin{array}{c}\text { smaller/ } \\
\text { def }\end{array}$ & $\begin{array}{c}\text { smaller/ } \\
\text { def }\end{array}$ & def & \multicolumn{2}{|c|}{ def } & def & $\begin{array}{c}\text { smaller/ } \\
\text { def }\end{array}$ \\
\hline $\begin{array}{l}\text { accepted } \\
\text { deceleration }\end{array}$ & n.a. & \multicolumn{2}{|c|}{ n.a. } & \begin{tabular}{c|}
$\begin{array}{c}\text { smaller/ } \\
\text { def }\end{array}$ \\
\end{tabular} & $\begin{array}{c}\text { smaller/ } \\
\text { def }\end{array}$ & def & \multicolumn{2}{|c|}{ def } & def & $\begin{array}{l}\text { higher/ } \\
\text { def }\end{array}$ \\
\hline \multicolumn{11}{|c|}{$\begin{array}{l}\text { *necessary lane change means a lane change which is necessary } \\
\text { overtaking because of higher own desired speed) } \\
{ }^{* *} \text { EABD (enforce absolute breaking distance) must be on } \\
\text { n.a. = not applicable }\end{array}$} \\
\hline & \multicolumn{8}{|c|}{ driving logic } & & \\
\hline & \multicolumn{2}{|c|}{ rail safe } & \multicolumn{2}{|c|}{ cautious** } & \multicolumn{2}{|c|}{ normal } & \multicolumn{2}{|c|}{ all knowing } & \multicolumn{2}{|c|}{ def } \\
\hline $\begin{array}{l}\text { parameter for } \\
\text { necessary lane } \\
\text { change* }\end{array}$ & own & $\begin{array}{l}\text { trailing } \\
\text { vehicle }\end{array}$ & own & $\begin{array}{l}\text { trailing } \\
\text { vehicle }\end{array}$ & own & $\begin{array}{l}\text { trailing } \\
\text { vehicle }\end{array}$ & own & $\begin{array}{l}\text { trailing } \\
\text { vehicle }\end{array}$ & own & $\begin{array}{l}\text { trailing } \\
\text { vehicle }\end{array}$ \\
\hline $\begin{array}{l}\text { maximum } \\
\text { deceleration }\end{array}$ & n.a. & n.a. & -3.5 & -2.5 & -4 & -3 & -4 & -4 & -4 & -3 \\
\hline $\begin{array}{l}-1 \mathrm{~m} / \mathrm{s} \text { per } \\
\text { distance }\end{array}$ & n.a. & n.a. & 80 & 80 & 100 & 100 & 100 & 100 & 100 & 100 \\
\hline $\begin{array}{l}\text { accepted } \\
\text { deceleration }\end{array}$ & n.a. & n.a. & -1 & -1 & -1 & -1 & -1 & -1.5 & -1 & -1 \\
\hline
\end{tabular}

Fig. 23. Recommended parameters related to lane change behavior Source: adapted from (Coexist D2.3, 2018) 


\begin{tabular}{|c|c|c|c|c|c|}
\hline \multirow[b]{2}{*}{ behavioral functionality } & \multicolumn{5}{|c|}{ driving logic } \\
\hline & rail safe & \multicolumn{2}{|c|}{ cautious** } & normal & all knowing \\
\hline Advanced merging ${ }^{*}$ & \multicolumn{2}{|c|}{ n.a. } & on $* *$ off & on $^{* * *}$ & on \\
\hline Cooperative lane change ${ }^{*}$ & n.a. & \multicolumn{2}{|c|}{ on $* * /$ off } & on $^{* * *}$ & on \\
\hline Safety distance reduction factor & \multicolumn{2}{|l|}{ n.a. } & higher+EABD & def/smaller & def/smaller \\
\hline min. headway (front/rear) & n.a. & \multicolumn{2}{|c|}{ higher } & def & def \\
\hline max. deceleration for cooperative braking & n.a. & \multicolumn{2}{|c|}{ smaller*** } & smaller $* * * /$ def & def \\
\hline \multicolumn{6}{|c|}{$\begin{array}{l}\text { "depends on technical equipment and implemented connec } \\
\cdots \text { EABD (enforce absolute breaking distance) must be on } \\
\cdots \text { If the AV cannot detect that the other vehicle wants to } \\
\text { n.a. = not applicable }\end{array}$} \\
\hline behavioral functionality & rail safe & cautious** & normal & all knowing & def \\
\hline Advanced merging* & n.a. & on $\cdots \%$ off & on $* *$ & on & on \\
\hline Cooperative lane change* ${ }^{*}$ & n.a. & on $* * /$ off & on $^{* * *}$ & on & off \\
\hline Safety distance reduction factor & n.a. & $1+\mathrm{EABD}$ & 0.6 & 0.5 & 0.6 \\
\hline min. headway (front/rear) & n.a. & 1 & 0.5 & 0.5 & 0.5 \\
\hline $\begin{array}{l}\text { max. deceleration for cooperative } \\
\text { braking }\end{array}$ & n.a. & -2.5 & -3 & -6 & -3 \\
\hline
\end{tabular}

Fig. 24. Recommended parameters related to lane change functionalities Source: adapted from Coexist D2.3 (2018).

As shown in 2.4.1, autonomous vehicles' characteristics were done based on CoEXist validated driver behavior parameters. Combining these parameter sets, and the platooning enabled, it is possible to simulate some aspects of CAVs, including the impacts on traffic performance.

\subsubsection{Data Output}

PTV VISSIM delivers many kinds of output data based on three main tools:
I. Data Collection Points
II. Vehicle Travel Times
III. Queue Counters

In this research, I. and II. were used as described below.

\subsubsection{Data Collection points}

The data collection points can be distributed at any position of the network. For example, on network 1, four collection points were added, as illustrated in Fig. 25. The position from each of them was chosen to bring more meaningful results to be analyzed. The same logic was applied for the other networks. 


\section{Data Collection Points}

Fig. 25. Data collection points on Network 1

Source: Author.

This tool takes much information from each lane, as Fig. 26 shows. This research's critical output element is harmonic average vehicle speed, queue delay, and occupation rate.

\begin{tabular}{|c|c|c|c|c|c|c|c|c|c|}
\hline \multicolumn{10}{|c|}{ 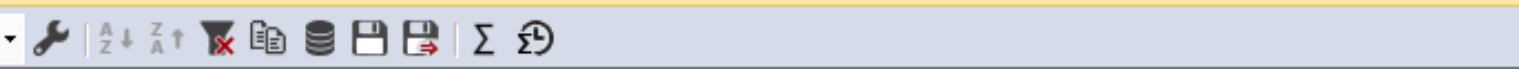 } \\
\hline Timelnt & Data & Acceler & Dist(All) & Length(All) & Vehs(All) & QueueDelay( $A$ & SpeedAvgArith & SpeedAvgHal & OccupRate(All) \\
\hline $0-200$ & 1: F1I & 0,02 & 149,07 & 4,06 & 41 & 0,00 & 12,24 & 12,13 & $24,61 \%$ \\
\hline $0-200$ & 2: F1 & 0,06 & 296,10 & 4,02 & 29 & 0,00 & 11,85 & 11,77 & $17,90 \%$ \\
\hline $0-200$ & 3: F1 & 0,04 & 416,62 & 4,02 & 18 & 0,00 & 12,13 & 11,90 & $10,89 \%$ \\
\hline $0-200$ & 4: F2I & $-0,01$ & 148,90 & 4,09 & 41 & 0,00 & 12,66 & 12,35 & $24,70 \%$ \\
\hline $0-200$ & 5: F2 & 0,03 & 293,94 & 3,98 & 30 & 0,00 & 13,71 & 13,11 & $16,46 \%$ \\
\hline
\end{tabular}

Source: Author.

Fig. 26. Data collection results example at PTV VISSIM

\subsubsection{Travel time measurement}

Travel time measurement is a tool that makes it possible to measure delta values in time between two points in the network. Fig. 27. illustrates this tool for network 1, where three travel time measurements were configured. The same logic was applied to other networks. 
Travel Time Measurement

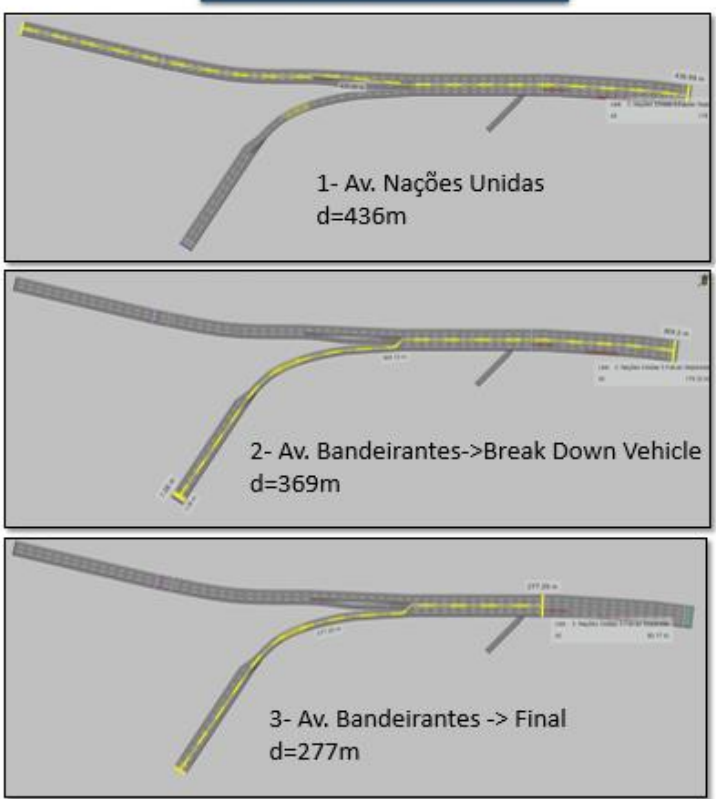

Fig. 27. Travel time measurements for Network 1 at PTV VISSIM.

Source: Author.

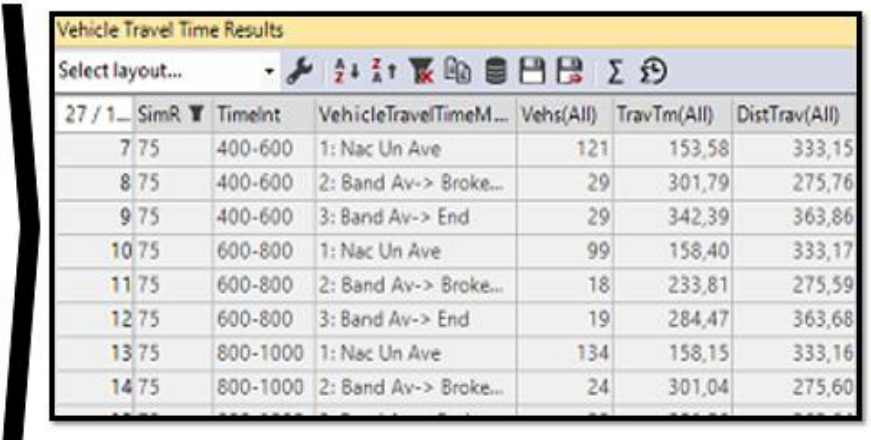

\subsection{ADDITIONAL MODEL ELEMENT: VEHICLE BREAK DOWN}

As described in Fig. 28, all the scenarios have a variation "X.2". This variation is a disturbance added to evaluate how the traffic is affected when a vehicle breaks down occurs. To simulate that, a bus stop was added to the model on a specific position where the traffic performance was most affected, as Fig. 28 shows. To keep the bus at a standstill for the complete simulation, the time that the doors remain opened was increased to a value higher than the total simulation time.

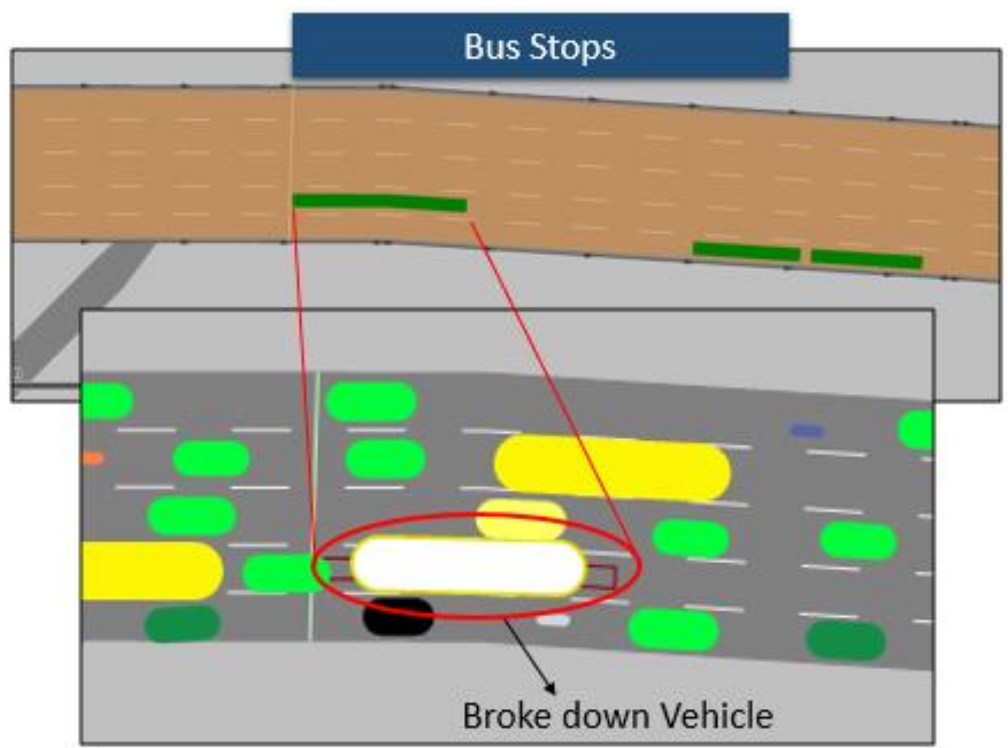

Source: Author.

Fig. 28. Simulation of a broken-down vehicle on the network 


\section{RESULTS AND DISCUSSION}

This section details the results from this study considering the scenarios described Chart 6 for three different networks.

The comparison between W74 and W99 is evaluated based on results evaluation from networks 1 and 2 (city application). Then a comparison between the scenarios is detailed for both networks. Additionally, an evaluation of disturbance effects for each scenario and network is described. Moreover, network 3 (highway) results are assessed based on W99 driver behavior for each scenario. A dedicated section is then used to assess results from the platooning (CACC) feature applied to simulate CAVs behavior at all networks. Finally, a general comparison between the networks and scenarios is presented.

\subsection{WIEDEMANN 74 X WIEDEMANN 99 COMPARISON}

As described in section 2.5.1, the PTV VISSIM software manual, as other references, recommends using the W74 model for network simulations with urban areas characteristics. However, as mentioned in the same referred section, the primary reference used in this study (Coexist D2.3, 2018) recommends using the W99 model for autonomous vehicles simulation due to the higher number of driver behavior parameters, which could make it more precise.

The results from Network 1 supported better to understand the differences between those two driver behaviors models. The calculation presented in Fig. 29 is presented in Fig. 30, the results comparing the travel time average ratio between W99 and W74. Travel time measurements were considered just after 300 s of simulation time to guarantee that the interactions and inputs were already stable.

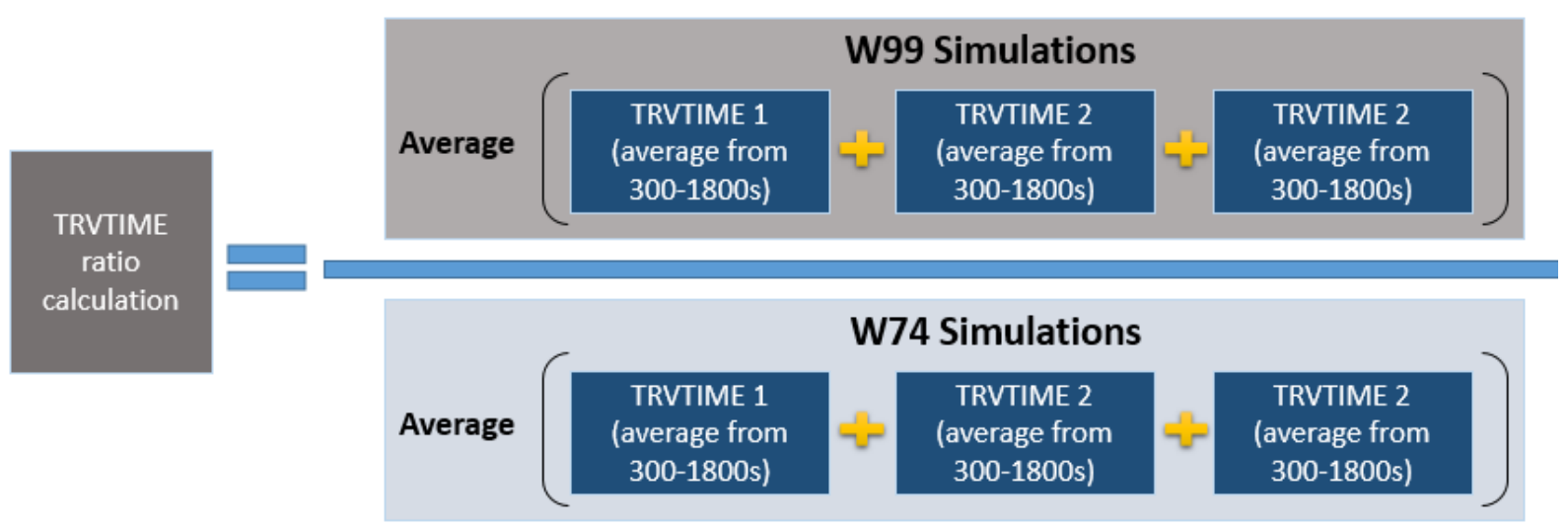

Source: Author.

Fig. 29. Travel Time ratio calculation between W99 and W74 


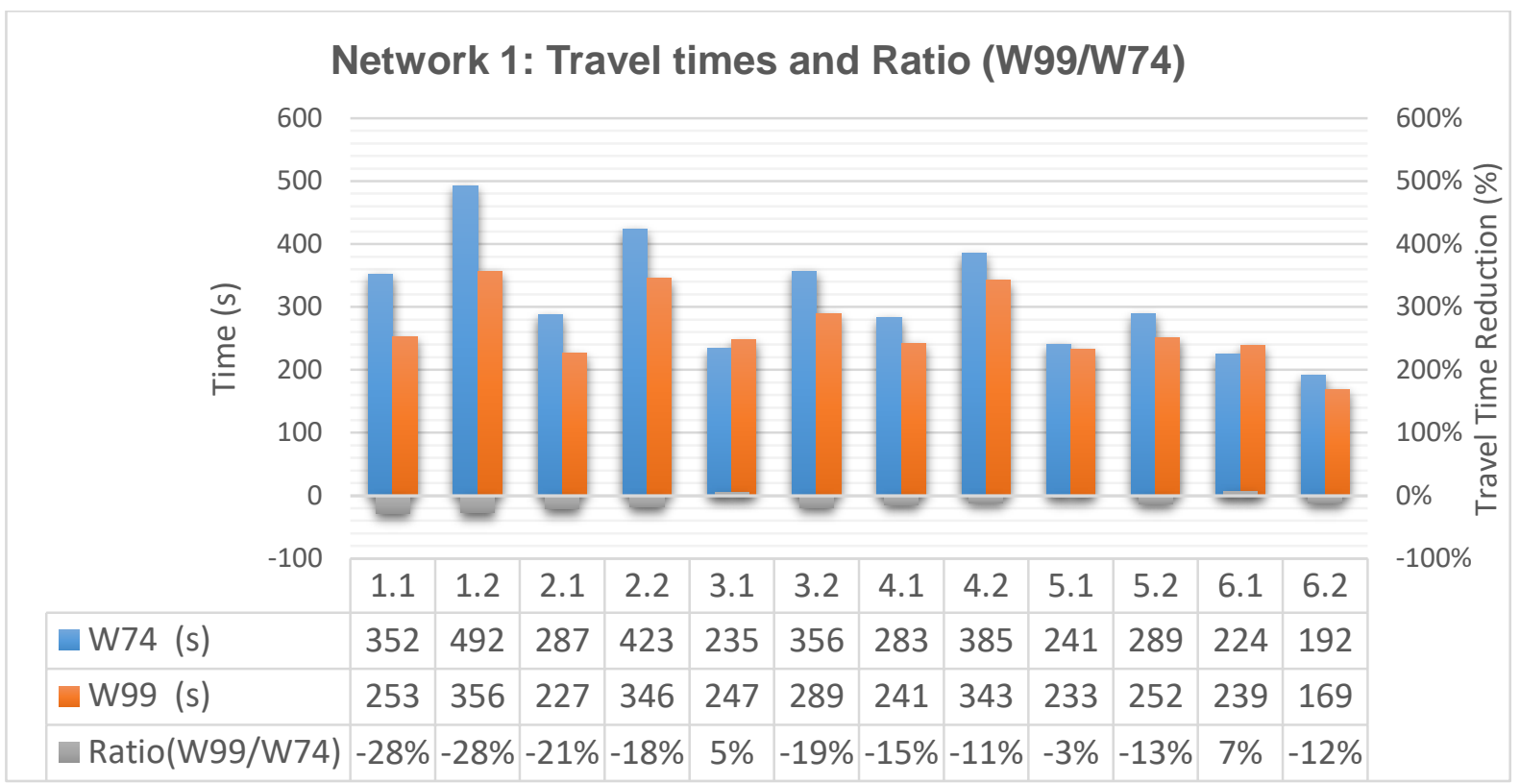

Fig. 30. Graphic from travel times and Relation between W99 and W74 simulations for Network 1. Source: Author.

In the analysis of the above results, the first general conclusion is that for the same scenario, the W99 driver behavior model presents lower travel time when compared to W74, but for scenarios 3.1 and 6.1. The tendency shows that the more significant is the percentage of AVs and CAVs, the lower is the difference. Scenarios 3.1 (100\% AVs) and 6.1 (100\% CAVs) bring interesting insights: they are the only fully autonomous, and the tendency is the opposite; W99 shows a slower travel time.

As those facts bring intrigues but non-concrete conclusions, a complimentary evaluation was done in the next section. On Networks 1 and 2, all the scenarios were simulated for both W74 and W99 models. It is essential to state that the next section's target is primarily to evaluate the impacts of AVs and CAVs on traffic performance, anyhow, as both models are evaluated. It supports bringing additional data to compare W74 and W99.

\subsection{NETWORKS 1 AND 2 (URBAN): COMPARISON BETWEEN SCENARIOS}

As Networks 1 and 2 were built based on city characteristics, they are assessed together. Although they are city networks, they differ in that Network 1 is a broad avenue with heavy traffic, while Network 2 is a typical downtown avenue, including a sequence of traffic lights. Once the base scenario 1.1 was calibrated, all the other scenarios were simulated for both W74 and W99 models. The additional relevant parameters are described in section 5.2.

To better understand the possible gains that the vehicle's automation can have on traffic conditions, a comparison from scenario $1 . X$ to all the other ones was performed. 


\subsubsection{Network 1}

Fig. 31 presents the results from all scenarios with and without breakdowns for the W74 model on Network 1.

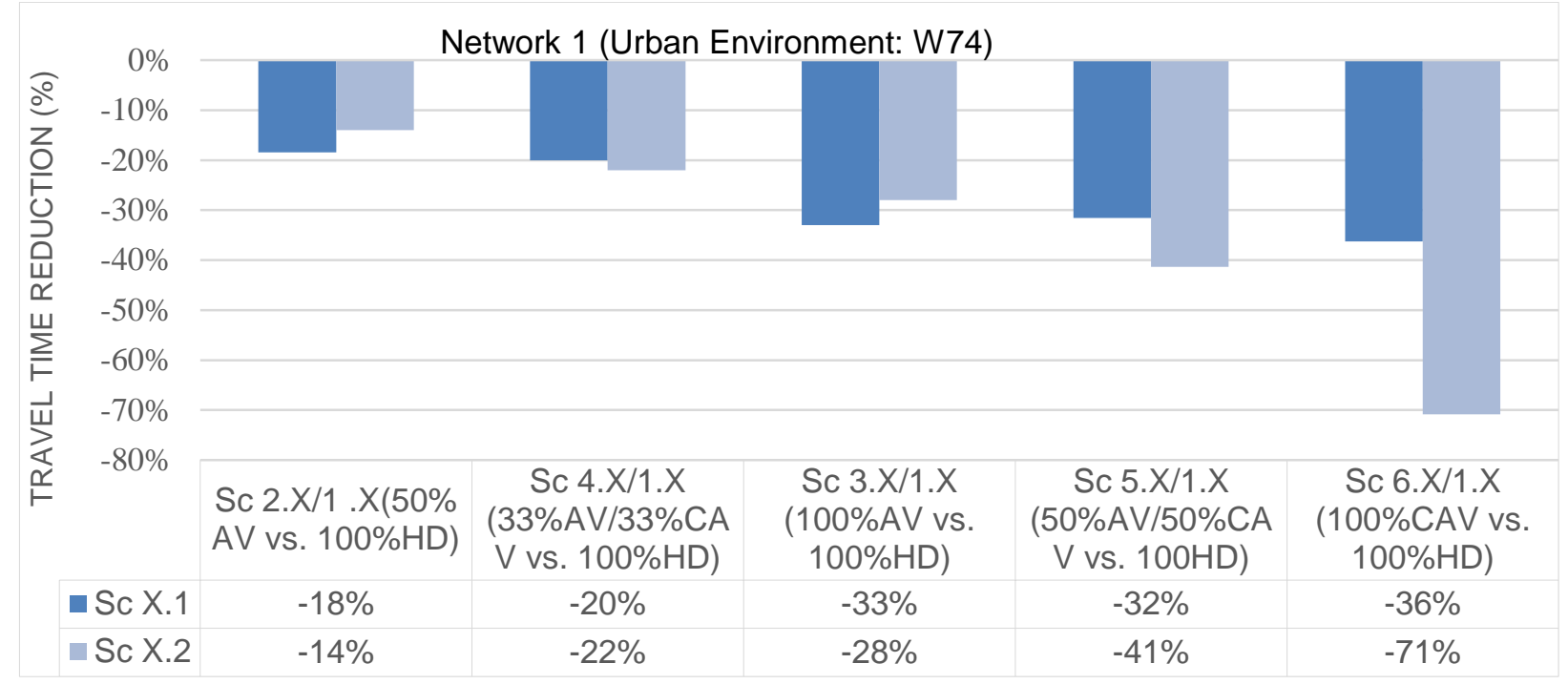

Fig. 31. Graphic for Travel Time Scenarios Comparison for W74 Model on Network 1 Source: Author.

The results from Network 1 for scenarios X.1 are in sequence of better travel times. It shows that scenarios 3.X had a higher reduction on time than scenarios $4 . X$. It leads to the first conclusion that the hybrid scenarios brought the lower-traffic performance to the network. In general, the scenarios with $100 \% \mathrm{AVs}$ and CAVs got better results on reducing travel time. Moreover, it is important to emphasize that mixed scenarios bring benefits to travel time. Anyhow, adaptation to traffic rules during this phase could still bring higher impacts, such as dedicated autonomous lanes. It should be highlighted because this kind of scenario (as 4.X) will probably be the most like reality for a long time.

One more point to notice is that the same conclusion can be extended to scenarios X.2 (with disturbance). There is also a substantial difference in travel time reduction between full CAVs scenarios 6.1 and 6.2 , from $-36 \%$ to $-71 \%$, respectively. These results lead to the conclusion that the capability of AVs and CAVs to keep smaller safety distances and faster acceleration on stop-and-go brings clear benefits in travel time for urban applications, mainly for worst traffic conditions (scenarios X.2).

\subsubsection{Network 2}

Fig. 32 presents the results from all scenarios with and without breakdowns for the W74 model on Network 2. 


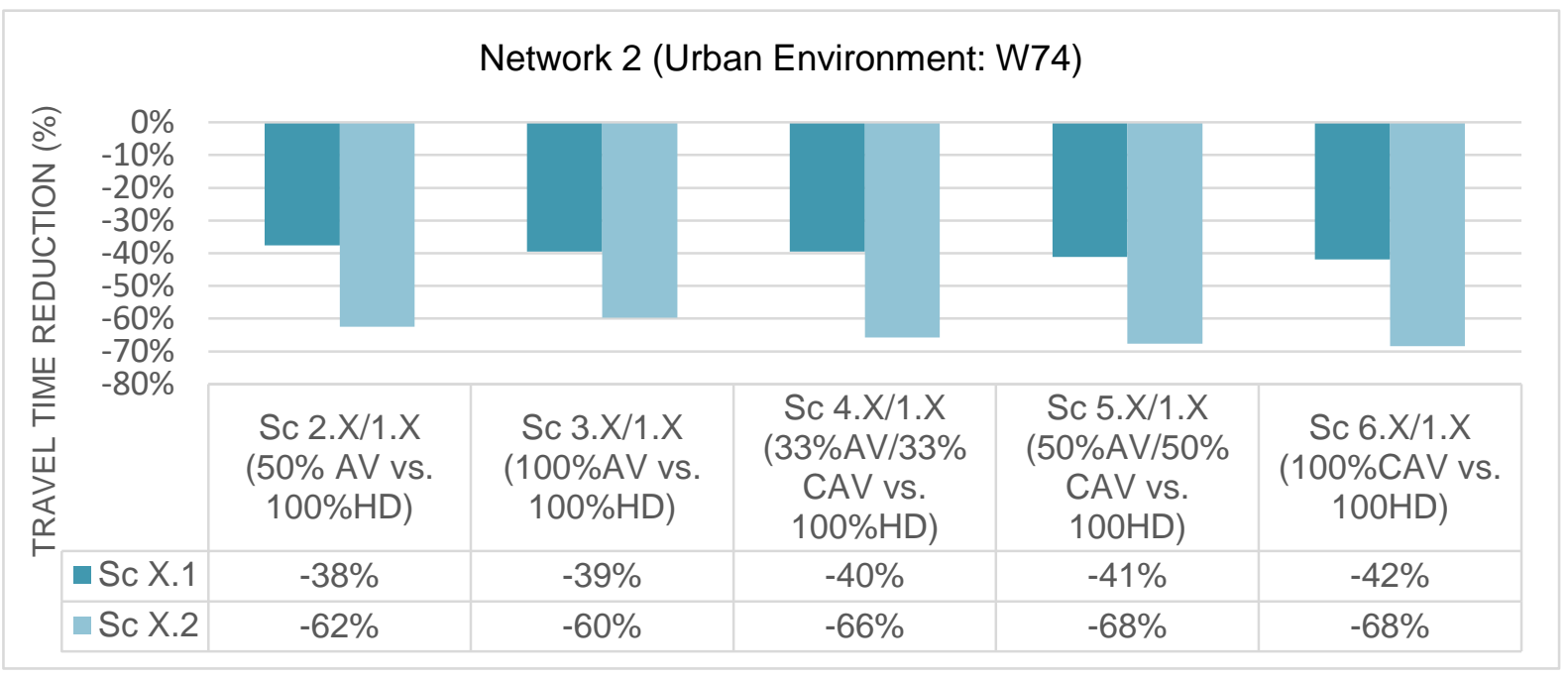

Fig. 32. Graphic for Travel Time Scenarios Comparison for W74 Model on Network 2 Source: Author.

Fig. 32 shows that there is an essential improvement in reducing travel time in scenario 2. There is little variation concerning other scenarios. This result is mainly due to the different characteristics of the network and the fact that it was calibrated for low traffic volumes. Therefore, in general, in traffic situations where there is no restriction for the driver to maintain the desired speed, there is no significant impact on travel time for higher percentages of AVs and CAVs. Looking specifically at scenarios X.2, a situation with a disturbance does not cause dramatic traffic jams due to vehicle volumes. In this situation, AVs and CAVs showed much better group performance on travel times due to reacting faster to the disturbance. It comes with the capability of keeping lower safety distances and improved reacceleration to the desired speed. Also, concerning Network 1, the Network 2 results follow the same tendency of improved travel times for scenarios where there is partial or total vehicle automation. Besides that, as expected, the results do not have many similarities due to the essential differences in traffic volume characteristics. These differences were essential to delineate how situation AVs and CAVs will benefit travel times or cities.

\subsubsection{City application: Comparison to the literature}

In the literature review, many studies were found showing the impacts of AVs and CAVs on traffic performance. For city application, mainly three of them show higher similarities with this one: BAILEY (2016), RIOS-TORRES et al. (2017), and CALVERT et al. (2020). BAO (2018) and YAO et al. (2020) also assessed urban environments with exciting results. Nevertheless, they measured only travel delays. In Chart 10, a summary of the references studied the urban environment compared with this one. 
Chart 10: Results comparison with references for urban application

\begin{tabular}{|c|c|c|c|c|}
\hline Reference & Simulator & $\begin{array}{c}\text { Applicati } \\
\text { on }\end{array}$ & Results & This study \\
\hline BAILEY (2016) & AIMSUM & City & $\begin{array}{l}20 \% \mathrm{AVs} \rightarrow \downarrow 53 \% \text { travel } \\
\text { time } \\
100 \% \mathrm{AVs} \rightarrow \downarrow 80 \% \\
\text { travel time }\end{array}$ & $\begin{array}{l}\text { Network 2, Sc.3.1: } \\
100 \% \text { AVs } \rightarrow \downarrow 39 \% \\
\text { travel time }\end{array}$ \\
\hline $\begin{array}{l}\text { RIOS-TORRES } \\
\text { et al. (2017) }\end{array}$ & AIMSUM & City & $\begin{array}{l}100 \% \mathrm{AVs} \rightarrow \downarrow 60 \% \\
\text { travel time }\end{array}$ & $\begin{array}{l}\text { Network 1, Sc. } 6.1: \\
100 \% \text { AVs } \rightarrow \downarrow 36 \% \\
\text { travel time }\end{array}$ \\
\hline BAZ (2018) & VISSIM & City & $\begin{array}{l}\downarrow 65 \% \text { total delays in } \\
\text { roundabouts } \\
\downarrow 85 \% \text { total delays on } \\
\text { signalized intersections }\end{array}$ & - \\
\hline $\begin{array}{l}\text { YAO et al. } \\
(2020)\end{array}$ & $\begin{array}{l}\text { SUMO/ } \\
\text { OMNET++ }\end{array}$ & City & $\begin{array}{l}60 \% \text { CACC } \rightarrow \downarrow 19 \% \\
\text { travel delays } \\
100 \% \text { CACC } \rightarrow \downarrow 27 \% \\
\text { travel delays }\end{array}$ & - \\
\hline $\begin{array}{l}\text { CALVERT et al. } \\
(2020)\end{array}$ & VISSIM & City & $\begin{array}{l}\leq 50 \% \text { CACC } \rightarrow \text { no } \\
\text { positive effect } \\
100 \% \text { CACC } \rightarrow \downarrow 11 \% \\
\text { travel time }\end{array}$ & $\begin{array}{l}\text { Network 2, Sc.3.1: } \\
50 \% \text { AVs } \rightarrow \downarrow 38 \% \\
\text { travel time } \\
100 \% \text { CAVs } \rightarrow \downarrow 39 \% \\
\text { travel time }\end{array}$ \\
\hline
\end{tabular}

In the BAILEY (2016) study, a simulation was done in the signalized intersection, not considering communication technologies. It is a framework like network two in scenario 3.1. The BAILEY (2016) obtained an $80 \%$ reduction in travel time for $100 \%$ AVs. In his study showed that a reduction in $39 \%$ in travel time was measured. The network setup's main difference is that BAILEY (2016) considers only one intersection with traffic lights and higher average vehicle speed limits than Network 2, which is longer with three.

In comparison with Network 2, CALVERT et al. (2020) simulated an ITS corridor in Amsterdam with five traffic lights equipped with $\mathrm{V} 2 \mathrm{I}$ technology to extend the green-time. CAVs vehicles can join in platoons. As mentioned in Chapter 3 , it was broad research, including an FOT. Their simulation setup can be compared to Network 2, considering that V2I was not part of this study. CALVERT et al.'s (2020) results showed benefits to the traffic only in percentages higher than $50 \%$ of CACCs. It differs from the results of this research Network 2, where since $50 \% \mathrm{AVs}$, the improvements were up to $39 \%$ reduction in travel times. It shows that urban applications with signalized intersection should be studied case by case to measure the effect of autonomous vehicles and their technologies.

RIOS-TORRES et al. (2017) focused on a merging zone to measure how CAVs can affect the travel time in this situation of conflict to the traffic. It is more like Network 1 on scenarios 6.1. 
In the merging zone, the authors proposed a V2I communication to a controller that implemented the first-in-first-out (FIFO) logic and achieved until 60\% reduction in travel time. The current study did not consider a specific strategy for merging and achieving the complete Network 1 , reducing $36 \%$ in travel time. It shows an opportunity to achieve even better results in implementing the V2I merging controller in future studies.

As these other studies show, traffic performance's measured impacts can vary significantly, depending on the network's characteristics and CAVs capability configuration. The convergent point is that they show positive impacts.

Additional evaluations considering the platoon feature focus are described in chapter 6.4.

\subsubsection{Comparison W74xW99:}

The experiment results of Networks 1 and 2 (based on the W99 model) are presented on graphics from Fig. $\mathbf{3 3}$ and Fig. $\mathbf{3 4}$ to enable the comparison.

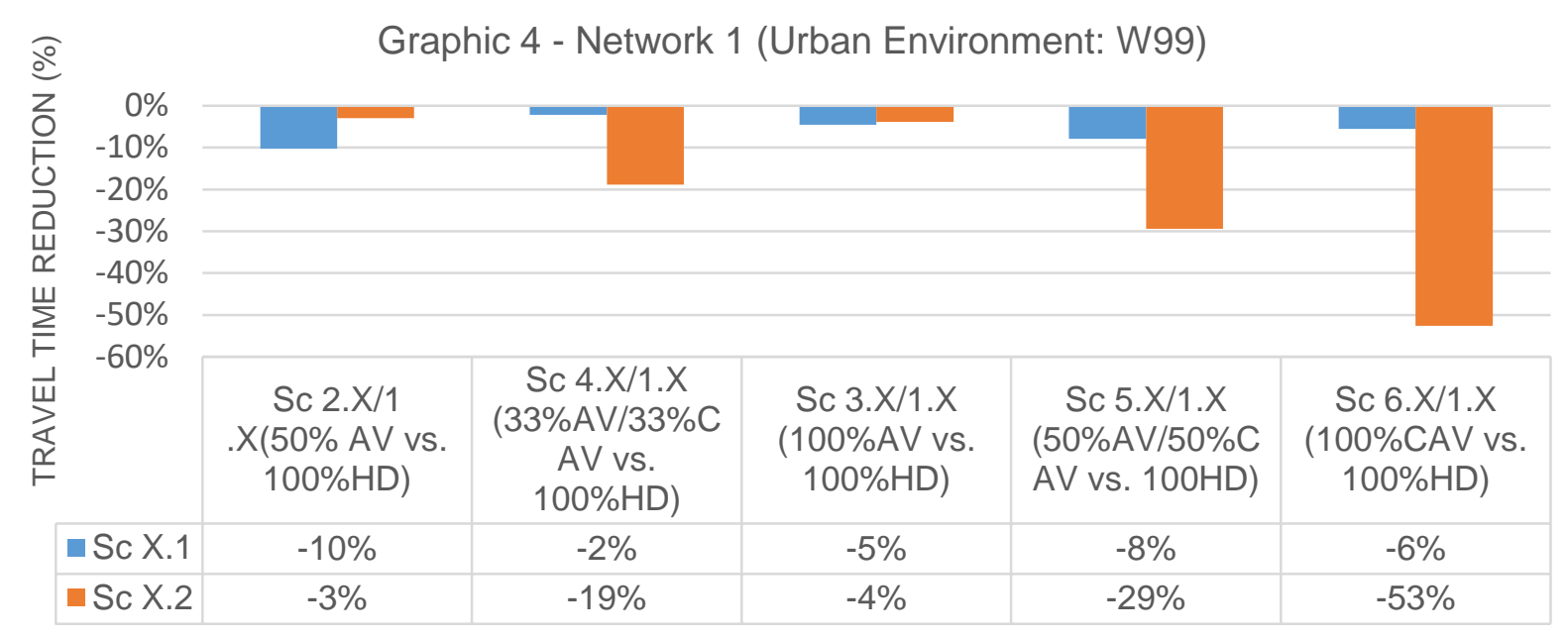

Fig. 33. Graphic for Travel Time Scenarios Comparison for W99 Model on Network 1 Source: Author.

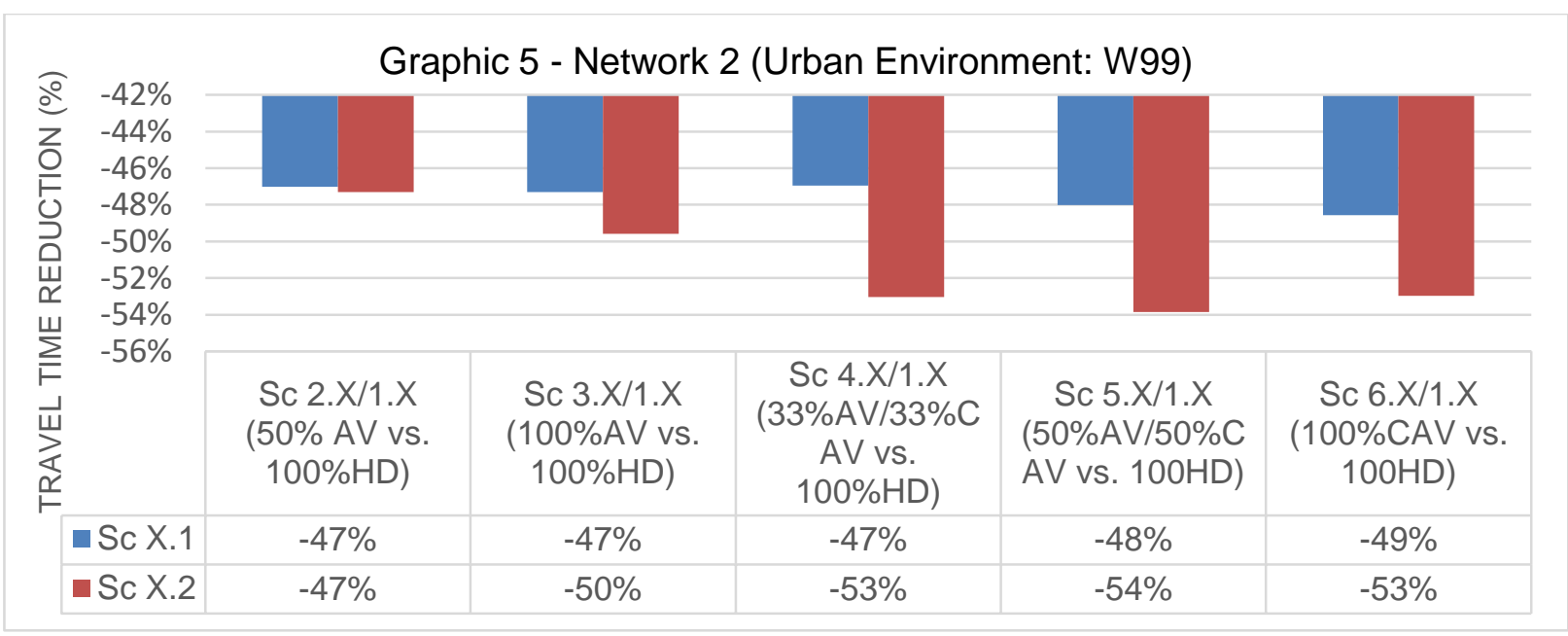

Fig. 34. Graphic for Travel Time Scenarios Comparison for W99 Model on Network 2 Source: Author. 
After evaluating all scenarios, the comparison from W74 to W99 on city networks leads to the following points:

- General conclusions from chapter 6.1 are confirmed.

- The travel time variation along the scenarios is more meaningful for the W74 model:

- Based on general characteristics set in the simulator for higher autonomous levels, the results from W99 shows low coherence, and it does not contribute to getting relevant conclusions.

- W99 model on a graphic from Fig. 34 shows no clear tendency, as found on W74.

- For Network 2 (Fig. 35), the reduction in travel times along the scenarios is remarkably similar and even lower for higher autonomous penetration.

- Network 2 does not support this assessment as it has very similar results between the scenarios for both W74 and W99.

It leads us to the following statement: once the correct software configuration and parameters for autonomous vehicles are set, the W74 model showed to be more appropriate than W99 for city traffic simulation regarding travel time evaluation, even for high penetration of CV and CAVs.

\subsubsection{Platooning for city application}

The overall conclusion is that the CAVs in platooning mode do not bring relevant travel time improvements for city network characteristics. Only Network 1 scenarios with disturbance brought satisfactory results. Platooning gets more meaningful, looking at highway application, explored still inside this chapter.

However, some aspects are relevant to be assessed, as the platooning size. The results for scenarios 4, 5, and 6 presented on graphics from Figs. 31 to 34 were based on the best travel time results. It means that these results were found after evaluating a range of maximum vehicles allowed in each platoon, configured as a parameter mentioned in chapter 2.5.2. All the other parameters related to platooning were fixed to perform this evaluation.

As scenarios 6.X have full penetration of vehicles with platooning capability, it was evaluated with a broader range, from 2 to 25 vehicles. Fig. 35 and Fig. 36 show the travel time results for each configuration. 


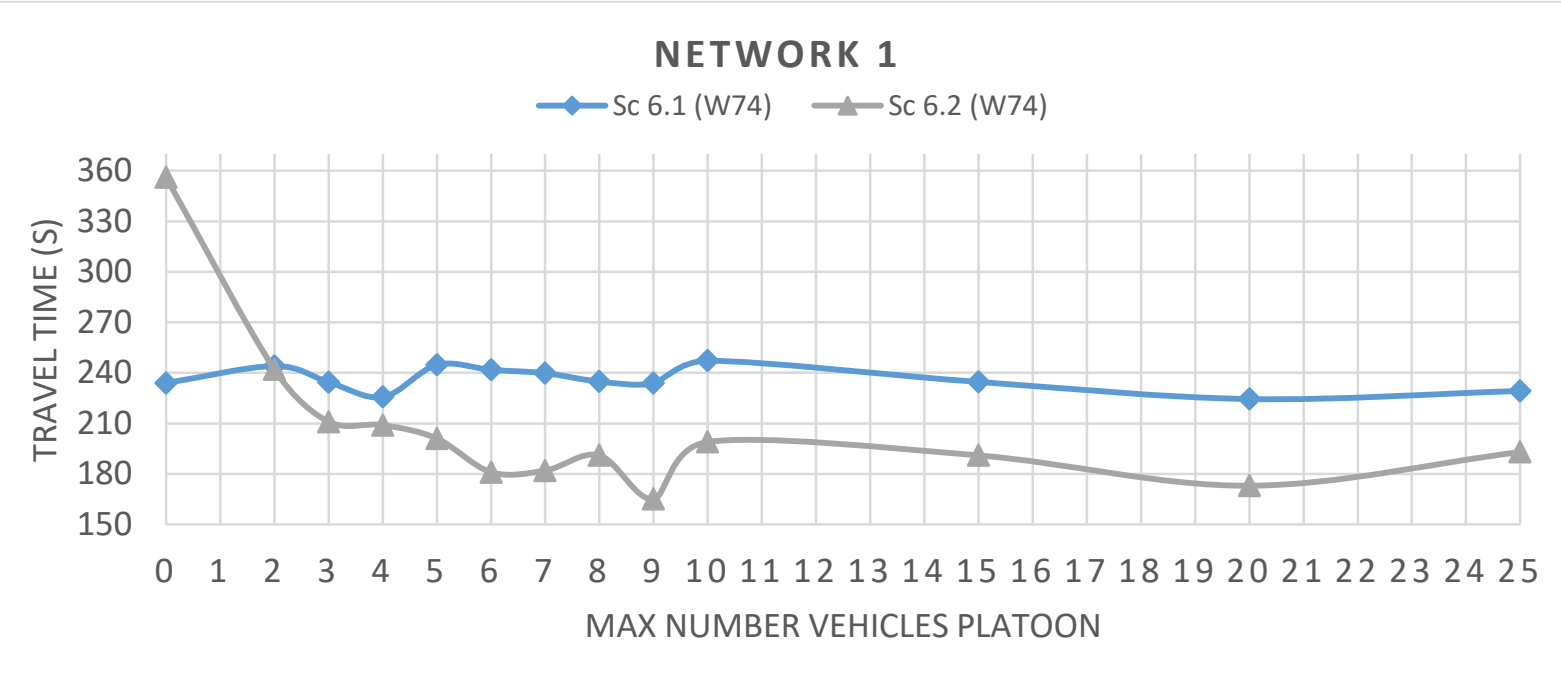

Fig. 35. Graphic for Travel time variation for a different maximum number of vehicles in a platoon on scenarios $6 . X$ for network 1

Source: Author.

From Fig. 35, it is noticed that the traffic conditions affect the results of travel time optimization through platoon size for the same network. In scenario 6.2, with the worst traffic conditions, the variation was higher. It is essential to highlight that platoon showed substantial improvements compared to the platoon disabled. In scenario 6.1, the results had a lower variation when compared to the platoon disabled.

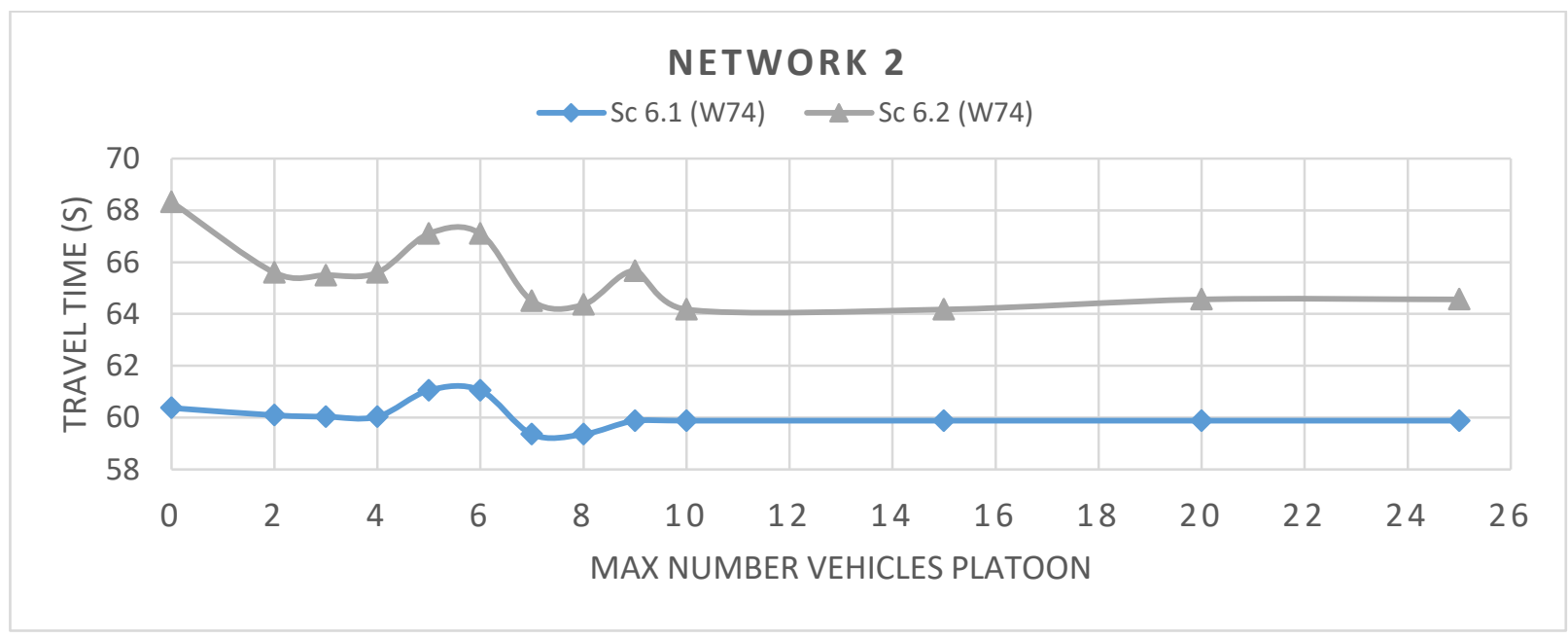

Fig. 36. Graphic for Travel time variation for a different maximum number of vehicles in a platoon on scenarios $6 . \mathrm{X}$ for network 2

Source: Author.

Network 2 is that setting the maximum platoon size for ten or more vehicles leads to remarkably similar results. It was hardly verified platooning with more than ten vehicles, mainly due to low volumes of traffic. The best results were found for 7 and 8 vehicles maximum platoon size for W74. 
In general, it is noticed that the number of vehicles in a platoon affect the travel time, even more for scenarios with disturbance. It is an essential input for traffic planners' studies of the future urban environment. The optimal platoon size for scenarios with CAVs that enables the platoon is presented in chapter 6.4.

A broader evaluation based on a highway network is described in section 6.3.

\subsubsection{Additional evaluation on Network 1}

One additional point is looking more specifically at segments of the Network 1 model for all scenarios and driver behavior types described in Fig. 37. Two behaviors are explicit:

i. Bandeirantes Avenue presents the worst traffic conditions (orange bars);

ii. Nações Unidas Avenue (blue bars) presents lower travel time variation between the scenarios than Bandeirantes Avenue. An additional conclusion is that the simulation with break down affected more Bandeirantes avenue than Nações Unidas Avenue due to the breakdown vehicle's position at lane 2 (as described in Fig. 28).

Travel time difference between Nac Unidas and Bandeirantes avenues

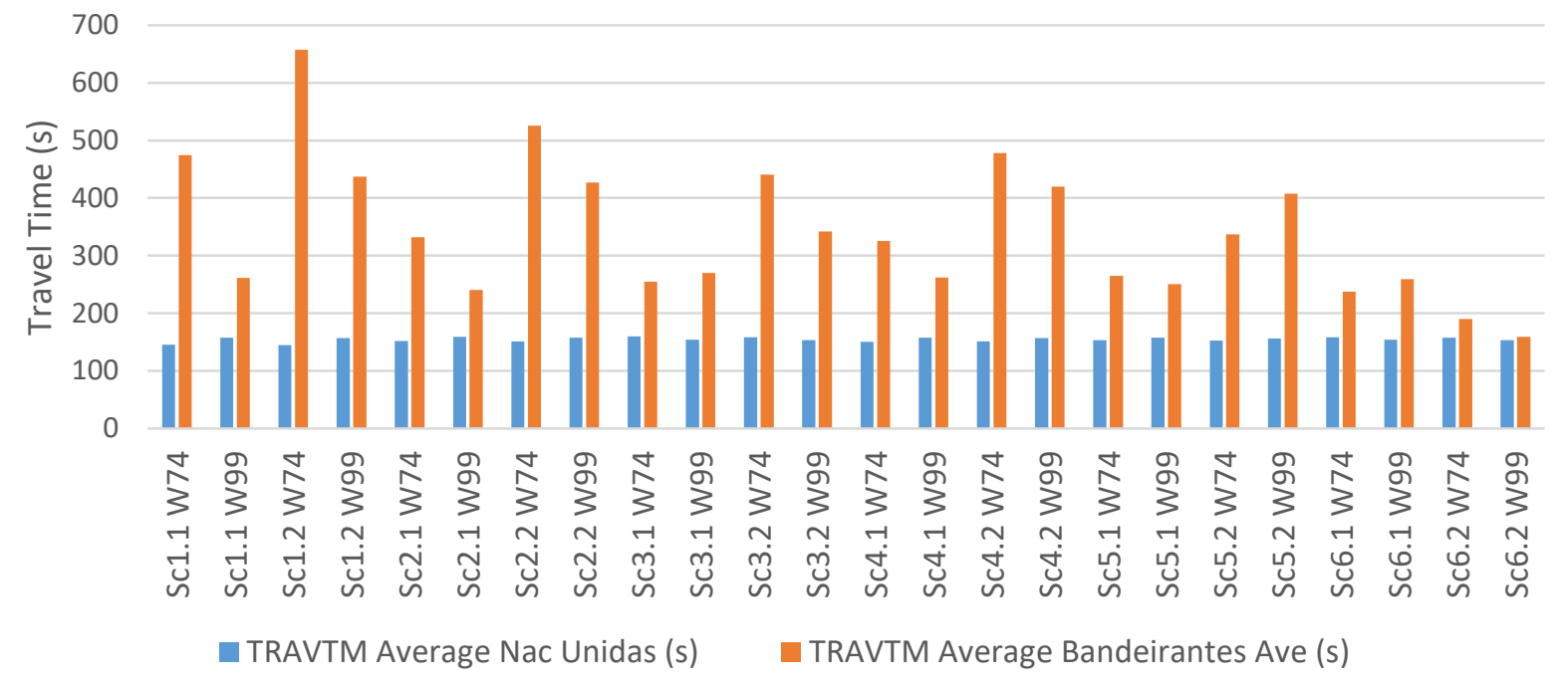

Fig. 37. Graphic for Travel time comparison between Nações Unidas and Bandeirantes avenue Source: Author.

\subsubsection{The proposition to faster overcome a disturbance}

A new proposition is presented with these based on X.2 scenarios. On the premise that the faster a disturbance is overcome, the faster the traffic flow, normal conditions are recovered. It is composed of two elements: a broken vehicle and a rescue vehicle. 
A mandatory requirement is that both elements should be equipped with the V2X communication feature. When a breakdown happens, an emergency condition is triggered, and this status is sent to surrounding vehicles and infrastructure.

If one of the surrounding vehicles can act as a rescue car supporting the breakdown vehicle, it will receive a display message. The rescue vehicle should move the other one out of the network to a safe point. The message on display should have the following content:

- Information of broke down vehicle ahead.

- Question asking permission to support.

- Additional travel time: to make it transparent how long it will take and motivate rescue vehicles to accept the request.

Fig. 38 and Fig. 39. describes the proposal from scenarios "X.3".

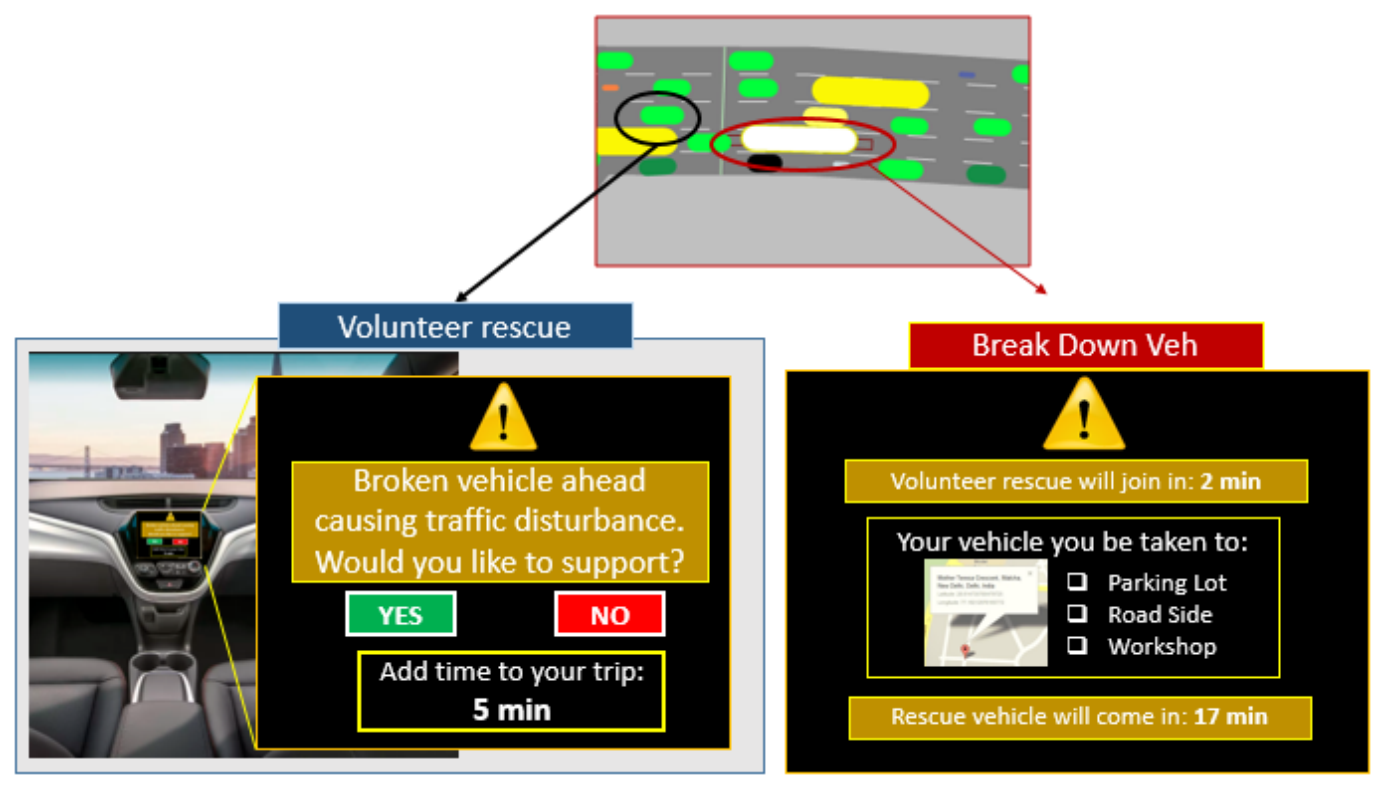

Source: Author.

Fig. 38. Proposal for scenario “X.3' (step 1).

Both should be equipped with trailer sockets to make an automatic trailer connection between the vehicles, as described in Fig. 39. 


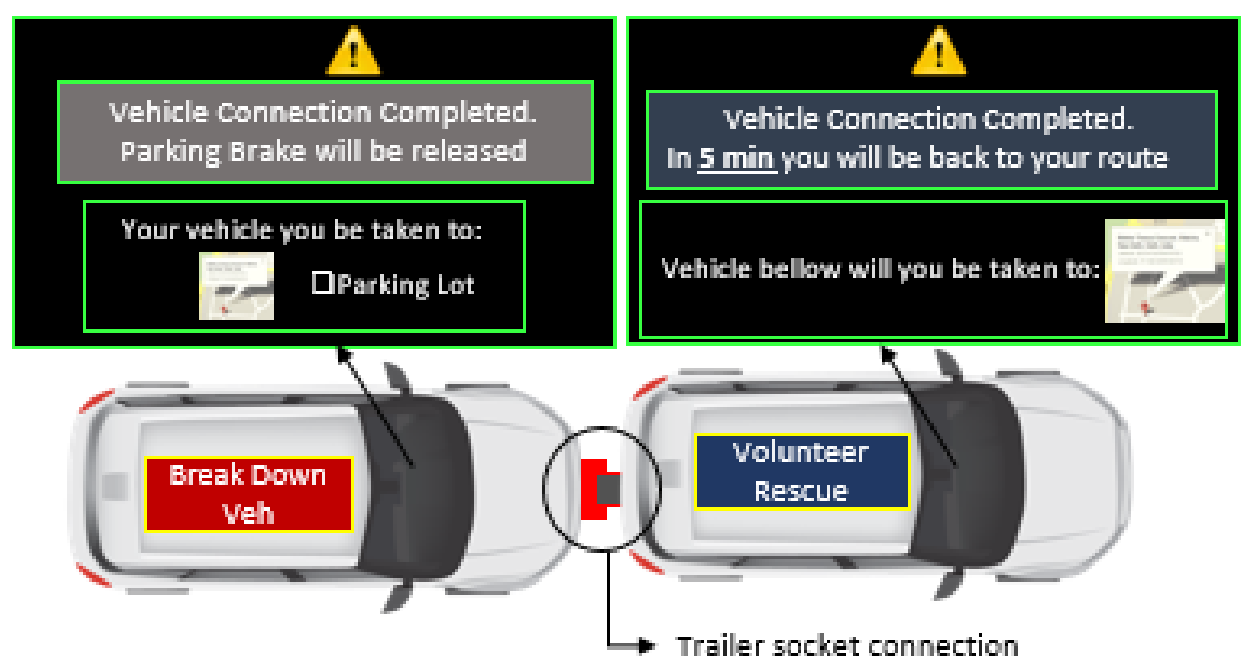

Source: Author.

Fig. 39. Proposal for scenario "X.3 (step 2)"

A reward can be offered in different ways to motivate even more the vehicles around to accept the request: cashback, reward programs like credit card, points for ranking (e.g., as used on the Waze app).

Considering that the faster the disturbance is overcome; the faster scenarios X.2 travel times will be close to scenarios X.1.

\subsubsection{The general conclusion for city application}

After all the considerations and assessments described in chapter 6.2, the general conclusions from Networks 1 and 2 studies are:

- The higher the vehicle automation level is, the lower is the travel time.

- The mix of technologies on the same road (HDVs, AVs, and CAVs) shows worse traffic performance than fully AVs.

-When a disturbance as a breakdown vehicle is added, automated vehicles' introduction brings significant travel time benefits, even when mixed up with HDVs.

- Comparing Networks 1 and 2: AVs and CAVs will place a more important role in traffic performance for roads with heavier traffic.

- The travel time variation along the scenarios is satisfactory for the W74 model

- Generally, platoons from 5 to 7 vehicles showed to be more appropriate for cities environment. A minimum volume of vehicles is required to assess the impact of this technology on travel times.

- The maximum number of vehicles in a platoon performs an essential role in minimizing travel times. For penetrations smaller than $50 \%$, this evaluation does not bring relevant outputs to travel time. 
- A high percentage of vehicles have platooning capability (higher than $50 \%$ ). It can reduce the impacts of disturbances on traffic, even in urban areas.

\subsection{NETWORK 3 (HIGHWAYS): COMPARISON AMONG SCENARIOS}

Networks 3.X are typical highways; all the simulations were performed based on the W99 model. the baseline Network 3.1 was built to get broader results. Afterward, two variations from this baseline were created, adding exits and entrances to evaluate how autonomous vehicles would perform under more complicated traffic situations.

As detailed in section 4.2, three additional sub scenarios arising from scenario 6.1 were also explored. Other than networks 1 and 2, the sub scenarios for network three are not related to disturbances. They were built after analyzing scenario 6.1 as a necessity to get a more indepth investigation of the platooning feature for highways. As presented for Networks 1 and 2 , the results for scenarios 4,5, and 6 presented in Fig. $\mathbf{4 0}$ were based on the best travel time results. It means that these results were found after evaluating a range of maximum vehicles allowed in each platoon, configured as a parameter mentioned in chapter 2.5.2. All the other parameters related to platooning were fixed to perform this evaluation.

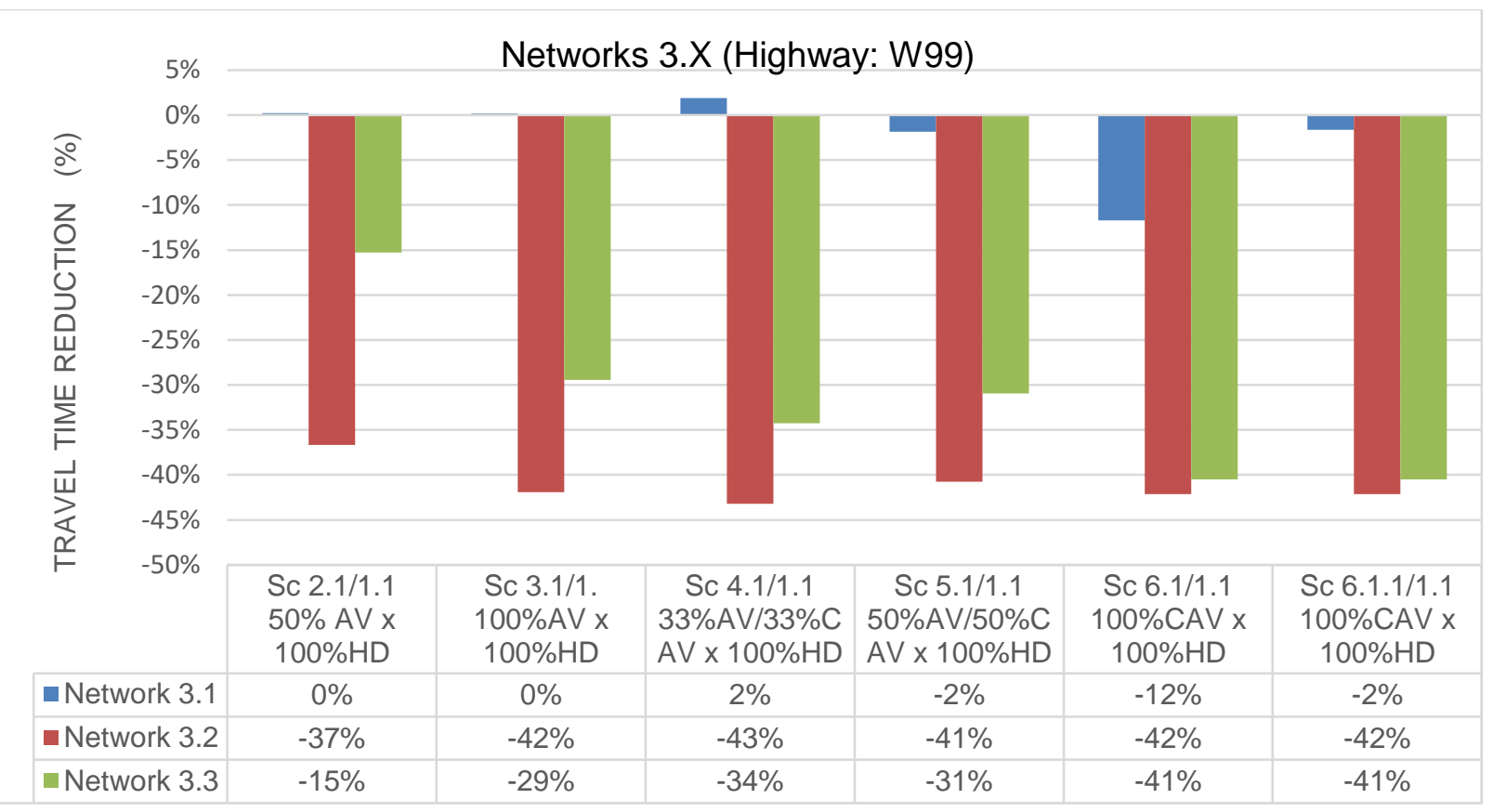

Fig. 40. Travel Time comparison among the scenarios for networks 3.1, 3.2, and 3.3. Source: Author.

As Network 3.1 has part of a road without exits or entrances, it reduces interaction among the vehicles, reducing lane changes, breaks, and acceleration. Furthermore, the traffic conditions enable drivers to keep the desired speed. Then, it is noticed that the benefits for scenarios 2 to 5 are almost null. For $100 \%$ CAVs (scenario 6.X) a slight reduction on travel time 
$(-12 \%)$ is found. It concludes that the AVs and CAVs do not bring relevant contributions to travel time in these highway segments. In any case, it is important to mention that all the simulations are considered a flat road. On the other hand, (GOÑI-ROS, et al., 2019) shows that the drivers change their longitudinal behaviors when they come from flat surfaces to slopes, reducing the free-flow capacity from $10-25 \%$. In this study, the microscopic traffic simulation showed that CACC high penetration rates (75\%) eliminated the traffic congestions in this situation.

On Networks 3.2 and 3.3, the results get a different profile. On Network 3.2, essential improvements are seen since scenario $2(-37 \%)$ and got just five more percent to scenario 6.1.1 $(-42 \%)$. As the first exit creates traffic jams, it is noticed that autonomous vehicles' capabilities of keeping lower safety distance and faster reaction on acceleration made an essential difference since $50 \%$ AVs penetration.

Network 3.3 has more interaction between vehicles than Network 2 due to exits and one more entrance leading to traffic jams. It led to more similar results to the tendency observed on Network 1 and achieved a reduction of $42 \%$ on travel time for $100 \%$ CAVs penetration. It means that the results showed for Network 3.3 on Fig. $\mathbf{4 0}$ have similar tendencies to Fig. $\mathbf{3 1}$ scenarios X.1. Even hybrid scenario 4 showed a better result than full AV scenario 3, showing a tendency that the $33 \%$ CAVs benefit travel time, mainly due to platoons easy forming on highways.

On the other hand, results in scenario 5 was not the one expected for Networks 3.2 and 3.3 as the reduction of travel time was lower than scenario 4 . This result brought some insights about platooning configuration further explored in the next section.

In general, highway network results show the more complex and intense traffic interaction on the road. The more similar the results are with the urban environment. This traffic characteristic also shows to be more affected by the introduction of AVs or CAVs.

\subsubsection{Comparison of Highways application to the literature:}

Chart 11 presents a summary of the references that studied the urban environment and compared it with this one. 
Chart 11: Results comparison with references for high application

\begin{tabular}{|c|c|c|c|c|}
\hline Reference & Simulator & $\begin{array}{l}\text { Applicat } \\
\text { ion }\end{array}$ & Results & PATERLINI (2020) \\
\hline $\begin{array}{l}\text { ARIA et al. } \\
(2016)\end{array}$ & VISSIM & Highway & $\begin{array}{l}100 \% \text { CACC } \rightarrow \uparrow \\
8.48 \%: \text { average vehicle } \\
\text { speed } \\
100 \% \text { CACC } \rightarrow \downarrow 9.00 \%: \\
\text { travel time }\end{array}$ & $\begin{array}{l}\text { Network } 3.1, \text { Sc.6.1: } \\
100 \% \text { AVs } \rightarrow \downarrow 12 \% \\
\text { travel time }\end{array}$ \\
\hline $\begin{array}{l}\text { GOÑI-ROS et } \\
\text { al. (2019) }\end{array}$ & $\begin{array}{l}\text { Not } \\
\text { mentioned }\end{array}$ & Highway & $\begin{array}{l}50 \% \text { CACC } \rightarrow \downarrow 15 \% \\
\text { travel time } \\
\downarrow 55 \% \text { average veh delay } \\
100 \% \text { CACC } \rightarrow \downarrow 20 \% \\
\text { travel time } \\
\downarrow 64 \% \text { average veh delay }\end{array}$ & $\begin{array}{l}\text { Network } 3.1 \\
\text { Sc.3.1: } \downarrow 2 \% \text { travel time } \\
\text { Sc.6.1: } \\
\text { 100\% CAVs } \rightarrow \downarrow 12 \% \\
\text { travel time }\end{array}$ \\
\hline $\begin{array}{l}\text { CHEN et al. } \\
(2019)\end{array}$ & VISSIM & Highway & $\begin{array}{l}90 \% \text { ACC } \rightarrow \downarrow 9 \% \text { travel } \\
\text { time } \\
90 \% \text { CACC } \rightarrow \downarrow 11 \% \\
\text { travel time. }\end{array}$ & $\begin{array}{l}\text { Network } 3.1 \\
100 \% \text { CAVs } \rightarrow \downarrow 42 \% \\
\text { travel time }\end{array}$ \\
\hline $\begin{array}{l}\text { CALVERT et al. } \\
(2019)\end{array}$ & $\begin{array}{l}\text { Not } \\
\text { mentioned }\end{array}$ & $\begin{array}{l}\text { Highway } \\
\text { (Trucks } \\
\text { only) }\end{array}$ & $\begin{array}{l}\leq 80 \% \text { CACC } \rightarrow \text { no } \\
\text { positive effect } \\
100 \% \text { CACC } \rightarrow 2,9 \% \\
\text { travel time reduction }\end{array}$ & 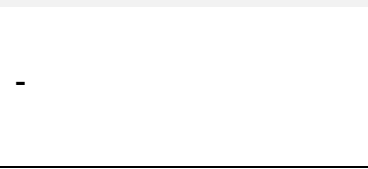 \\
\hline
\end{tabular}

Source: Author.

ARIA et al. (2016) simulated CAV on highways when the network is crowded (e.g., peak hours) using PTV VISSIM. In a similar approach to Network 3.1, they found a reduction of $9 \%$ in travel time, near the $12 \%$ reduction found in this study (where the traffic was heavy but not crowded). GOÑI-ROS et al. (2019) also evaluated a highway segment without exits or additional entrances, similar o Network 3.1. As mentioned in chapter 3, their focus was on longitudinal behaviors from flat surfaces to slopes, reducing the free-flow capacity from 10 to $25 \%$. Based on these network characteristics, a reduction of $20 \%$ in travel times for $100 \%$ CACC penetration was measured. On 50\% CACC penetration, the researchers achieved a reduction of $15 \%$ in travel time, where for the simulated Network 3.1 on scenarios 2.1 or 5.1 , the benefits of travel time were near zero. It means that considering a slope profile, the results on travel time reduction from Network 1 would probably be higher.

CHEN et al. (2019) simulated a highway like Network 3.2 on PTV VISSIM, applying their proposed control algorithm without platoon. On $90 \%$ of the CACC penetration rate, the reduction was $11 \%$ on travel time was. In this study, Scenario 6.1 achieved up to $42 \%$ reduction. It shows that their algorithm could get the results improved with platoons enabled. CALVERT et al. (2019) released actual results, but it is difficult to compare as they considered just the trucks with CAVs capabilities.

As in urban application, the measured impacts on traffic performance can vary significantly, depending on the network's characteristics and CAVs capability configuration. The positive impacts of $A V s$ and $C A V s$ were also a convergent point that shows a much higher potential for penetration rates above $50 \%$. 
Additional evaluations considering the platoon feature focus are described in the next chapters.

\subsubsection{Platooning for highways application}

After assessing all the highway networks when the platoon is enabled, some non-trivial results were found. It was mentioned in the evaluation of scenarios 4 and 5 from networks 3.2 and 3.3. So, a more detailed study of this feature was required. Then sub scenario X.1.1, X.1.2, and X.1.3 were created.

Sub scenarios X.1.1, X.1.2, and X.1.3 vary from the respective scenario X.1, built to study specifically platooning on highways. They differ, as on X.1, the platooning is enabling between all vehicle types. On X.1.1, just vehicles with similar dynamic behavior can perform a platoon, i.e., a passenger car cannot join a platoon with trucks and busses. Scenario X.1.2, platooning is allowed only in a part of the road, after the first segment for networks 3.2 and 3.3. In this scenario, platooning is allowed among all types of vehicles, as in 6.1. Finally, scenario X.1.3 is a combination of X.1.1 and X.1.2. They were evaluated as follow:

- Scenario X.1.1 was assessed for Scenarios and sub scenarios 4, 5, and 6;

- Sub scenarios X.1.2 and X.1.3 were assessed only 6 , as $100 \%$ of vehicles can perform platoons.

Figs. 41, 42, and 43 show the results for Scenarios 4 and 5 and their sub scenarios. Figs. 44,45 , and 46 show the results for Scenarios 6 and its sub scenarios.

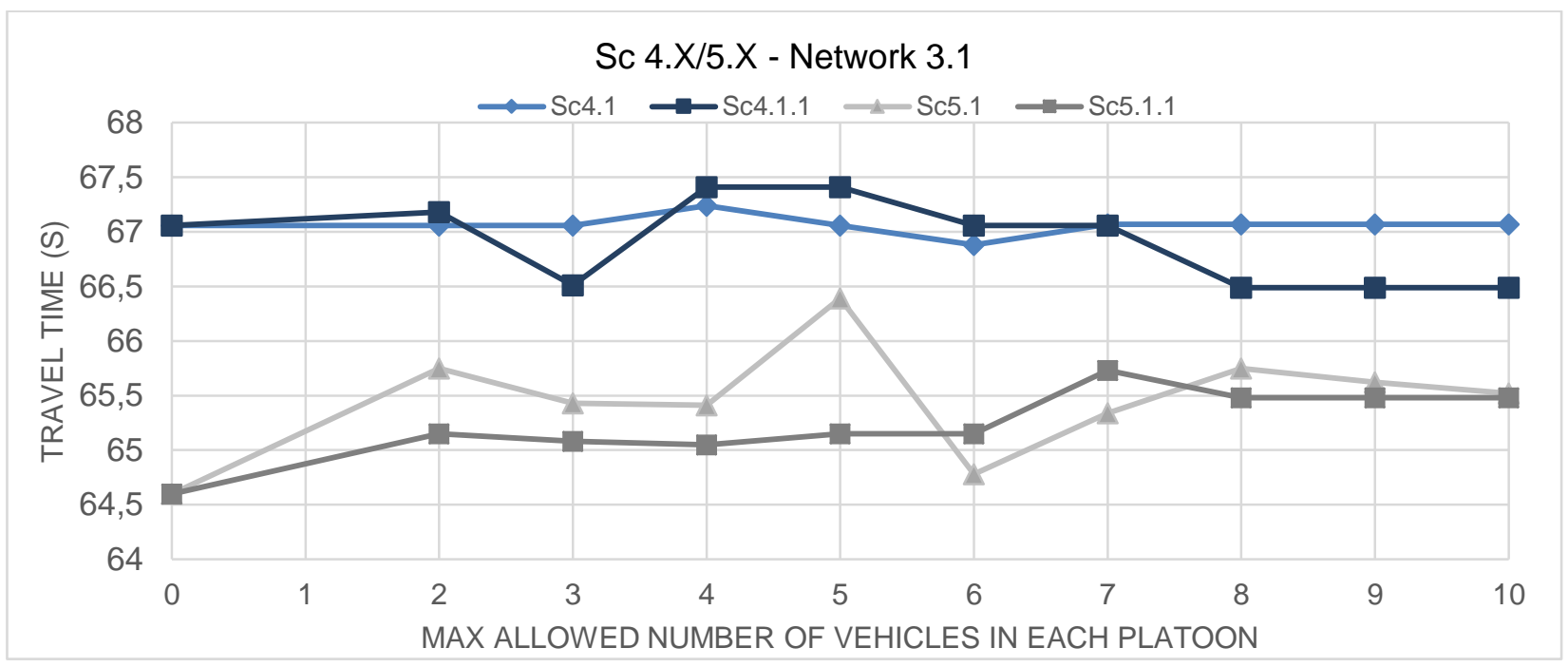

Source: Author.

Fig. 41. Travel Time results for Network 3.1 on Scenarios 4 and 5

Fig. 41 shows the results for Network 3.1. It is a segment of a highway without entrances or exits. The most relevant contribution from this experiment was the increased percentage of 
vehicles with platooning possibly brought benefits to the traffic performance. It is because Scenario 5 had a slight reduction in travel times by $5 \%$ on average. Furthermore, it is noticed that the maximum allowed number of vehicles in platooning for scenarios $4 . X$ and $5 . X$ did not bring significant differences in travel time (less than $2 \%$ ). It also applies to sub scenarios.

For networks 3.2 and 3.3 on Fig. 42 and Fig. 43, the tendency of better results on Scenario 5 is not confirmed.

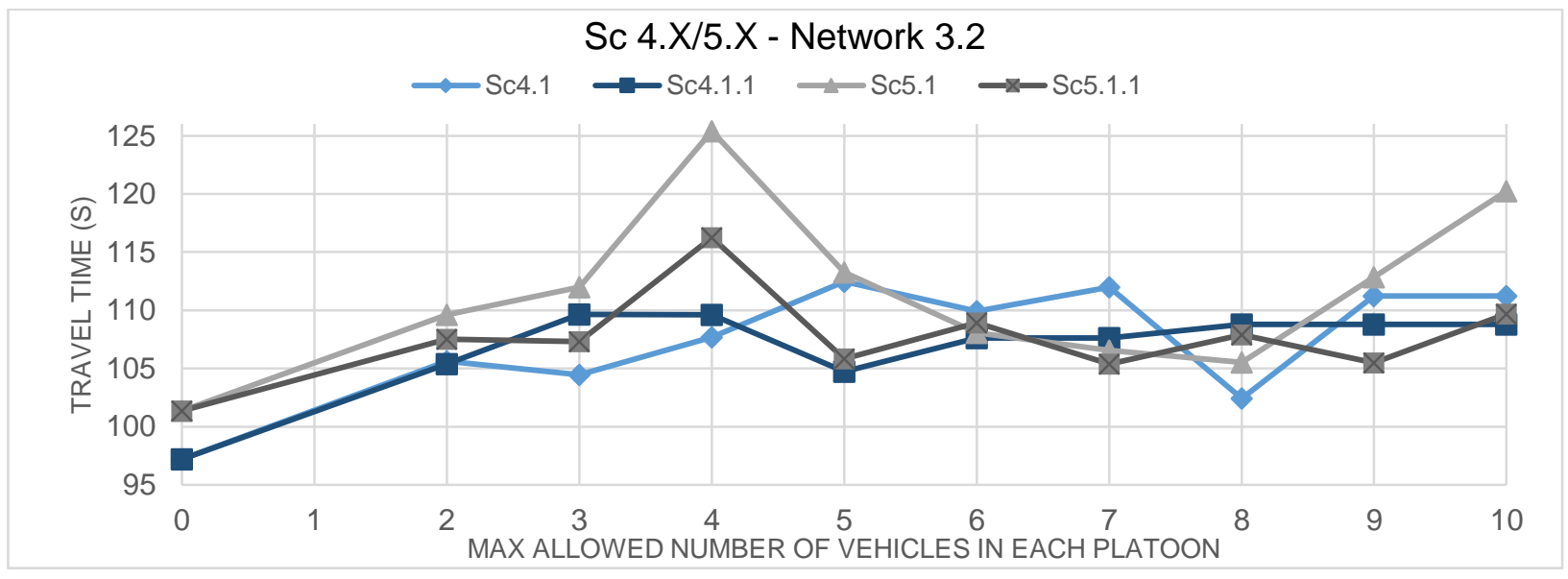

Source: Author.

Fig. 42. Travel Time results for Network 3.2 on Scenarios 4 and 5

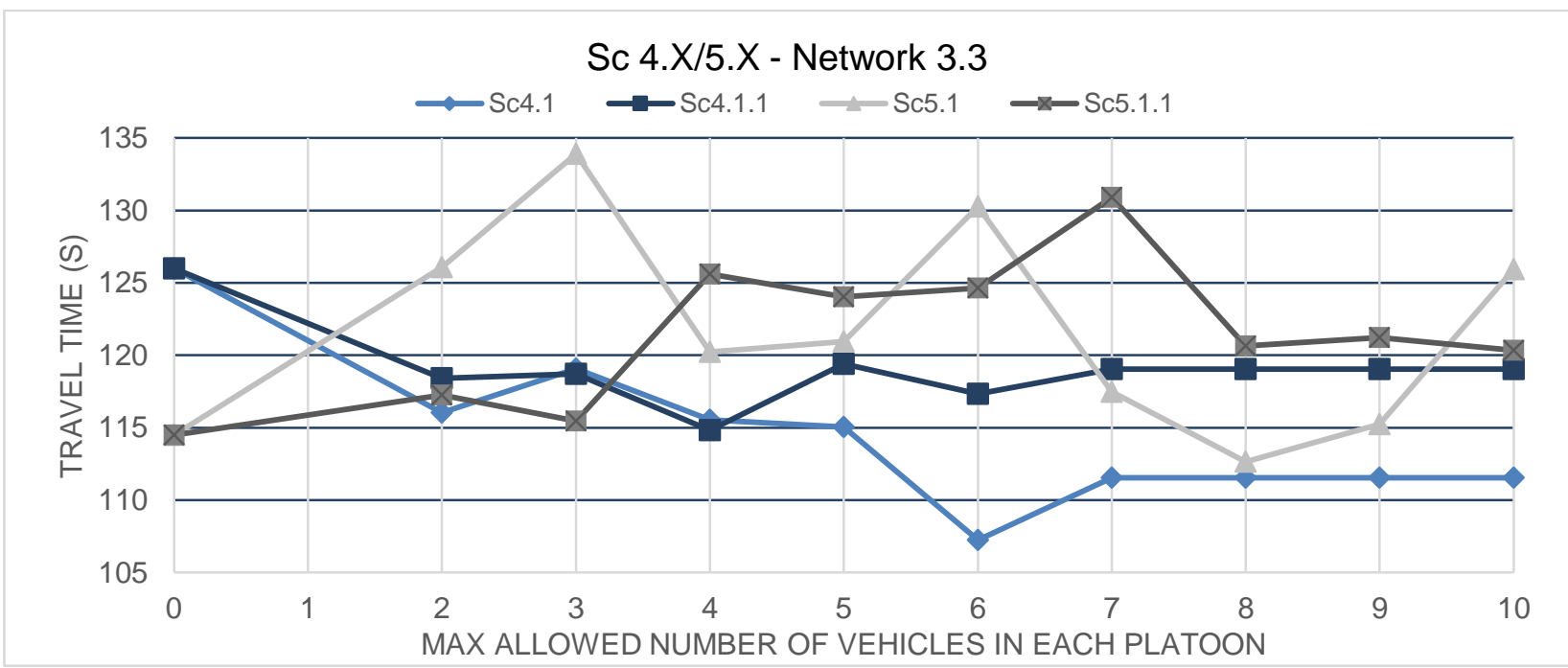

Source: Author.

Fig. 43. Travel Time results for Network 3.3 on Scenarios 4 and 5

These two experiments showed that by adding complexity to the networks, where vehicles are forced to change lanes more frequently, platooning does not bring better traffic performance on every application. On these networks, it is noticed that CAVs with platooning enabled did not improve traffic performance. Mainly on Network 3.3, where scenario 4 over-performed scenario 5. 
They also bring the expected result that the higher the percentage of CAVs, the higher the variation on travel time in the platoon size function. This behavior is confirmed in Scenario 6 , where $100 \%$ of vehicles are CAVs.

For Scenarios 6.X, as they have full penetration of CAVs with platooning capabilities, a more comprehensive range of platoon size was simulated, from 0 to 25, as shown in Graphics from Figs. 44, 45, and 46.

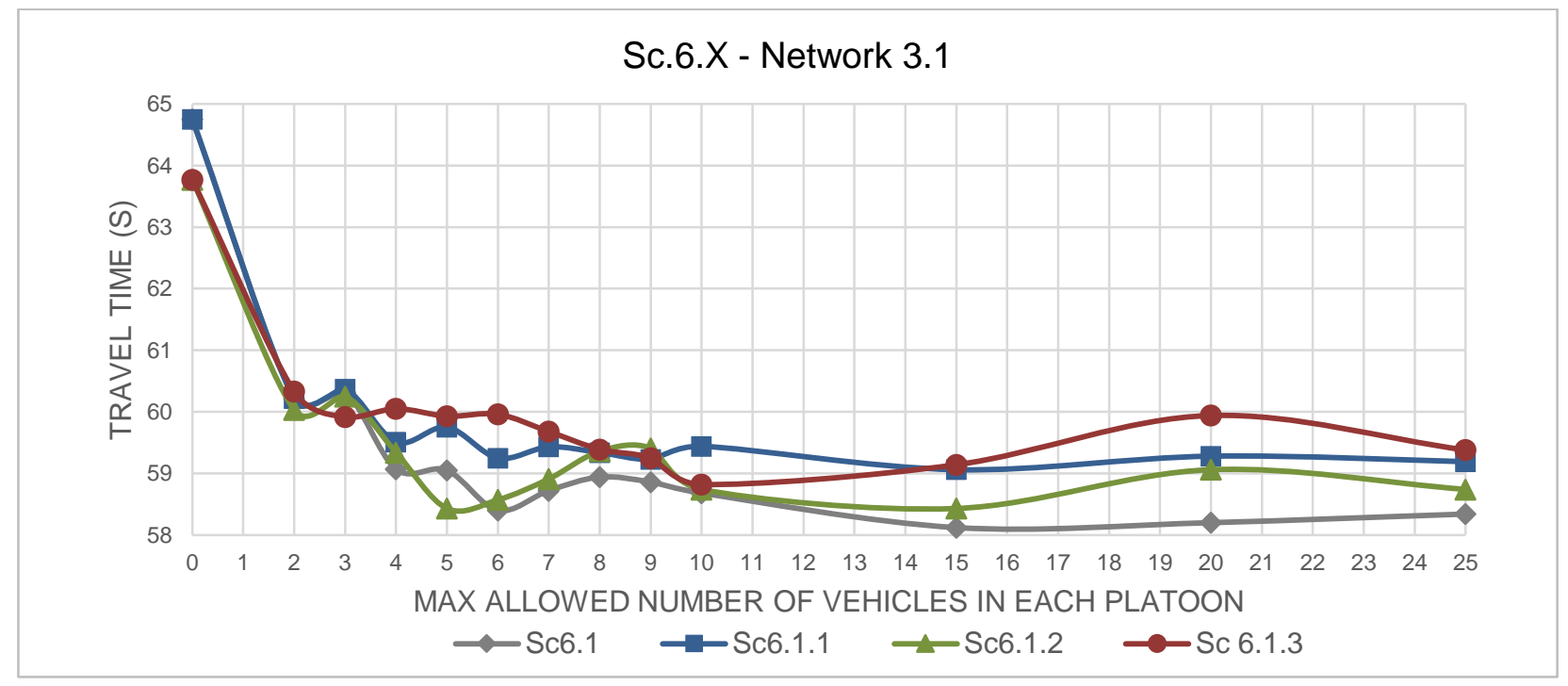

Source: Author.

Fig. 44. Travel Time results for Network 3.1 on Scenario 6

Fig. 44 shows that the best results were achieved with platooning enabled. From 2 to 25 vehicles platoon size, the variation in travel time was low. For this road, the changes of sub scenarios 6.1.1, 6.1.3, and 6.1.3 did not cause significant effects due to its characteristics of reduced interaction among the vehicles. Comparing Fig. 41 and Fig. 44 shows that the travel times can be reduced by up to $12 \%$ by increasing the CAVs penetration rate from $33 \%$ to $100 \%$.

However, in networks 3.2 and 3.3 presented in Fig. 45 and Fig. 46, these sub scenarios showed higher impacts. 


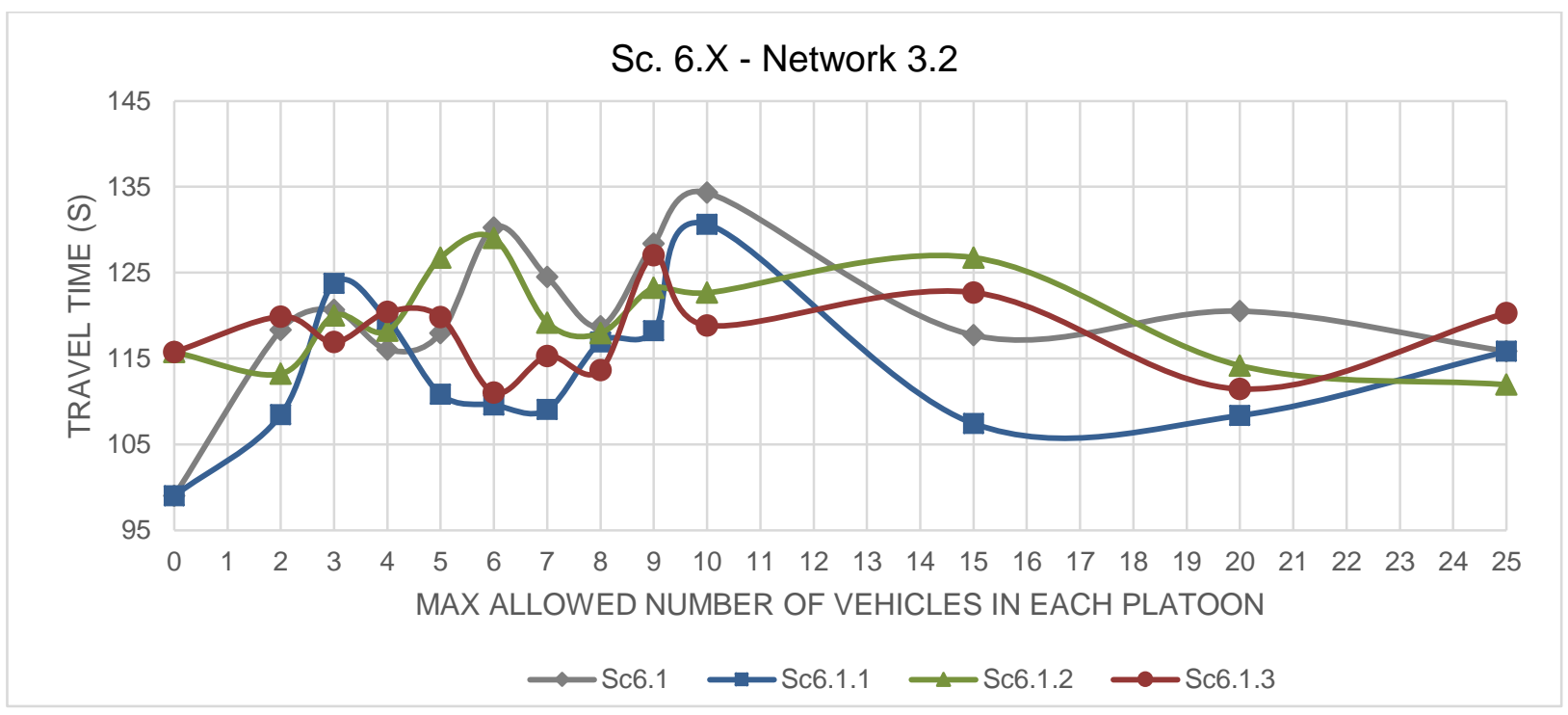

Source: Author.

Fig. 45. Travel Time results for Network 3.2 on Scenario 6

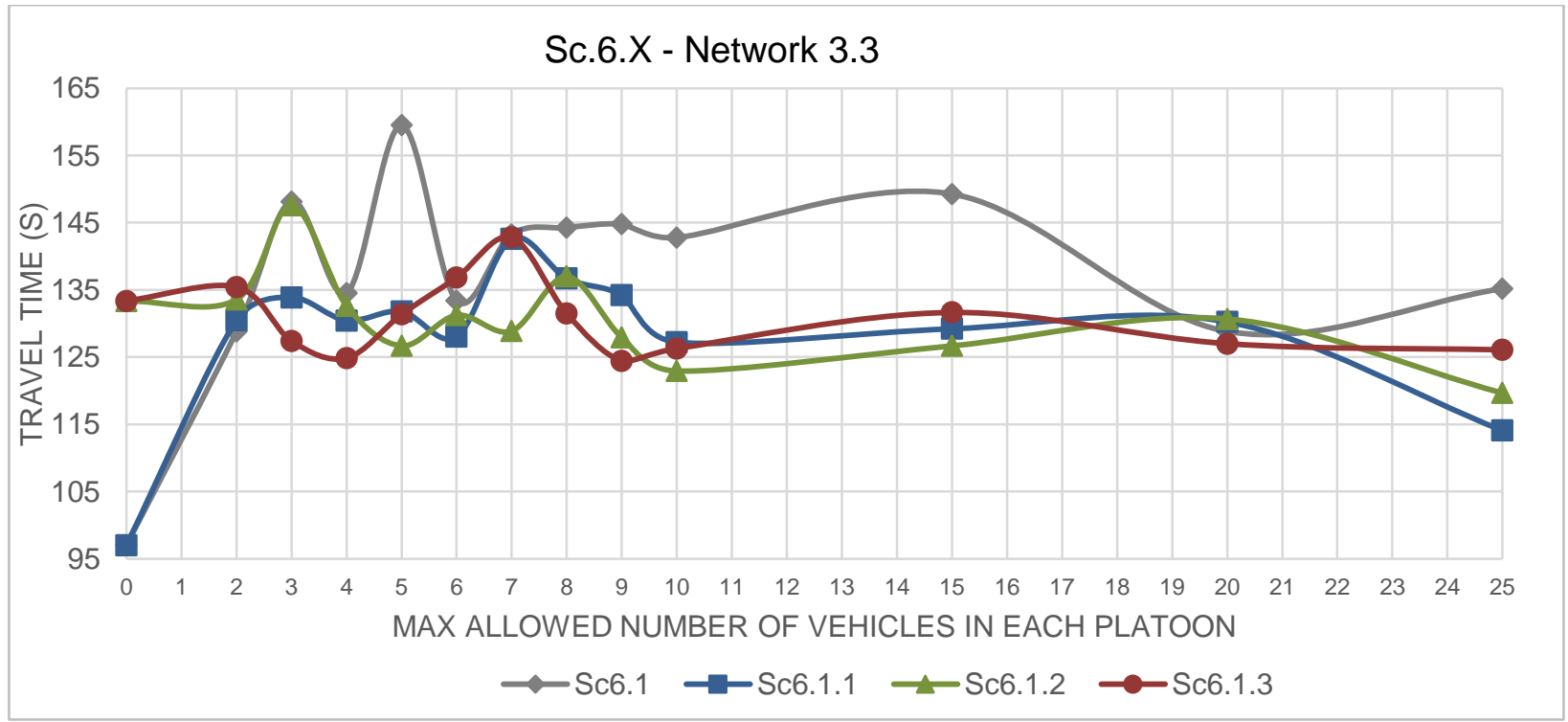

Source: Author.

Fig. 46. Travel Time results for Network 3.3 on Scenarios 6

We can see in Fig. 46 that scenario 6.1 had worse travel times for most platoon sizes than the proposed sub scenarios. Then, sub scenarios 6.1 .2 (platoon possible on the 2 nd segment of networks 2.2 and 2.3) and 6.1.3 (combination from 6.1.1 and 6.1.2) showed similar results. The average travel time among all platoon sizes for both scenarios are nearly the same. Also, on sub scenarios 6.1 and 6.1.1, the platoon disabled reduced the travel time dramatically. Comparing that to results from network one leads to the point that segmenting the highways in parts where platoon is allowed or not bring benefits to total travel time. In other words, allowing or not the platoon in highways, depending on the segment characteristics, can affect traffic performance. 
Besides, scenarios 6.1.2 and 6.1.3 showed that when the platoon is enabled among vehicles with different dynamic characteristics and maximum legal speed (as trucks and passenger cars), the traffic performance is reduced.

The next chapter brings a complete overview and conclusions about the platooning feature.

\subsection{GENERAL PLATOONING EVALUATION ON TRAVEL TIME PERFORMANCE}

The results for urban and highway applications on scenarios where platooning was enabled leads to some conclusions. To complement these conclusions, Table 3 brings a summary of the best travel time results for each network.

Table 3: List of the best maximum number of vehicles in a platoon configuration based on travel time results for each scenario on Networks 1, 2and 3.

\begin{tabular}{|c|c|c|c|c|c|c|}
\hline \multicolumn{7}{|c|}{ The best travel time results for Max Number Vehicles Platoon (Highway) } \\
\hline & $\begin{array}{c}\text { Network } \\
1\end{array}$ & $\begin{array}{c}\text { Network } \\
2\end{array}$ & $\begin{array}{c}\text { Network } \\
3.1\end{array}$ & $\begin{array}{c}\text { Network } \\
3.2\end{array}$ & Network 3.3 & $\begin{array}{c}\text { Simulated } \\
\text { Range }\end{array}$ \\
\hline Sc 4.1 & 4 & 4-10 & $0 *-\underline{5}-10$ & $\underline{\mathbf{0}}^{*}, 8$ & $\underline{\mathbf{6}}-10$ & $0-10$ \\
\hline Sc 4.2 & $7-10$ & $\underline{\mathbf{5}}, 9,10$ & - & - & - & $0-10$ \\
\hline Sc 4.1 .1 & - & - & $0 *-7-10$ & $0^{*}$ & $\underline{4}, 6$ & $0-10$ \\
\hline Sc 5.1 & $0 *, 5,8, \underline{9}$ & $\underline{4-10}$ & $0 *-\overline{6}-10$ & $\underline{0}^{*}, 7,8$ & $0 *, \underline{8}, 9$ & $0-10$ \\
\hline Sc 5.1 .1 & - & $=$ & $\underline{0}^{*}-10$ & $0,5,7,9$ & $0, \overline{2,3}$ & $0-10$ \\
\hline Sc 5.2 & $\underline{\mathbf{5}}, 10$ & $8, \underline{9}, 10$ & - & - & - & $0-10$ \\
\hline Sc 6.1 & $4, \underline{20}$ & $5,6,7,8,9$ & $2-\underline{15}-25$ & $0^{*}$ & $0^{*}$ & $0-25$ \\
\hline Sc 6.1.1 & - & - & $2-15-25$ & $\underline{0,15}$ & $0^{*}$ & $0-25$ \\
\hline Sc 6.1 .2 & - & - & $2-\underline{5}-25$ & $0,2,20, \underline{25}$ & $5,10,25$ & $0-25$ \\
\hline Sc 6.1 .3 & - & - & $2-10-25$ & $0, \underline{\mathbf{6}}, 8,20$ & $3,4, \underline{9}, 10,20,25$ & $0-25$ \\
\hline Sc 6.2 & $\underline{\underline{9}, 20}$ & $\underline{10,15}$ & - & - & - & $0-25$ \\
\hline & \multicolumn{6}{|c|}{ *Platoon disabled, vehicles with CAVs parameters set } \\
\hline
\end{tabular}

Source: Author.

\subsubsection{City application:}

- It is recommended platoons from 5 to 7 vehicles for cities environment. Even with good results, longer platoon should be avoided as they form a long vehicle that difficult necessary lane changes. As an example, a platoon with ten passenger cars can be up to 40 meters long. CALVERT also found this conclusion et al. (2019) justified the results because longer platoons outperformed the lane changes from vehicles around and suggested the application of platoons in non-congested traffic,

- For streets and avenues with low volumes of vehicles, this technology's impact on travel times will not be relevant. It was simulated on Network 2.

- Over intense traffic situations, the maximum number of vehicles in a platoon plays a vital role in minimizing travel times. 
- This study concludes that a high percentage of vehicles with platooning capability $(>50 \%$ ) can reduce the impacts of traffic disturbances. For lower penetration rates, the improvements are not consistent because few platoons are formed. CALVERT et al. (2019) suggested the application of platoons in non-congested traffic. CALVERT et al. (2020) released a new study from an FOT and simulation experiment of CACC city environments. The authors considered the savings in travel time enjoyable in heavy traffic, mainly if the V2I "traffic lights green extension" features are applied. YAO et al.. (2020) also found reductions of up to $27 \%$ in traffic delays for $100 \%$ CAVs in city environments.

\subsubsection{Highways}

- Network 3.1: segments without entrances and exits:

- The platoon enabled is recommended.

- It is also recommended to disable platoons between passenger car to trucks or busses as their different dynamic behavior and maximum allowed speed can lead to a lower overall traffic performance.

- Platoon sizes: as vehicles do not change lanes frequently in these segments, longer platoons can be allowed:

- For CAVs penetration rates, up to $50 \%$ simulation results indicate 6 to 8 vehicles as the best configuration to minimize travel times.

- For CAVs $100 \%$ CAVs scenarios, platoon sizes by up to 25 showed promising results.

- Networks 3.2 and 3.3: segments with higher complexity, including exits and entrances:

- Platooning should be studied in detail depending on the highway geometry and topology. The simulation performed in this study showed that it did not bring relevant improvements in travel time. It can change considerably, mainly on slopes, as a study by GOÑI-ROS et al. (2019).

- Improvements in platooning algorithms are recommended to increase the sensitivity for cut-in and gaps, opening possibilities to others in these segments. A temporary change in driving behaviors is recommended to increase traffic performance.

- Max recommended platoon size: up to 5 vehicles. Platoons with several vehicles should be avoided as they form a long vehicle that difficult, necessary lane changes.

In summary, depending on each network's network and traffic characteristics and the penetration of CAVs, platooning plays an essential role in minimizing travel times. 
Regarding platoon sizes, on SERAJ, LI, \& QIU (2018), the maximum benefits were found for 5 to 6 platoon size. Anyhow, the traffic conditions and network characteristics cause essential variations. It comes to the point that even on the same network, a dynamic platoon configuration brings benefits to traffic performance. CHANG et al. (2020) assessed platoons up to 8 vehicles and concluded that the maximum platoon size is advantageous for improving the mixed flow capacity. The platoon size can place an important role and should be assessed based on traffic characteristics from the roads. For penetrations smaller than $50 \%$, this evaluation does not bring relevant outputs to travel time. 


\section{CONCLUSIONS}

This research proposed a methodology to assess the impacts of Connected and Autonomous Vehicles (CAVs) on traffic flow through microscopic simulation. The methodology was validated from five different networks built to enable the experiments, including city and highway environments. The scenarios were evaluated, starting with a baseline with no vehicle automation, coming to heterogeneous scenarios considering the coexistence among HDVs, $A V s$, and CAVs. Finally, the full penetration of AVs and CAVs.

The first general conclusion that the experiment results brought was that $A V s$ and CAVs to keep smaller safety distance, and their faster reaction time brings clear benefits in travel time. It was up to $71 \%$ reduction in travel time on the urban environment, and $43 \%$ for highways. It shows the more complex and intense traffic interaction on the road, the higher the impacts.

Two networks were built on cities environment considering a high intense traffic expressway and a signalized intersection with lighter traffic conditions. For both, the higher the automation level was, the lower was the travel time. The mix of technologies on heterogeneous scenarios decreases the benefits of $A V s$ or $C A V s$, especially on traffic performance. As they will be necessary steps towards full automation, some actions should be further studied to increase these technologies' impacts, like dedicated lanes. One crucial output came from a simulation of disturbances along the streets, as a vehicle break-down. In these situations, the AVs and CAVs brought much higher benefits than normal traffic conditions, even in heterogeneous scenarios. Furthermore, comparing city Networks 1 and 2, it is noticed that AVs and CAVs will place a more important role in traffic performance for roads with heavier traffic.

On highways, three different networks were compared, considering an increasing complexity of vehicle interactions among them. The results reinforce that the more complex and intense traffic interaction in the road is, the more AVs and CAVs impact travel time. Without entrances, exits, or sloped profiles for highway segments, the higher impacts should come from the higher safety AVs and CAVs bring. Else, the impacts on traffic performance are evident.

This study also releases an extensive assessment of the platoon influence using a builtin software feature that enabled robust comparability among the results. These platoon characteristics showed a variation of up to $30 \%$ on travel time, mainly for high-intensity traffic situations. It should be studied in detail depending on the highway geometry and topology. In general, this study recommends maximum platoons' size from 5 to 7 vehicles size for cities environment, and up to 5 for highways. Platoons with a higher number of vehicles should be avoided as they form a long vehicle line that difficult necessary lane changes. It was also 
observed that platoons allowed only for vehicles with similar dynamic characteristics improve the overall traffic performance.

In summary, depending on each network and traffic conditions and the penetration of CAVs, platooning performs a vital role in minimizing travel times. Platooning sizes can place an important role and should be assessed based on traffic characteristics from the roads. For penetrations smaller than $50 \%$, this evaluation does not bring relevant outputs to travel time. It was also done a specific investigation comparing W74 and W99 driver models application for autonomous vehicles simulation for PTV VISSIM. Although W99 is a more complex model, it did not show meaningful results for city environments. The recommendation is to use the W74 model for city environment even on AVs scenarios, and CAVs introduction W99 model is recommended for all kinds of highway simulation.

Finally, as these other studies show, traffic performance's measured impacts can vary significantly, depending on the network's characteristics and CAVs capability configuration. The convergent point is that they show positive impacts.

\subsection{FUTURE WORKS}

Recommendations for future research are:

- To integrate simulators that can increase the study's capabilities on V2I and V2V features, including communication to the traffic lights on cross-sections and communication among the vehicles on merging and platoon situations.

- To assess CAVs and platooning on roads with variations on topography.

- Explore the cut-in function on platooning application. A refined algorithm can support an optimal lane change strategy. 


\section{REFERENCES}

5G Automotive Association. 5gaa. Retrieved September 12, 2019, from 5G Automotive Association: 5gaa.org. 2019

AGHABAYK, K., SARVI, M., YOUNG, W., \& KAUTZSCH, L. (2013). Novel Methodology for evolutionary calibration of Vissim by multi-threading. Australasian Transport Research Forum Proceedings, Brisbane, Australia. pp.1-15, 2013.

AISSIOUI, A., KSENTINI, A., \& TALEB, T. On Enabling 5G Automotive Systems Using Follow me edge-cloud concept. IEEE Transaction on Vehicular Technology. 2018. doi:10.1109/TVT.2018.2805369

ALAM, A., BESSELINK, B., TURRI, V., MARTENSSON, J., \& JOHANSSON, K. Heavy-Duty Vehicle Platooning for sustainable freight transportation - A cooperative method Safety and efficiency. In: IEEE Control Systems Magazine. Vol. 35, No. 6, pp. 34-56. 2015 ALIXPARTNERS. Betting big in electrification and autonomous - AlixPartners Global Automotive Outlook. New York, NY. 2018.

ALMANNAA, M., CHEN, H., RAKHA, A., \& LOULIZI, I. (2019). Field implementation and testing of an automated eco-cooperative. Transportation Research Part D. 2019. doi: 10.1016/j.trd.2018.11.019

ANDERSON, M. The road ahead for self-driving cars: The AV industry has had to reset expectations as it shifts its focus to level 4 autonomy. IEEE Spectrum. pp. 8-9, 2020. doi:10.1109/MSPEC.2020.9078402

AOYAGI, Y. et al. $76 \mathrm{GHz}$ spread spectrum radar for autonomous intelligent cruise control.

Proceedings of Conference on Intelligent Transportation Systems. Boston, MA, USA,.1997. doi:10.1109/ITSC.1997.660555

AREM, B., DRIEL, C., \& VISSER, R. The Impact of Cooperative Adaptive Cruise Control on Traffic-Flow Characteristics. IEEE Transactions on Intelligent Transportation Systems, Vol.7, N.4. 2006

ARIA, E., OLSTAM, J., \& SCHWIETERING, C. Investigation of Automated Vehicle Effects on Driver's. Transportation Research Procedia, Vol. 15. pp. 761-770, 2016 doi: 10.1016/j.trpro.2016.06.063

AUDI. audi.com. Retrieved from Future of mobility: https://www.audi.com/en/experienceaudi/mobility-and-trends/autonomous-driving/future-of-mobility.html. 2019.

BAILEY, N.. Simulation and Queueing Network Model Formulation of Mixed Automated and Non-automated Traffic in Urban Settings. MIT, DEPARTMENT OF CIVIL AND ENVIRONMENTAL ENGINEERING, Massachusetts. 2016 
BANSAL, P., \& KOCKELMAN, K. Forecasting Americans' long-term adoption of connected and autonomous vehicle technologies. Transportation Research Part A, Vol.95. pp. 49-63, 2017. doi: 10.1016/j.tra.2016.10.013

BAZ, A. Autonomous Vehicle decision making at intersection using game theory. University of Akron. 2018.

BHOOPALAM, A., AGATZ, N., \& ZUIDWIJK, R. Planning of truck platoons: A literature review and directions for future research. Transportation Research Part B 107. 2018 doi: 10.1016/j.trb.2017.10.016

BIDÓIA, M. Simulação de um sistema de reputação centralizado para VANETs. UNESP, São José do Rio Preto. 2015.

BJORNBERG, A. Autonomous Intelligent Cruise Control. In IEEE (Ed.), Proceedings of IEEE Vehicular Technology Conference (VTC). Stockholm, Sweden.

doi:10.1109/VETEC.1994.345091. 1994.

CALVERT, S., KLUNDER, G., STEENDIJK, J., \& SNELDER, M. The impact and potential of cooperative and automated driving for intelligent traffic signal corridors: A field-operationaltest and simulation experiment. Case Studies on Transport Policy. 2020. doi: 10.1016/j.cstp.2020.05.011.

CALVERT, S., SCHAKEL, W., \& VAN AREM, B. Evaluation and modeling of the traffic flow effects of truck platooning. Transportation Research Part C, pp. 1-22. 2019.

doi:https://doi.org/10.1016/j.trc.2019.05.019

CARIANHA, A. Uma abordagem para aumentar a privacidade de localização asegurada por mix-zone em redes veiculares. UFBA. Salvador: UFBA. 2011.

CARREA, P., \& SAROLDI, P. Integration Between Anticollision And AICC Functions The ALERT Project. Proceedings of the Intelligent Vehicles '93 Symposium. Tokyo, Japan. 1993. doi:10.1109/IVS.1993.697309

CET. Mobilidade no Sistema Viário Principal (MSVP) Volume e Velocidade - 2017. Urban mobility research, São Paulo. Fonte: http://www.cetsp.com.br/media/714822/msvp-2017volume-e-velocidade.pdf. 2018.

CHAl, L. et al. Simulation and testing method for evaluating the effects o position errors, communication delay and penetration rate to connected vehicles safety. Chinese

Automation Congress (CAC), pp. 4389-4394, 2017 doi:10.1109/CAC.2017.8243552

CHANG, X., LI, H., RONG, J., ZHAO, X., \& LI, A. Analysis on traffic stability and capacity for mixed traffic flow with platoons of intelligent connected vehicles. Physica A. 2020. doi: 10.1016/j.physa.2020.124829 
CHEHRI, A., QUADAR, N., \& SAADANE, R. Communication and Localization Techniques in VANET Network for Intelligent Traffic System in Smart Cities: A Review. Smart

Transportation Systems 2020. Smart Innovation, Systems, and Technologies, vol 185, pp. 167-177, 2020. doi: https://doi.org/10.1007/978-981-15-5270-0_15.

CHEN, J., ZHOU, Y., \& LIANG, H.Effects of ACC and CACC vehicles on traffic flow based on an improved variable time headway spacing strategy. IET Intelligent Transport Systems. 2019. doi:10.1049/iet-its.2018.5296

CHIEN, C., \& IOANNOU, P. Autonomous intelligent cruise control. IEEE Transactions on Vehicular Technology. pp. 657-672, 1993.

CHOUDHURY, A., MASZCZYK, T., MATH, C., LI, H., \& DAUWELS, J. An integrated simulation environment for testing V2X protocols and applications. The International Conference on Computational (ICCS). pp. 2042-2052, 2016. doi:10.1016 C-ITS. C-ITS platform phase II. C-ITS Europe. Retrieved from https://ec.europa.eu/transport/sites/transport/files/2017-09-c-its-platform-final-report.pdf. 201 CNT. Anuário CNT do transporte - Estatísticas consolidadas 2019. Retrieved September 2019, 2019, from https://anuariodotransporte.cnt.org.br/2019/. 2020.

Coexist D2.3.. Default behavioural parameter sets for AVs: Coexist Deliverable 2.3. European Union's Horizon 2020, Karshule. 2018.

Coexist D2.4. Default behavioural parameter sets for AVs: Coexist Deliverable 2.4. European Union's Horizon 2020, Karshule. 2018

Coexist D2.5. Micro-simulation guide for automated vehicles. European Union's Horizon 2020, Karshule. 2018

Coexist D2.6. Technical report on data collection and validation. European Union's Horizon 2020. Retrieved March 19, 2019, from https://www.h2020-coexist.eu/wpcontent/uploads/2018/10/D2.6-Technical-report-on-data-collection-and-validationprocess_FINAL.pdf. Karshule. 2018.

CoEXist D5.6. Report on integrated CAV demonstration. Fonte: h2020-coexist.eu D. C. DAIMLER AG. Retrieved September 13, 2019, from CASE: https://www.daimler.com/case/en/. 2019.

DAIMLER AG. Daimler Innovation. Retrieved September 12, 2019, from https://www.daimler.com/innovation/case/autonomous/automated-driving-daimlertrucks.html. 2019 
DAIMLER TRUCKS. Daimler Trucks and Torc Robotics expand public road testing in the U.S. for automated truck technology. Source:

https://media.daimler.com/marsMediaSite/en/instance/ko/Daimler-Trucks-and-Torc-Roboticsexpand-public-road-testing-in-the-US-for-automated-truck-technology--safety-highestpriority.xhtml?oid=45657269. 2020.

DE RANGO et al. Grey Wolf Optimization in VANET to manage Platooning of Future Autonomous Electrical Vehicles. IEEE 17th Annual Consumer Communications \& Networking Conference (CCNC). Las Vegas, NV, USA. pp. 1-2, 2020. doi:10.1109/CCNC46108.2020.9045632 DERBEL, O. et al. Modified Intelligent Driver Model for driver safety and traffic stability improvement. IFAC Proceedings Volumes, 46, pp. 744-749. 2013. doi:https://doi.org/10.3182/20130904-4-JP-2042.00132

DO, W., ROUHANI, O., \& MIRANDA-MORENO, L. Simulation-Based Connected and Automated Vehicle Models on Highway Sections: A Literature Review. Journal of Advanced Transportation. 2019. doi:https://doi.org/10.1155/2019/9343705 DOLLAR, R., \& VAHIDI, A. Quantifying the Impact of Limited Information and Control Robustness on Connected Automated Platoons. IEEE 20th International Conference on Intelligent Transportation Systems (ITSC). 2017.

DOSOVITSKIY, A., ROS, G., CODEVILLA, F., LOPEZ, A., \& KOLTUN, V. CARLA: an open urban driving simulator. 1st Conference on Robot Learning (CoRL). Mountain View, USA. 2017

ERIKSSON, L., \& AS, B. A high-performance automotive radar for automatic AICC.

Proceedings International Radar Conference. Alexandria, VA, USA. 1995. doi:10.1109/RADAR.1995.522576

EU. Saving Lives: Boosting Car Safety in the EU. Brussels: EUR-Lex. Retrieved from https://eur-lex.europa.eu/legal-content/EN/TXT/?uri=CELEX\%3A52016DC0787. 2016. EUROPEAN COMMISSION. Communication from the Commission to the European Parlament, The Council, The European Economic, and Social Committee, and The Committee of regions. Europe on the move. Brussels. pp. 1-13, 2018.

EVANSON, A. Connected autonomous vehicle (CAV) simulation using PTV Vissim. Em IEEE (Ed.), Winter Simulation Conference (WSC). Las Vegas, NV, USA. 2017 doi:10.1109/wsc.2017.8248148

FERNANDES, P., \& NUNES, U. Platooning with IVC-enable autonomous vehicles: strategies to mitigate communication delays, improve safety and traffic flow. IEEE Transaction on Intelligent Transportation Systems, Vol.14, pp. 91-106, 2012. 
FHWA. Synthesis of Human Factor Research on the older driver and highway safety, Vol.1. FHWA, USDOT, Wahington, DC. 1997.

FRANSSON, E. Driving behavior modeling, and evaluation of merging control strategies - $A$ microscopic simulation study on Sirat Expressway. Linköping University, Department of Science and Technology, Norrköping, Sweden. 2018.

FROST \& SULLIVAN. Vehicle-to-Everything Technologies for Connected Cars - DSRC and Cellular Technologies Drive Opportunities. TechVision Group of Frost \& Sullivan, Frost \& Sullivan Consulting. 2017.

GÁLVAN, W. Estudo do impacto dos modelos de propagação no desempenho de protocolos AD HOC em um ambiente VANET urbano. Master Thesis, UFTPR, Brazil. 2016.

GAO, Y. Calibration and Comparison of the VISSIM and INTEGRATION Microscopic. Ph.D. Thesis, Virginia Polytechnic Institute, and State, Blacksburg, Virginia. 2008.

GE, J. et al. Experimental validation of connected automated vehicle design among humandriven vehicles. Transportation Research Part C. 2018.

doi:https://doi.org/10.1016/j.trc.2018.04.005

GHIASI, A., LI, X., \& MA, J. A mixed traffic speed harmonization model with connected.

Transportation Research Part C, vol. 104. pp. 210-213, 2019.

doi:https://doi.org/10.1016/j.trc.2019.05.005

GOEBEL, N. Inter-Vehicular Communication Simulation based on Cellular Network Traces.

Ph.D. Thesis, Heinrich-Heine-University of Dusseldorf. 2017.

GONG, S., \& DU, L. Cooperative platoon control for a mixed traffic flow including human drive vehicles and connected and autonomous vehicles. Transportation Research Part B 116. pp. 25-61, 2018. doi:https://doi.org/10.1016/j.trb.2018.07.005

GOÑI-ROS, B. et al. Using advanced adaptive cruise control systems to reduce congestion at sags: An evaluation based on microscopic traffic simulation. Transportation Research

Part C. pp. 411-426, 2019. doi:https://doi.org/10.1016/j.trc.2019.02.021

GUO, Q., \& BAN, X. Urban traffic signal control with connected and automated.

Transportation Research Part C 101. pp. 313-334, 2019.

doi:https://doi.org/10.1016/j.trc.2019.01.026

HAAS, I., \& FRIEDRICH, B. Developing a micro-simulation tool for autonomous, connected vehicle platoons used in city logistics. Transportation Research Procedia. pp. 1203-1210, 2017.

$\mathrm{HAO}$, P. et al. Intra-platoon vehicle sequence optimization for Eco-Cooperative Adaptive Cruise Contro. IEEE 20th International Conference on Intelligent Transportation Systems (ITSC). Yokohama, Japan. 2017. 
HE, J. et al. Cooperative Connected Autonomous Vehicles (CAV): Research, Applications and Challenges. IEEE 27th International Conference on Network Protocols (ICNP). Chicago, USA. 2019. doi:10.1109/ICNP.2019.8888126 HE, Q., MENG, X., \& QU, R. (2017). Survey on cybersecurity of CAV. Forum on Cooperative Positioning and Service (CPGPS). Harbin, China. 2017. doi:10.1109/CPGPS.2017.8075153 HELBING, D. Micro and Macro Simulation of Freeway Traffic. Mathematical and Computer Modelling 35. pp. 517-547, 2002.

HIGGS, B., ABBAS, M., \& MEDINA, M. Analysis of the Wiedemann Car Following Model over Different Speeds using Naturalistic Data. 3rd International Conference on Road Safety and Simulation. Indianapolis., USA. 2011

$\mathrm{HU}, \mathrm{S}$. et al. Stability of platoon of adaptive cruise control vehicles with time delay.

Transportation Letter. pp. 1-10, 2017.

HUSSAIN, R., HUSSAIN, F., \& ZEADALLY, S. Integration of VANET and 5G Security: A review of design and implementation issues. Future Generation Computer Systems. pp. 843-864, 2019. doi:https://doi.org/10.1016/j.future.2019.07.006 IBGE. Retrieved September 15, 2019, from Instituto Brasileiro de Geografia e Estatística: https://www.ibge.gov.br. 2019.

IEEE. IEEE Standard for Information Technology - Part 11: Wireless LAN Medium Access Control (MAC) and Physical Layer (PHY) Specification. Amendment 6: Wireless Acess in Vehicular Environment. 2010.

IEEE Spectrum. Retrieved September 6, 2019, from IEEE Spectrum: https://spectrum.ieee.org/cars-that-think/transportation/self-driving/the-audi-a8-the-worldsfirst-production-car-to-achieve-level-3-autonomy. 2019.

ITS Forge. Retrieved July 3, 2019, from https://www.itsforge.net/. 2019. JIA, D., \& NGODUY, D. (11 de May de 2016). Enhanced cooperative car-following traffic model with the combination of V2V and V2I communication. Transportation Research Part B 90. pp. 172-191, 2016. doi:10.1016/j.trb.2016.03.008 JO, Y., KIM, J., OH, C., KIM, I., \& LEE, G. Benefits of travel time savings by truck platooning in Korean freeway. Transport Policy 83, pp. 37-45, 2019. doi: 10.1016/j.tranpol.2019.09.003 KATSAROS, K., RIECK, D., \& KERNCHEN, R. Performance study of a Green Light Optimized Speed Advisory (GLOSA) application using an integrated cooperative ITS simulation platform. 7th International Wireless Communications and Mobile Computing Conference (IWCMC). Istanbul, Turkey. pp. 918-923. 2011. 
KESTING, A., TREIBER, M., SCHONHOF, M., \& HELBING, D. (Adaptive cruise control design for active congestion avoidance. Transportation Research Part C: Emerging Technologies, vol. 16, pp. 668-683, 2008. doi:https://doi.cir-

mcs.e.corpintra.net/10.1016/j.trc.2007.12.004

KESTING, A., TREIBER., M., \& HELBING, D. Enhanced intelligent driver model to access. Philosophical Transactions of the Royal Society of London. Mathematical, Physical and Engineering Sciences, vol. 368, no. 1928, pp. 4585-4605. 2010.

KING, P. et al. Autonomous intelligent cruise control-a review and discussion. Proceedings of VNIS '93 - Vehicle Navigation and Information Systems Conference. Ottawa, Ontario, Canada. 1993. doi:10.1109/VNIS.1993.585679

LACERDA, V., \& NETO, M. Considerações sobre a calibração do modelo de car-following do VISSIM para vias arteriais urbanas. Congresso de Pesquisa e ensino em transporte (XXVIII ANPET). Curitiba, Brazil. 2014.

LEE, J., \& PARK, B. (2012, March). Development and Evaluation of a Cooperative Vehicle Intersection Control Algorithm Under the Connected Vehicles Environment. IEEE

Transactions on Intelligent Transportation Systems, vol. 13. 2012. doi: 10.1109/TITS.2011.2178836

LESLIE, A., RAYMOND, J., MEITZNER, M., \& FLANNAGAN, C. (2019). Analysis of the field effectiveness of General Motors production active safety advanced headlighting systems.

UMTRI and GM LLC, Transportation Research Institute. Michigan, USA. 2019

LI, Y. et al. Platoon Control of Connected Multi-Vehicle Systems Under V2X Communications: Design and Experiments. IEEE Transactions on Intelligent Transportation Systems. pp. 1891-1901, 2020 doi:10.1109/TITS.2019.2905039

LIU, $\mathrm{H}$. et al. Modeling impacts of Cooperative Adaptive Cruise Control on mixed traffic flow in multi-lane freeway facilities. Transportation Research Part C: Emerging Technologies, Vol. 95. 2018. doi:https://doi.cir-mcs.e.corpintra.net/10.1016/j.trc.2018.07.027 LIU, L. et al. Car-following behavior of connected vehicles in a mixed traffic flow:

Proceedings of 2018 IEEE 8th Annual International Conference on CYBER Technology in Automation, Control, and Intelligent Systems. Tianjin, China. 2018.

LU, C. et al. An Ecological Adaptive Cruise Control for Mixed. IEEE Access. 2019. doi:10.1109/ACCESS.2019.2923741

LUCERO, S. C-V2X offers a cellular alternative to IEEE 802.11p/DSRC. IHS Markit. 2016 MADHUWANTHI, R et al. Factors Influencing to Travel Behavior on Transport Mode Choice. Transactions of Japan Society of Kansei Engin. pp.50-62, 2015. doi:10.5057/ijae.|JAE-D$15-00044$ 
MAHMASSANI, H. (2016, November). Autonomous Vehicles and Connected vehicle systems: flow and operation considerations. Transportation Science, Vol. 50, No. 4, pp. 1140-1162, 2016. doi:https://doi.org/10.1287/trsc.2016.0712 MATEUS, B. Análise sobre o impacto da densidade veicular, da carga da rede e da mobilidade de protocolos de roteamento para redes veiculares. UFCE. Brazil. 2010. MEYER, G., \& SHAHEEN, S. Disrupting Mobility - Impacts of Sharing economy and innovative transportation on cities. Berkeley, California, USA. 2017

MIR, Z., \& FITALI, F. Simulation and Performance Evaluation of Vehicle-to-Vehicle (V2V) Propagation Model in Urban Environment. 7th International Conference on Intelligent Systems, Modelling and Simulation. Bangkok, Thailand. 2016 doi:10.1109/ISMS.2016.56 MOTO, K. et al. Field Experimental Evaluation on 5G V2N Low Latency Communication for Application to Truck Platooning. IEEE 90th Vehicular Technology Conference (VTC2019Fall). Honolulu, HI, USA. Pp. 1-5, 2019. doi:10.1109/VTCFall.2019.8891450 MUSSA, S., MANAF, M., GHAFOOR, K., \& DOUKHA, Z. Simulation tools for vehicular ad hoc networks: A comparison study and future perspectives. (International Conference on Wireless Networks and Mobile Communications (WINCOM). 2015. doi:10.1109/WINCOM.2015.7381319

NANAJI, U., RAO, N., KUMAR, C., BHATTACHARYYA, D., \& KIM, H. A Simulated Study on Performance Evaluation of a Communication Network Model with DSR Protocol using ViSim. International Journal of Control and Automation, Vol.10, No.6, pp. 95-106, 2017. doi: 10.14257/ijca.2017.10.6.10

NAUFAL, J. et al. A2CPS: A Vehicle-Centric Safety Conceptual Framework for Autonomous Transport Systems. IEEE Transactions on Intelligent Transportation Systems, vol. 19, no. 6. 2018. doi:10.1109/TITS.2017.2745678

NETO, E., RENTES, A., ROMÃO, V., \& SPRICIGO, V. Rodovias inteligentes: contextualização, simulação e adequação do projeto geométrico. USP, São Paulo, Brazil. 2016

NTOUSAKIS, I., NIKOLOS, I., \& PAPAGEORGIOU, M. On Microscopic Modelling of Adaptive Cruise Control Systems. Transportation Research Procedia, vol.6, pp. 111-127, 2015.

OLIA, A., RAVAZI, S., ABDULLAH, B., \& ABDELGAWARD, H. (2018). Traffic Capacity implications of automated vehicles mixed with regular vehicles. Journal of Intelligent Transportation System, vol.22, no.3, pp. 244-262.

OLSTAM, J., \& TAPANI, A. (2004). Comparison of Car-following models. Linköping. Retrieved October from https://pdfs.semanticscholar.org/c5c7/5200817a05e570b8cf0f2e7a059693309422.pdf. 2019. 
OSMAN, O., \& ISHAK, S. A network-level connectivity robustness measure for connected vehicle environments. Transportation Research Part C, vol. 53, pp. 48-58, 2015. Retrieved from http://dx.doi.org/10.1016/j.trc.2015.01.023

PARK, H., BHAMIDIPATI, C., \& SMITH, B. Development and evaluation of enhanced intellidrive-enabled lane changing advisory algorithm to address freeway merge conflict. Transportation Research Record: Journal of the Transportation Research Board, No.2243, pp. 146-157, 2011. doi:10.3141/2243-17

PARK, S., KIM, J., LEE, S., \& HWANG, K. Experimental Analysis on control constraints for connected vehicles using Vissim. International Symposium of Transport Simulation (ITCS). pp. 269-280, 2017.

PENDLETON, S. et al. Perception, Planning, Control, and Coordination for Autonomous Vehicles. Machines, vol 5. 2017doi:10.3390/machines5010006

PLOEG, J., VAN NUNEN, E., VAN de WOUW, N., \& NIJMEIJER, H. Design and experimental evaluation of cooperative adaptive cruise control. 14th International IEEE Conference on Intelligent Transportation Systems (ITSC), pp. 260-265, 2011. PNAD. ibge.gov. Retrieved from Pesquisa Nacional de Amostras e Domicílios contínua: https://www.ibge.gov.br/estatisticas/sociais/trabalho/9171-pesquisa-nacional-por-amostrade-domicilios-continua-mensal.html?=\&t=0-que-e. 2019 PTV. What is new in PTV Vissim/Viswalk 2020. Retrieved on September 7, 2019, Retrieved on PTV Group:

https://www.ptvgroup.com/fileadmin/user_upload/Products/PTV_Vissim/Documents/ReleaseHighlights/Vissim_2020_what_s_new.pdf. 2019

PTV VISSIM 2020 USER MANUAL. PTV VISSIM 2020 USER MANUAL. Karlsruhe, Germany. Source: www.ptvgroup.com. 2019.

RAHMAN, M., \& ABDEL-ATY, M. Longitudinal safety evaluation of connected vehicles' platooning. Accident Analysis and Prevention, vol. 117. 2017.

doi:https://doi.org/10.1016/j.aap.2017.12.012

RAJESH, R. Vehicle Dynamics and Control. University of Minnesota, USA. 2006

RIOS-TORRES, J., \& MALIKOPOULOS, A. Impact of Connected and Automated Vehicles on traffic flow. IEEE 20th International Conference on Intelligent Transportation Systems (ITCS). 2017. doi: 10.1109/ITSC.2017.8317654

RIOS-TORRES, J., \& MALIKOPOULOS, A. Impact of Partial Penetrations of Connected and Automated Vehicles on Fuel Consumption and Traffic Flow. IEEE Transactions on Intelligent Systems, vol. 3, no. 4, 2018. doi:10.1109/TIV.2018.2873899 SAE. SAE automation level standards. Retrieved September 6, 2019, from SAE.org: https://www.sae.org/news/press-room/2018/12/sae-international-releases-updated-visual- 
chart-for-its-\%E2\%80\%9Clevels-of-driving-automation\%E2\%80\%9D-standard-for-selfdriving-vehicles. 2018.

SAGIR, F., \& UKKUSURI, S. Mobility Impacts of Autonomous Vehicle Systems. IEEE 21st International Conference on Intelligent Transportation Systems (ITSC). Hawaii, USA. 2018. doi:10.1109/ITSC.2018.8569933

SAIDALLAH, M., EL FERGOUGUI, R., \& ELALAOUI, A. A Comparative Study of Urban Road Traffic Simulators. MATEC conference ICTTE. 2016.

doi:10.1051/matecconf/20168105002

SANCHEZ, F., \& DIEZ, J. L. Cooperative Driving. Vision Zero, 66-67. 2016.

SANTOS, A., YOSHIOKA, L. R., MARTE, C. R., \& CINTRA, J. P. Estudo de viabilidade do uso de rede de sensores integrada a sistemas inteligentes de transporte para monitoramento de condições ambientais. XVII ANPET - Congresso de Pesquisa e Ensino em Transportes. Brazil. 2013

SBD. Autonomous Car Guide - AUT Q4. United Kingdon. 2018

SCHAKEL, W., Van Arem, B., \& NETTEN, B. Effects of Cooperative Cruise Control on traffic flow stability. 13th IEEE International Annual Conference on Intelligent Transportation Systems. Madeira Island, Portugal. pp. 759-764, 2018.

SCHLADOVER, S., NOWAKOWSKI, C., \& O'CORNELL, J. Cooperative Adaptive Cruise Controls: driver selection of Car-Following gaps. ITS World Congress. 2010.

SERAJ, M., LI, J., \& QIU, Z. (2018). Modeling Microscopic Car-Following Strategy of Mixed Traffic to Identify Optimal Platoon Configurations for Multiobjective Decision-Making. Journal of Advanced Transportation. 2018. doi:10.1155/2018/7835010

SHLADOVER, S., SU, D., \& LU, X. Impacts of Cooperative Adaptive Cruise Control on Freeway Traffic Flow. Transportation Research Record: Journal of the Transportation Research Board. pp. 63-70, 2012. doi:10.3141/2324.08

SINGH, P., NANDI, S., \& NANDI, S. A tutorial survey on a vehicular communication state of the art and future research directions. Vehicular Communications, vol.18.

2019.doi:10.1016/2019.100164

SONG, M., CHEN, F., \& MA, X. Simulation of the Traffic Behavior with Autonomous Truck Platoons Based on Cellular Automaton. The 5th International Conference on Transportation Information and Safety (ICTIS), Liverpool, UK. pp. 416-423, 2019. doi:10.1109/ICTIS.2019.8883834

SONGCHITRUKSA, P., BIBEKA, A., LIN, L., \& ZHANG, Y. Incorporating Driver Behaviors into Connected and Automated Vehicle Simulation. University of Michigan and Texas A\&M Transportation Institute, ATLAS CENTER: Advancing Transportation Leadership and Safety, Ann Harbor, MI, USA. 2016. 
SPTans 2. SPTrans itinerary search São Paulo. Source: http://www.sptrans.com.br/buscade-itinerarios/. 2019

SPTrans. API Developers SPTrans. Source: SPTeans developers:

http://www.sptrans.com.br/desenvolvedores/api-do-olho-vivo-guia-dereferencia/documentacao-api/. 2019.

STEVANOVIK, A., STEVANOVIK, J., \& KERGAYE, C. impact of signal phasing information accuracy on the green light optimized advisory system. 92nd Annual Meeting of the Transportation. Washington, DC, USA. 2013.

TAKAHASHI, J. (01 de November de 2018). An Overview of Cyber Security for Connected Vehicles. IEICE Transactions on Information and Systems, Vol. E101.D Issue 11, pp. 2561-2575, 2018. doi:10.1587/transinf.2017ICI0001

TELEBPOUR, A., \& MAHMASSANI, H. Influence of connected and autonomous vehicles on traffic flow stability and throughput. Transportation Research Part C: Emerging Technologies, vol. 71. pp. 143-163. 2016. doi: 10.1016/j.trc.2016.07.007

TIAN, D., WU, G., BORIBONNSOMSIN, K., \& BARTH, M. (2018). Performance Measurement Evaluation Framework and Co-Benefit/Tradeoff Analysis for Connected and Automated Vehicles (CAV) Applications: A Survey. IEEE Intelligent Transportation System Magazine. pp.110-122. 2018. doi: 10.1109/MITS.2018.2842020 TIBLJAS , A. et al. Introduction of Autonomous Vehicles: Roundabouts Design and Safety Performance Evaluation. Sustainability, vol. 10. 2018. doi:10.3390/su10041060 TILG, G., YANG, K., \& MENENDEZ, M. Evaluating the effects of automated vehicle technology on the capacity of freeway weaving sections. Transportation Research Part C vol. 96. pp. 3-21, 2018 doi:https://doi.org/10.1016/j.trc.2018.09.014 Traffic Technology International. 5G. Traffic Technology International Magazine, 20-26. Retrieved from www.traffictechnologytoday.com. 2017 Transportation Research Circular. Traffic and Transportation Simulation, Vol. E-C195. (T. R. Academies, Ed.) Washington D.C., USA. 2015

TREIBER, M., \& KESTING, A. Traffic flow dynamics: data, models, and simulation. Dresden, Germany. Springer. 2013. doi:10.1007/978-3-642-32460-4

TREIBER, M., HENNECKE, A., \& HELBING, D. Congested traffic states in empirical observations and microscopic simulations. Physics Review, Ed 62. 2000. doi: 10.1103/PhysRevE.62.1805 TSUGAWA, S. Results and issues of an automated truck platoon within the energy ITS project. IEEE Intelligent Vehicles Symposium Proceedings. 2014. doi:10.1109/ivs.2014.6856400 
UHLEMANN, E. Introducing Connected Vehicles. IESS Vehicular Technology Magazine. pp.23-31, 2013

UNITED NATIONS 1. United Nations Organization. Retrieved September 29, 2019, from United Nations: https://population.un.org/wpp/Graphs/Probabilistic/POP/TOT/900. 2018. UNITED NATIONS 2. United Nations Organization. Retrieved September 2019, 2019, from United Nations: https://population.un.org/wup/Maps/. 2019.

VALIDI, A., LUDWIG, T., \& OLAVERRI-MONREAL, C. Analyzing the Effects of V2V and ADAS-ACC Penetration Rates on the Level of Road Safety in Intersections: Evaluating Simulation Platforms SUMO and Scene Suite. IEEE International Conference on Vehicular Electronics and Safety (ICVES). Vienna, Austria.pp. 38-43, 2017. doi:

10.1109/ICVES.2017.7991898

Van AREM, B., VAN ARIEL, C., \& VISSER, R. (2006). The impact of Cooperative Adaptive Cruise Control on Traffic-Flow Characteristics. IESS Transaction, Intelligent Transportation System, vol. 7. pp. 429-436, 2006. doi: 10.1109/TITS.2006.884615 Vissim User Manual. PTV Vissim 11 User Manual. Source: PTV Group: www.ptvgroup.com. 2019

VUKADINOVIC, V. et al. 3GPP C-V2X and IEEE 802.11p for Vehicle-to-Vehicle communications in highway platooning scenarios. Ad Hoc Networks, vol. 74. pp. 17-29, 2018. doi: 10.1016/j.adhoc.2018.03.004

WANG, G., WU, G., HAO, P., BORIBOONSOMSIN, K., \& BARTH, M. (2017, June). Developing a platoon-wide Eco-Cooperative Adaptive Cruise. Proceedings of the 28th IEEE Intelligent Vehicles Symposium, pp. 1256-1261. 2017.

WAYMO. Waymo website. Source: https://waymo.com/journey/. 2020

WERF, J., SLADOVER, S., MILLER, M., \& KOURJANSKAIA, N. (2002). Effects of Adaptive Cruise Control Systems on Highway Traffic. Transportation Research, vol. 1800, pp. 74-84. 2002. doi:10.3141/1800-10

WHO. World Health Organization - Global status report on road safety 2018. Geneva: WHO. 2018. doi: 978-92-4-156568-4

WIEDEMANN, R. Simulation des Verkehrfusses. Karlsruhe Institute of Technology (KIT), Karlsruhe. 1974.

XIE, D., ZHAO, X., \& HE, Z. Heterogeneous Traffic Mixing Regular and Connected Vehicles: Modeling and Stabilization. IEEE Transactions on Intelligent Transportation Systems, vol. 20. 2019. doi:10.1109/TITS.2018.2857465

YANG, K., GULER, S., \& MENENDEZ, M. (2016). Isolated intersection control for various levels of vehicle technology: Conventional, connected, and automated vehicles.

Transportation Research Part C 72, pp. 109-129. 2016. doi: 10.1016/j.trc.2016.08.009 
YAO, S., SHET, R., \& FRIEDRICH, B. Managing Connected Automated Vehicles in Mixed Traffic Considering Communication Reliability: a Platooning Strategy. Transportation Research Procedia, vol. 47. 2020. doi:10.1016/j.trpro.2020.03.071

YE, L., \& YAMAMOTO, T. Modeling connected and autonomous vehicles in heterogeneous traffic flow. Physica A. pp. 270-277, 2017. doi:10.1016/j.physa.2017.08.015

ZHANG, X., \& BHAM, G. Estimation of driver reaction time from detailed vehicle trajectory data. Proceedings of the 18th IASTED International Conference on Modelling, Simulation, and Optimization. Innsbruck, Austria. pp. 575-579. 2007. ZHANG, Y. et al. Force-Driven Traffic Simulation for a Future Connected Autonomous Vehicle-Enabled Smart Transportation System. IEEE Transactions on Intelligent Transportation Systems. 2018. doi: 10.1109/TITS.2017.2787141 ZHAO, L., \& SUN, J. Simulation Framework for Vehicle Platooning and Car-following Behaviors Under Connected-vehicle Environment. Procedia - Social and Behavioral Sciences, vol. 96. pp. 914-924, 2013. doi:10.1016/j.sbspro.2013.08.105 ZHOU, M., QU, X., \& JIN, S. On the Impact of Cooperative Autonomous Vehicles in Improving Freeway Merging: A Modified Intelligent Driver Model-Based Approach. IEEE Transactions on Intelligent Transportation Systems, vol 18. pp. 1422 - 1428. 2017. doi:10.1109/TITS.2016.2606492

ZHOU, Y., ZHU, H., \& ZHOU, J. Impact of CACC vehicles' cooperative driving strategy on mixed four-lane highway traffic flow. Physica A. 2019. doi: 10.1016/j.physa.2019.122721 
ANNEX 1 - ADAS SYSTEM CLASSIFICATION

Based on the SAE automation level definition, several ADAS being made available qualify to be classified as a Level 2 system. However, the functionality and system delivery level varies between the different systems and their implementation by different OEMs. Therefore to make a more apparent distinction, SBD classifies the system into 2.1, 2.2, and 2.3. See table below for distinction:

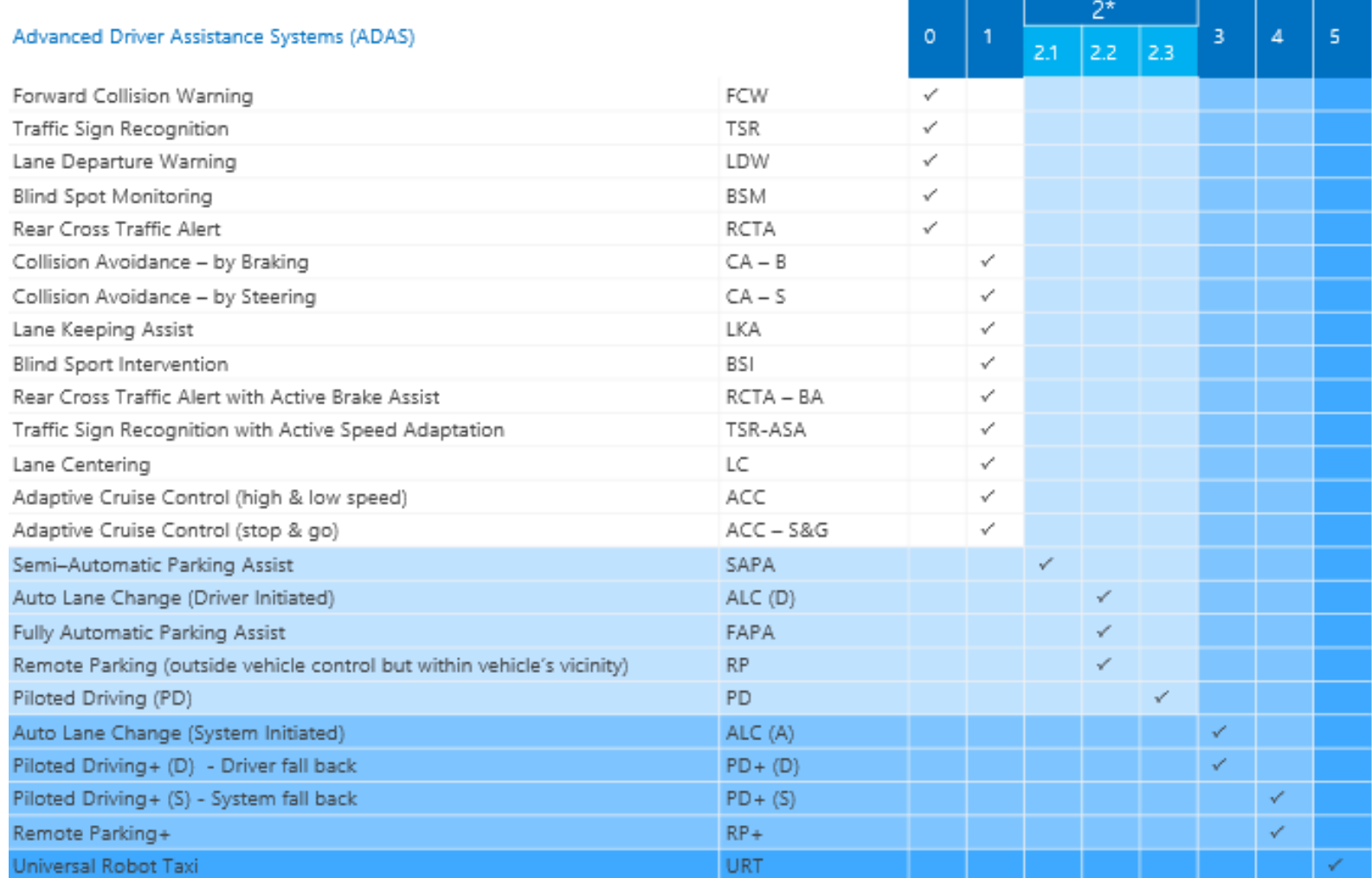

Source: (SBD, 2018). 
ANNEX 2 - LIST OF C-ITS PRIORITY SERVICES

\begin{tabular}{|c|c|c|}
\hline \multicolumn{3}{|c|}{ Vehicle-to-vehicle services } \\
\hline \multirow[t]{2}{*}{ Traffic jam } & Dangerous end of queue & $\begin{array}{l}\text { Already deployed using LTE- } \\
\text { V2X long-range mode when } \\
\text { considered as "hazard } \\
\text { information" (otherwise similar } \\
\text { service as "electronic } \\
\text { emergency brake light") }\end{array}$ \\
\hline & Traffic jam ahead & \multirow{4}{*}{$\begin{array}{l}\text { Already deployed using LTE- } \\
\text { V } 2 X \text { long-range mode }\end{array}$} \\
\hline \multirow{3}{*}{ Stationary vehicle warning } & Stopped vehicle & \\
\hline & Broken-down vehicle & \\
\hline & Post-crash & \\
\hline \multirow{3}{*}{ Special vehicle warning } & Emergency vehicle in operation & \multirow{3}{*}{$\begin{array}{l}\text { Already deployed using LTE- } \\
\text { V2X long-range mode }\end{array}$} \\
\hline & $\begin{array}{l}\text { Stationary safeguarding } \\
\text { emergency vehicle }\end{array}$ & \\
\hline & $\begin{array}{l}\text { Stationary recovery service } \\
\text { warning }\end{array}$ & \\
\hline \multirow{2}{*}{ Exchange of IRCs } & Request IRC & \\
\hline & Response IRC & \\
\hline \multirow{6}{*}{ Dangerous situation } & $\begin{array}{l}\text { Electronic emergency brake } \\
\text { light }\end{array}$ & \\
\hline & Automatic brake intervention & \\
\hline & $\begin{array}{l}\text { Reversible occupant restraint } \\
\text { system intervention }\end{array}$ & \\
\hline & Fog & \multirow{3}{*}{$\begin{array}{l}\text { Already deployed using LTE- } \\
\text { V2X long-range mode }\end{array}$} \\
\hline & Precipitation & \\
\hline & Traction loss & \\
\hline
\end{tabular}

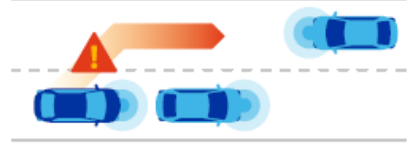

Do not pass warning (DNPW)

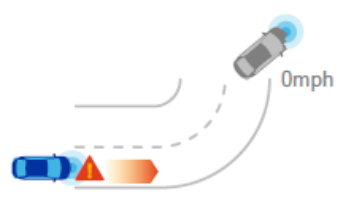

Blind curve/ Local hazard warning

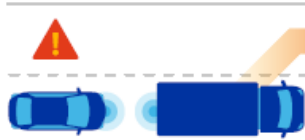

Road works warning

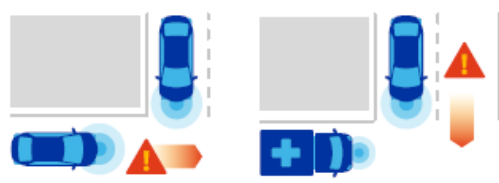

Intersection movement assist (IMA) at a blind intersection

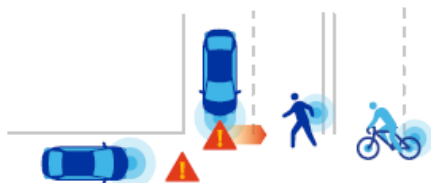

Vulnerable road user (VRU) alerts at a blind intersection

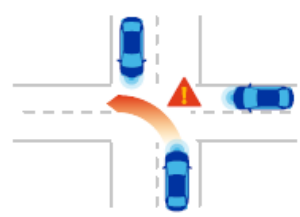

Left turn assist (LTA)

Source: (5G Automotive Association, 2019) 


\section{ANNEX 3 - TRAFFIC SIMULATION GENEALOGY}

Transpartation Research Circular E-C195: Traffic and Transportatian Simulation

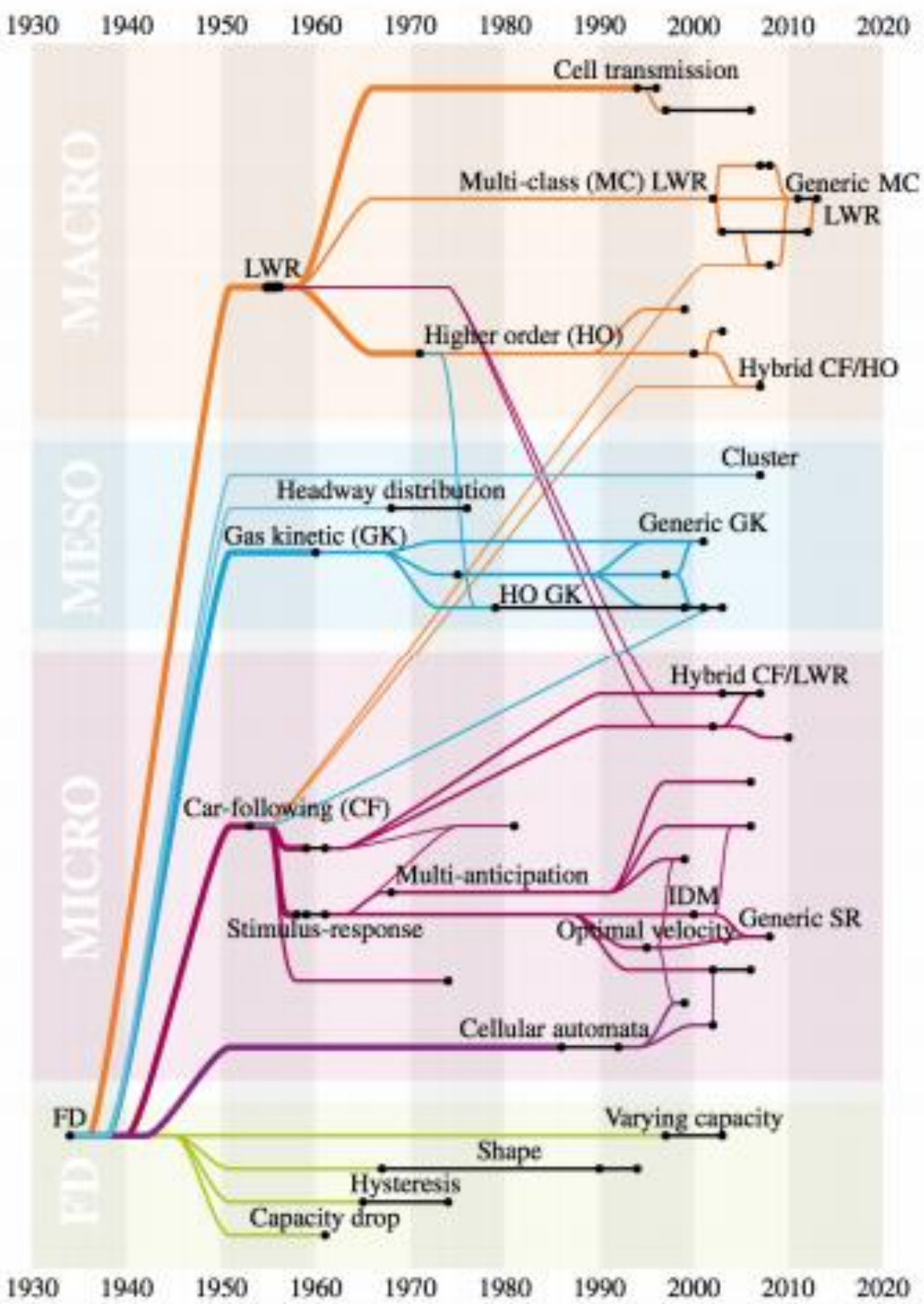

Source: Transportation Research Circular E-C195: Traffic and Transportation Simulation (2015) 
ANNEX 4- WIEDEMANN 99 ADJUSTABLE PARAMETERS

\begin{tabular}{|l|l|}
\hline \multicolumn{1}{|c|}{ Element } & \multicolumn{1}{c|}{ Description } \\
\hline CC0 (Standstill distance) & $\begin{array}{l}\text { The desired distance between two stationary } \\
\text { vehicles. Correspond to AX in Table 1. }\end{array}$ \\
\hline CC1 (Headway time) & $\begin{array}{l}\text { Refers to the time the driver wants to } \\
\text { maintain to the preceding vehicle. A high } \\
\text { value yields a more cautious driver. }\end{array}$ \\
\hline CC2 ('Following' variation) & $\begin{array}{l}\text { Restrains the longitudinal oscillation of a } \\
\text { vehicle in relation to the vehicle in front. }\end{array}$ \\
\hline CC3 (Threshold for entering 'Following') & $\begin{array}{l}\text { Defines at what time the deceleration } \\
\text { process will begin in terms of seconds } \\
\text { before reaching the safety distance. }\end{array}$ \\
\hline CC4 and CC5 ('Following' thresholds) & $\begin{array}{l}\text { Regulates the speed differences during the } \\
\text { 'Following' state. Lower values corresponds } \\
\text { to a more careful driver e.g. vehicles will be } \\
\text { allowed to be more close to each other. }\end{array}$ \\
\hline CC6 (Speed dependency of oscillation) & $\begin{array}{l}\text { Refers to the impact of distance on speed } \\
\text { oscillation within the following regime. }\end{array}$ \\
\hline CC7 (Oscillation acceleration) & $\begin{array}{l}\text { Defines the actual acceleration during the } \\
\text { oscillation process. }\end{array}$ \\
\hline CC8 (Standstill acceleration) & $\begin{array}{l}\text { Desired acceleration when starting from a } \\
\text { stationary state. }\end{array}$ \\
\hline CC9 (Acceleration at 80 km/h) & Desired acceleration at a speed of $80 \mathrm{~km} / \mathrm{h}$. \\
\hline
\end{tabular}

Source: (Vissim User Manual, 2019) 


\section{ANNEX 5- DATA INPUT FOR SIMULATED NETWORKS}

\section{NETWORK 1:}

\begin{tabular}{|c|c|c|c|c|c|c|c|c|c|c|c|c|c|}
\hline \multirow[b]{2}{*}{$\begin{array}{l}\text { I. Nações } \\
\text { Unidas Ave. }\end{array}$} & \multicolumn{2}{|c|}{ Sc1.1 / 1.2 100\% Human } & \multicolumn{2}{|c|}{$\begin{array}{l}\text { Sc2.1 } / 2.250 \% \\
\text { Human }\end{array}$} & \multicolumn{2}{|c|}{$\begin{array}{c}\text { Sc3.1/ } 3.2100 \% \\
\text { AV }\end{array}$} & \multicolumn{2}{|c|}{$\begin{array}{r}\text { Sc4.1/4.2 33\%HD } \\
33 \% \text { AV } \\
33 \% \text { CAV }\end{array}$} & \multicolumn{2}{|c|}{$\begin{array}{r}\text { Sc5.1/5.2 50\% AV } \\
\text { CAV }\end{array}$} & \multicolumn{2}{|c|}{ Sc6.1/ $6.2100 \%$ CAV } & \multirow[t]{2}{*}{$\begin{array}{c}\text { Des Veh } \\
\text { Speed }\end{array}$} \\
\hline & $\begin{array}{l}\text { Rel Flow } \\
\text { (\%) }\end{array}$ & Volume CET & $\begin{array}{l}\text { Rel } \\
\text { Flow } \\
(\%)\end{array}$ & Volume & $\begin{array}{l}\text { Rel } \\
\text { Flow } \\
(\%)\end{array}$ & Volume & $\begin{array}{l}\text { Rel } \\
\text { Flow } \\
(\%)\end{array}$ & Volume & $\begin{array}{l}\text { Rel } \\
\text { Flow } \\
(\%)\end{array}$ & Volume & $\begin{array}{l}\text { Rel Flow } \\
(\%)\end{array}$ & Volume & \\
\hline 100: Car & 73 & 1801,64 & 37 & 913,16 & 0 & 0 & 25 & 525 & 0 & 0 & 0 & 0 & 7 \\
\hline 200: HGV & 1 & 24,68 & 0,5 & 0,02 & 0 & 0 & 0,5 & 10,5 & 0 & 0 & 0 & 0 & 7 \\
\hline 300: Bus & 12 & 296,16 & 6,5 & 160,42 & 0 & 0 & 4 & 84 & 0 & 0 & 0 & 0 & 7 \\
\hline 610: Motorcylce & 14 & 345,52 & 12 & 296,16 & 0 & 0 & 12 & 252 & 0 & 0 & 0 & 0 & 7 \\
\hline 630: Car_AV & 0 & 0 & 37 & 913,16 & 81 & 1999,08 & 25 & 525 & 40 & 987,2 & 0 & 0 & 7 \\
\hline 650: HGV_AV & 0 & 0 & 0,5 & 12,34 & 1 & 24,68 & 0,5 & 10,5 & 1 & 24,68 & 0 & 0 & 7 \\
\hline 660: BUS_AV & 0 & 0 & 6,5 & 160,42 & 18 & 444,24 & 4 & 84 & 10 & 246,8 & 0 & 0 & 7 \\
\hline 670: Car_CAV & 0 & 0 & 0 & 0 & 0 & 0 & 25 & 525 & 40 & 987,2 & 80 & 1974,4 & 7 \\
\hline 680: Bus_CAV & 0 & 0 & 0 & 0 & 0 & 0 & 4 & 84 & 9 & 222,12 & 20 & 493,6 & 7 \\
\hline Total & 100 & 2468 & 100 & 2468 & 100 & 2468 & 100 & 2100 & 100 & 2468 & 100 & 2468 & \\
\hline $\begin{array}{c}\text { Il. } \\
\text { Bandeirantes } \\
\text { Ave. }\end{array}$ & $\begin{array}{l}\text { Same } \\
\text { split as } \\
\text { Nacões } \\
\text { Unidas } \\
\text { Ave. }\end{array}$ & 1000 & $\begin{array}{c}\text { Same } \\
\text { split as } \\
\text { Nacões } \\
\text { Unidas } \\
\text { Ave. }\end{array}$ & 1000 & $\begin{array}{c}\text { Same } \\
\text { split as } \\
\text { Nacões } \\
\text { Unidas } \\
\text { Ave. }\end{array}$ & 1000 & $\begin{array}{l}\text { Same } \\
\text { split as } \\
\text { Nacões } \\
\text { Unidas } \\
\text { Ave. }\end{array}$ & 1000 & $\begin{array}{c}\text { Same } \\
\text { split as } \\
\text { Nacões } \\
\text { Unidas } \\
\text { Ave. }\end{array}$ & 1000 & $\begin{array}{l}\text { Same } \\
\text { split as } \\
\text { Nacões } \\
\text { Unidas } \\
\text { Ave. }\end{array}$ & 1000 & \\
\hline $\begin{array}{l}\text { III. Dr. Cardoso } \\
\text { de Melo Ave. }\end{array}$ & $\begin{array}{l}\text { Same } \\
\text { split as } \\
\text { Nacões } \\
\text { Unidas } \\
\text { Ave. }\end{array}$ & 400 & $\begin{array}{c}\text { Same } \\
\text { split as } \\
\text { Nacões } \\
\text { Unidas } \\
\text { Ave. }\end{array}$ & 400 & $\begin{array}{c}\text { Same } \\
\text { split as } \\
\text { Nacões } \\
\text { Unidas } \\
\text { Ave. }\end{array}$ & 400 & $\begin{array}{c}\text { Same } \\
\text { split as } \\
\text { Nacões } \\
\text { Unidas } \\
\text { Ave. }\end{array}$ & 400 & $\begin{array}{c}\text { Same } \\
\text { split as } \\
\text { Nacões } \\
\text { Unidas } \\
\text { Ave. }\end{array}$ & 400 & $\begin{array}{l}\text { Same } \\
\text { split as } \\
\text { Nacões } \\
\text { Unidas } \\
\text { Ave. }\end{array}$ & 400 & \\
\hline
\end{tabular}

Source: Author

\section{Continue to the next page}


NETWORK 2:

\begin{tabular}{|c|c|c|c|c|c|c|c|c|c|c|c|c|c|}
\hline \multirow[b]{2}{*}{$\begin{array}{l}\text { I. Cardeal } \\
\text { Arco Verde t }\end{array}$} & \multicolumn{2}{|c|}{ Sc1.1 / 1.2 100\% HDV } & \multicolumn{2}{|c|}{ Sc2.1/ 2.2 50\% HDV } & \multicolumn{2}{|c|}{ Sc3.1/ 3.2 100\% AV } & \multicolumn{2}{|c|}{$\begin{array}{c}\text { Sc4.1 / } 4.2 \\
33 \% \mathrm{HD} / 33 \% \mathrm{AV} / \\
33 \% \mathrm{CAV}\end{array}$} & \multicolumn{2}{|c|}{$\begin{array}{r}\text { Sc5.1/ } 5.250 \% \text { AV } \\
50 \% \text { CAV }\end{array}$} & \multicolumn{2}{|c|}{ Sc6.1 / 6.2 100\% CAV } & \multirow{2}{*}{$\begin{array}{c}\begin{array}{c}\text { Des Veh } \\
\text { Speed }\end{array} \\
\mathrm{km} / \mathrm{h}\end{array}$} \\
\hline & $\begin{array}{c}\text { Rel Flow } \\
(\%)\end{array}$ & Volume CET & $\begin{array}{l}\text { Rel Flow } \\
(\%)\end{array}$ & Volume & $\begin{array}{l}\text { Rel Flow } \\
(\%)\end{array}$ & Volume & $\begin{array}{c}\text { Rel Flow } \\
(\%)\end{array}$ & Volume & $\begin{array}{l}\text { Rel Flow } \\
(\%)\end{array}$ & Volume & $\begin{array}{c}\text { Rel Flow } \\
(\%)\end{array}$ & Volume & \\
\hline 100: Car & 75 & 1125 & 37,5 & 562,5 & 0 & 0 & 25 & 375 & 0 & 0 & 0 & 0 & 30 \\
\hline 300: Bus & 10 & 150 & 5 & 75 & 0 & 0 & 4 & 60 & 0 & 0 & 0 & 0 & 30 \\
\hline 610: Motorcylce & 15 & 225 & 15 & 225 & 0 & 0 & 13 & 195 & 0 & 0 & 0 & 0 & 40 \\
\hline 630:Car_AV & 0 & 0 & 37,5 & 562,5 & 80 & 1200 & 25 & 375 & 40 & 600 & 0 & 0 & 30 \\
\hline 660: BUS_AV & 0 & 0 & 5 & 75 & 20 & 300 & 4 & 60 & 10 & 150 & 0 & 0 & 30 \\
\hline 670: Car_CAV & 0 & 0 & 0 & 0 & 0 & 0 & 25 & 375 & 40 & 600 & 80 & 1200 & 30 \\
\hline 680: Bus_CAV & 0 & 0 & 0 & 0 & 0 & 0 & 4 & 60 & 10 & 150 & 20 & 300 & 30 \\
\hline Total & 100 & 1500 & 100 & 1500 & 100 & 1500 & 100 & 1500 & 100 & 1500 & 100 & 1500 & \\
\hline \multicolumn{14}{|l|}{$\begin{array}{l}\text { II. Horácio } \\
\text { Lane St } \\
\end{array}$} \\
\hline 100: Car & 85 & 85 & 42,5 & 42,5 & 0 & 0 & 29 & 29 & 0 & 0 & 0 & 0 & 25 \\
\hline 300: Bus & 0 & 0 & 0 & 0 & 0 & 0 & 0 & 0 & 0 & 0 & 0 & 0 & - \\
\hline 610: Motorcylce & 15 & 15 & 15 & 15 & 0 & 0 & 13 & 13 & 0 & 0 & 0 & 0 & 30 \\
\hline 630:Car_AV & 0 & 0 & 42,5 & 42,5 & 100 & 100 & 29 & 29 & 50 & 50 & 0 & 0 & 25 \\
\hline 660: BUS_AV & 0 & 0 & 0 & 0 & 0 & 0 & 0 & 0 & 0 & 0 & 0 & 0 & - \\
\hline 670: Car_CAV & 0 & 0 & 0 & 0 & 0 & 0 & 29 & 29 & 50 & 50 & 100 & 100 & 25 \\
\hline 680: Bus_CAV & 0 & 0 & 0 & 0 & 0 & 0 & 0 & 0 & 0 & 0 & 0 & 0 & - \\
\hline Total & 100 & 100 & 100 & 100 & 100 & 100 & 100 & 100 & 100 & 100 & 100 & 100 & \\
\hline \multicolumn{14}{|l|}{$\begin{array}{l}\text { III. Francisco } \\
\text { Leitão St }\end{array}$} \\
\hline 100: Car & 85 & 85 & 42,5 & 85 & 0 & 0 & 29 & 58 & 0 & 0 & 0 & 0 & 25 \\
\hline 300: Bus & 0 & 0 & 0 & 0 & 0 & 0 & 0 & 0 & 0 & 0 & 0 & 0 & - \\
\hline
\end{tabular}




\section{NETWORK 2 (page 2):}

\begin{tabular}{|c|c|c|c|c|c|c|c|c|c|c|c|c|c|}
\hline \multirow[b]{2}{*}{$\begin{array}{l}\text { I. Cardeal } \\
\text { Arco Verde t }\end{array}$} & \multicolumn{2}{|c|}{ Sc1.1 / 1.2 100\% HDV } & \multicolumn{2}{|c|}{ Sc2.1/2.2 50\% HDV } & \multicolumn{2}{|c|}{ Sc3.1 / 3.2 100\% AV } & \multicolumn{2}{|c|}{$\begin{array}{c}\text { Sc4.1 / } 4.2 \\
33 \% \text { HDV / } 33 \% \text { AV/33\% CAV }\end{array}$} & \multicolumn{2}{|c|}{$\begin{array}{c}\text { Sc5.1 / } 5.2 \\
50 \% \text { AV/ } \\
50 \% \text { CAV }\end{array}$} & \multicolumn{2}{|c|}{ Sc6.1 / $6.2100 \%$ CAV } & \multirow{2}{*}{$\begin{array}{c}\text { Des Veh } \\
\text { Speed } \\
\mathrm{km} / \mathrm{h}\end{array}$} \\
\hline & $\begin{array}{l}\text { Rel Flow } \\
(\%)\end{array}$ & Volume CET & $\begin{array}{l}\text { Rel Flow } \\
(\%)\end{array}$ & Volume & $\begin{array}{l}\text { Rel Flow } \\
(\%)\end{array}$ & Volume & $\begin{array}{l}\text { Rel Flow } \\
(\%)\end{array}$ & Volume & $\begin{array}{l}\text { Rel Flow } \\
(\%)\end{array}$ & Volume & $\begin{array}{l}\text { Rel Flow } \\
(\%)\end{array}$ & Volume & \\
\hline 610: Motorcylce & 15 & 15 & 15 & 30 & 0 & 0 & 13 & 26 & 0 & 0 & 0 & 0 & 30 \\
\hline 630: Car_AV & 0 & 0 & 42,5 & 85 & 100 & 200 & 29 & 58 & 50 & 100 & 0 & 0 & 25 \\
\hline 660: BUS_AV & 0 & 0 & 0 & 0 & 0 & 0 & 0 & 0 & 0 & 0 & 0 & 0 & - \\
\hline 670: Car_CAV & 0 & 0 & 0 & 0 & 0 & 0 & 29 & 58 & 50 & 100 & 100 & 200 & 25 \\
\hline 680: Bus_CAV & 0 & 0 & 0 & 0 & 0 & 0 & 0 & 0 & 0 & 0 & 0 & 0 & - \\
\hline Total & 100 & 200 & 100 & 200 & 100 & 200 & 100 & 200 & 100 & 200 & 100 & 200 & \\
\hline \multicolumn{14}{|c|}{ IV. Joaquim Antunes St } \\
\hline 100: Car & 85 & 85 & 42,5 & 35,7 & 0 & 0 & 29 & 24,36 & 0 & 0 & 0 & 0 & 25 \\
\hline 300: Bus & 0 & 0 & 0 & 0 & 0 & 0 & 0 & 0 & 0 & 0 & 0 & 0 & - \\
\hline 610: Motorcycle & 15 & 15 & 15 & 12,6 & 0 & 0 & 13 & 10,92 & 0 & 0 & 0 & 0 & 30 \\
\hline 630:Car_AV & 0 & 0 & 42,5 & 35,7 & 100 & 84 & 29 & 24,36 & 50 & 42 & 0 & 0 & 25 \\
\hline 660: BUS_AV & 0 & 0 & 0 & 0 & 0 & 0 & 0 & 0 & 0 & 0 & 0 & 0 & - \\
\hline 670: Car_CAV & 0 & 0 & 0 & 0 & 0 & 0 & 29 & 24,36 & 50 & 42 & 100 & 84 & 25 \\
\hline 680: Bus_CAV & 0 & 0 & 0 & 0 & 0 & 0 & 0 & 0 & 0 & 0 & 0 & 0 & - \\
\hline Total & 100 & 84 & 100 & 84 & 100 & 84 & 100 & 84 & 100 & 84 & 100 & 84 & \\
\hline \multicolumn{14}{|c|}{ V. Virgílio Carvalho St } \\
\hline 100: Car & 85 & 85 & 42,5 & 51 & 0 & 0 & 29 & 34,8 & 0 & 0 & 0 & 0 & 25 \\
\hline 300: Bus & 0 & 0 & 0 & 0 & 0 & 0 & 0 & 0 & 0 & 0 & 0 & 0 & - \\
\hline 610: motorcycle & 15 & 15 & 15 & 18 & 0 & 0 & 13 & 15,6 & 0 & 0 & 0 & 0 & 30 \\
\hline 630: Car_AV & 0 & 0 & 42,5 & 51 & 100 & 120 & 29 & 34,8 & 50 & 60 & 0 & 0 & 25 \\
\hline 660: BUS_AV & 0 & 0 & 0 & 0 & 0 & 0 & 0 & 0 & 0 & 0 & 0 & 0 & - \\
\hline 670: Car_CAV & 0 & 0 & 0 & 0 & 0 & 0 & 29 & 34,8 & 50 & 60 & 100 & 120 & 25 \\
\hline 680: Bus_CAV & 0 & 0 & 0 & 0 & 0 & 0 & 0 & 0 & 0 & 0 & 0 & 0 & - \\
\hline Total & 100 & 120 & 100 & 120 & 100 & 120 & 100 & 120 & 100 & 120 & 100 & 120 & \\
\hline
\end{tabular}




\section{NETWORK2 3.X:}

\begin{tabular}{|c|c|c|c|c|c|c|c|c|c|c|c|c|c|}
\hline \multirow[b]{2}{*}{$\begin{array}{l}\text { I. Networks 3.X } \\
\text { (primary input) }\end{array}$} & \multicolumn{2}{|c|}{$\begin{array}{c}\text { Sc1.1 / } 1.2100 \% \\
\text { Human }\end{array}$} & \multicolumn{2}{|c|}{$\begin{array}{c}\text { Sc2.1 / } 2.250 \% \\
\text { Human }\end{array}$} & \multicolumn{2}{|c|}{ Sc3.1 / 3.2 100\% AV } & \multicolumn{2}{|c|}{$\begin{array}{r}\text { Sc4.1 / } 4.233 \% \mathrm{HD} \\
33 \% \mathrm{AV} \\
33 \% \mathrm{CAV}\end{array}$} & \multicolumn{2}{|c|}{$\begin{array}{c}\text { Sc5.1 / } 5.250 \% \text { AV } \\
\text { CAV }\end{array}$} & \multicolumn{2}{|c|}{ Sc6.1 / $6.2100 \%$ CAV } & \multirow[t]{2}{*}{$\begin{array}{l}\text { Des Veh } \\
\text { Speed }\end{array}$} \\
\hline & $\begin{array}{l}\text { Rel Flow } \\
(\%)\end{array}$ & $\begin{array}{l}\text { Volume } \\
\text { CET }\end{array}$ & $\begin{array}{l}\text { Rel Flow } \\
(\%)\end{array}$ & Volume & $\begin{array}{l}\text { Rel Flow } \\
(\%)\end{array}$ & Volume & $\begin{array}{l}\text { Rel Flow } \\
\text { (\%) }\end{array}$ & Volume & $\begin{array}{l}\text { Rel Flow } \\
(\%)\end{array}$ & Volume & $\begin{array}{l}\text { Rel Flow } \\
(\%)\end{array}$ & Volume & \\
\hline 100: Car & 70 & 3500 & 35 & 1750 & 0 & 0 & 23,3 & 375 & 0 & 0 & 0 & 0 & 90 \\
\hline 200: HGV & 20 & 1000 & 10 & 500 & 0 & 0 & 7 & 60 & 0 & 0 & 0 & 0 & 70 \\
\hline 300: Bus & 10 & 500 & 5 & 0 & 0 & 0 & 3,3 & 60 & 0 & 0 & 0 & 0 & 70 \\
\hline 630: Car_AV & 0 & 0 & 35 & 1750 & 70 & 3500 & 23,3 & 375 & 35 & 600 & 0 & 0 & 90 \\
\hline 660: HGV_AV & 0 & 0 & 10 & 500 & 20 & 1000 & 7 & 60 & 10 & 150 & 0 & 0 & 70 \\
\hline 660: BUS_AV & 0 & 0 & 5 & 0 & 10 & 0 & 3,3 & 60 & 5 & 150 & 0 & 0 & 70 \\
\hline 640: Car_CAV & 0 & 0 & 0 & 0 & 0 & 0 & 23,3 & 375 & 35 & 600 & 70 & 1200 & 90 \\
\hline 660: HGV_CAV & 0 & 0 & 0 & 0 & 0 & 0 & 7 & 60 & 10 & 150 & 20 & 300 & 70 \\
\hline 680: Bus_CAV & 0 & 0 & 0 & 0 & 0 & 0 & 3,3 & 60 & 5 & 150 & 10 & 300 & 70 \\
\hline Total & 100 & 5000 & 100 & 5000 & 100 & 5000 & 100,8 & 5000 & 100 & 5000 & 100 & 5000 & \\
\hline \multicolumn{14}{|l|}{$\begin{array}{l}\text { II. Network } 3.3 \\
\text { (add input) }\end{array}$} \\
\hline 100: Car & 70 & 350 & 35 & 175 & 0 & 0 & 23,3 & 375 & 0 & 0 & 0 & 0 & 90 \\
\hline 200: HGV & 20 & 100 & 10 & 50 & 0 & 0 & 7 & 60 & 0 & 0 & 0 & 0 & 70 \\
\hline 300: Bus & 10 & 50 & 5 & 0 & 0 & 0 & 3,3 & 60 & 0 & 0 & 0 & 0 & 70 \\
\hline 630: Car_AV & 0 & 0 & 35 & 175 & 70 & 350 & 23,3 & 375 & 35 & 600 & 0 & 0 & 90 \\
\hline 660: HGV_AV & 0 & 0 & 10 & 50 & 20 & 100 & 7 & 60 & 10 & 150 & 0 & 0 & 70 \\
\hline 660: BUS_AV & 0 & 0 & 5 & 0 & 10 & 0 & 3,3 & 60 & 5 & 150 & 0 & 0 & 70 \\
\hline 640: Car_CAV & 0 & 0 & 0 & 0 & 0 & 0 & 23,3 & 375 & 35 & 600 & 70 & 1200 & 90 \\
\hline 660: HGV_CAV & 0 & 0 & 0 & 0 & 0 & 0 & 7 & 60 & 10 & 150 & 20 & 300 & 70 \\
\hline 680: Bus_CAV & 0 & 0 & 0 & 0 & 0 & 0 & 3,3 & 60 & 5 & 150 & 10 & 300 & 70 \\
\hline Total & 100 & 500 & 100 & 500 & 100 & 500 & 100,8 & 500 & 100 & 500 & 100 & 500 & \\
\hline
\end{tabular}

Source: Author 
